UNIVERSIDADE DE SÃO PAULO

FACULDADE DE FILOSOFIA, CIÊNCIAS E LETRAS DE RIBEIRÃO PRETO DEPARTAMENTO DE PSICOLOGIA PROGRAMA DE PÓS-GRADUAÇÃO EM PSICOLOGIA

Relações entre estratégias de aprendizagem e traços de personalidade em treinamentos corporativos presenciais

Luana Paula de Oliveira

RIBEIRÃO PRETO

2019 


\title{
Relações entre estratégias de aprendizagem e traços de personalidade em treinamentos corporativos presenciais
}

\author{
Versão corrigida
}

(Versão original encontra-se na unidade que aloja o Programa de Pós-graduação)

Dissertação apresentada à Faculdade de Filosofia,

Ciências e Letras de Ribeirão Preto da

Universidade de São Paulo como parte das exigências para a obtenção do título de Mestre em

Psicologia.

Área de Concentração: Psicologia em Saúde e Desenvolvimento

Orientadora: Prof ${ }^{\mathrm{a}}$. Dra ${ }^{\mathrm{a}}$. Thaís Zerbini 
Autorizo a reprodução e divulgação total ou parcial deste trabalho, por qualquer meio convencional ou eletrônico, para fins de estudo e pesquisa, desde que citada a fonte.

Treinamento Corporativo. Estratégias de Aprendizagem. Traços de Personalidade. Big Five.

Catalogação na publicação Serviço de Biblioteca e Documentação

Faculdade de Filosofia, Ciências e Letras de Ribeirão Preto - USP

Oliveira, Luana Paula de.

Relações entre estratégias de aprendizagem e traços de personalidade em treinamentos corporativos presenciais / Luana Paula de Oliveira; orientadora: Thais Zerbini - Ribeirão Preto, 2018.

$130 \mathrm{f}$.

Dissertação de Mestrado, apresentada à Faculdade de Filosofia, Ciências e Letras de Ribeirão Preto, Universidade de São Paulo - USP. Área de concentração: Psicologia em Saúde e Desenvolvimento.

1. Treinamento corporativo. 2. Estratégias de aprendizagem. 3. Traços de personalidade. 4. Big Five. 


\title{
Relações entre estratégias de aprendizagem e traços de personalidade em treinamentos corporativos presenciais
}

\author{
Versão corrigida
}

Dissertação apresentada como parte das exigências para a obtenção do título de Mestre em Psicologia financiada pela CAPES/CNPq.

RIBEIRÃO PRETO

2019 
Nome: Oliveira, Luana Paula de.

Título: Relações entre estratégias de aprendizagem e traços de personalidade em treinamentos corporativos presenciais

Dissertação apresentada à Faculdade de Filosofia, Ciências e Letras de Ribeirão Preto da Universidade de São Paulo para obtenção do título de Mestre em Psicologia

Aprovada em:

Banca Examinadora

Prof. Dr.

Instituição:

Assinatura:

Prof. Dr.

Instituição: Assinatura:

Prof. Dr.

Instituição: Assinatura: 


\section{AGRADECIMENTOS}

À Thaís Zerbini pela oportunidade, confiança, incentivo e, principalmente, pelos ensinamentos de ética, comprometimento e amor pela pesquisa científica. Foi muito gratificante ser orientada por essa profissional que, mesmo antes de conhecer pessoalmente, já admirava pelo trabalho que realiza.

À empresa parceira por acreditar neste trabalho, pela abertura e pela inestimável colaboração durante todo o processo de pesquisa, principalmente durante a coleta de dados. Aos participantes agradeço pela disponibilidade e interesse em contribuir.

À CAPES, pelo apoio financeiro que possibilitou minha dedicação ao processo de pesquisa.

À Editora Vetor, pela doação das aplicações e correções online do Questionário de Personalidade - NEO-FFI-R.

A todo grupo do Laboratório de Psicologia Organizacional e do Trabalho LabPOT/USP, com o qual aprendi muito durante todo o Mestrado. Sem as nossas valiosas trocas o processo de construção do conhecimento não teria sido o mesmo. Em especial, agradeço à Priscila Fidelis e à Priscila Miquelino. Além da troca de conhecimentos, trocamos os medos, as angústias e os momentos de estresse. Vocês se transformaram em amigas queridas que levarei para sempre.

Ao meu esposo Sérgio que, mesmo sem entender como alguém podia passar tantas horas sentada na frente de um computador e ainda assim não finalizar um trabalho, sempre me apoiou incondicionalmente e ofereceu condições para a realização deste sonho.

Aos meus pais e ao meu irmão pela compreensão da minha ausência nos últimos meses. Mesmo tão longe, estão sempre presentes me fazendo acreditar que sou capaz de realizar tudo aquilo que sonhar.

E a todos aqueles que de alguma forma contribuíram para a construção deste trabalho. 
"A única maneira de fazer um bom trabalho é amando o que você faz. Se você ainda não encontrou, continue procurando. Não se desespere. Assim como no amor, você saberá quando tiver encontrado". Steve Jobs 


\section{RESUMO}

Oliveira, L. P.de. (2018). Relações entre estratégias de aprendizagem e traços de personalidade em treinamentos corporativos presenciais. (Dissertação de Mestrado). Faculdade de Filosofia, Ciências e Letras de Ribeirão Preto, Universidade de São Paulo, Ribeirão Preto.

As rápidas transformações e a competitividade do mercado de trabalho têm exigido das organizações e das pessoas um constante processo de aperfeiçoamento. Assim, uma prática comum nas organizações é avaliar as lacunas nas competências dos funcionários e desenvolvêlas por meio de ações de Treinamento, Desenvolvimento e Educação (TD\&E) sistemáticas e estruturadas. Todavia, se a aprendizagem ocorre ou não, depende de características individuais e também contextuais. Estudos têm mostrado que o reconhecimento dos aspectos individuais neste processo contribui para desenvolvimento profissional bem-sucedido dos funcionários, bem como para os resultados de treinamentos esperados pela organização. Nesta perspectiva, a presente pesquisa pretende contribuir com a área de avaliação de sistemas instrucionais ao investigar as relações entre as variáveis estratégias de aprendizagem e traços de personalidade - segundo a teoria dos Cinco Grandes Fatores (Big Five) - em treinamentos corporativos presenciais. A coleta de dados foi realizada numa população composta por 115 funcionários de uma empresa do segmento de Telecomunicações, situada em Minas Gerais, que participou de um treinamento intitulado "Gestão à Vista". Foram utilizados, em formato online, o inventário de personalidade Neuroticism, Extraversion, Openness Personality Inventary Revised (NEOFFI-R) e a Escala de Estratégias de Aprendizagem. A taxa de retorno obtida se apresenta como um diferencial entre os estudos da área, com participação de $74,78 \%$ da população estudada. Foram realizadas análises estatísticas descritivas das variáveis e Testes de Coeficiente de Correlação de Pearson. Os resultados evidenciaram que as estratégias mais utilizadas pela amostra foram as Autorregulatórias e que o traço de personalidade mais presente foi o da Conscienciosidade. As correlações mostraram que as estratégias de aprendizagem intituladas Elaboração e Aplicação Prática e Controle da Motivação se relacionam positivamente com os traços da personalidade Extroversão, Abertura, Amabilidade e Conscienciosidade, e negativamente com o Neuroticismo. Já as Estratégias Cognitivas e Busca de Ajuda mostraram relação positiva apenas com a Amabilidade, enquanto Controle da Emoção se relacionou negativamente com o Neuroticismo. Esta pesquisa oferece contribuições para o subsistema de avaliação na medida em que suscita a possibilidade da inserção da variável traços de personalidade, até então não utilizada em pesquisas nacionais, mas que tem sido correlata estável, robusta, previsível e determinante de outras variáveis envolvidas no processo de TD\&E.

Palavras-Chaves: Treinamento Corporativo. Estratégias de Aprendizagem. Traços de Personalidade. Big Five. 


\begin{abstract}
Oliveira, L. P.de. (2018). Relações entre estratégias de aprendizagem e traços de personalidade em treinamentos corporativos presenciais. (Dissertação de Mestrado). Faculdade de Filosofia, Ciências e Letras de Ribeirão Preto, Universidade de São Paulo, Ribeirão Preto.
\end{abstract}

The rapid changes and the competitiveness of the labor market have demanded the organizations and individuals a constant process of improvement. Thus, a common practice in organizations is to evaluate the gaps in employee competencies and to develop them through systematic and structured Training, Development and Education (TD\&E) actions. However, whether learning occurs or not depends on individual and contextual characteristics. Studies have shown that recognition of individual aspects in this process contributes to the successful professional development of employees as well as to the results of training expected by the organization. In this perspective, the present research intends to contribute with the area of instructional evaluation systems when investigating the relations between the variables learning strategies and personality traits - according to the theory of the Big Five - in face-to-face corporate training. Data collection was carried out in a population of 115 employees of a telecommunications company located in Minas Gerais, Brazil, which participated in a training titled "Gestão à Vista". Neuroticism, Extraversion, Openness Personality Inventary Revised (NEO-FFI-R) and the Learning Strategies Scale were used in online format. The rate of return obtained is a differential among the studies of the area, with participation of $74.78 \%$ of the studied population. Descriptive statistical analyzes of the variables and Pearson Correlation Coefficient Tests were performed. The results evidenced that the strategies most used by the sample were the self-regulatory ones and that the most present personality trait was the Conscientiousness. The correlations show that the learning strategies entitled Practical Elaboration and Application and Motivation Control are positively related to personality traits Extroversion, Openness, Kindness and Conscientiousness, and negatively with Neuroticism. Already the Cognitive Strategies and Search for Help showed a positive relationship only with Kindness, while Emotion Control was negatively related to Neuroticism. This research offers contributions to the evaluation subsystem insofar as it raises the possibility of the insertion of variable personality traits, hitherto unused in national surveys, but which has been stable, robust, predictable and determinant correlation of other variables involved in the process of $\mathrm{T}$ $\& \mathrm{E}$.

Keywords: Corporate Training. Learning Strategies. Personality traits. Big Five. 


\section{Lista de Figuras}

Figura 1. Estrutura geral do desenvolvimento do texto.

Figura 2. Relação entre os conceitos e ações educacionais associadas (Vargas \& Abbad, 2006)

Figura 3. TD\&E: Sistema integrado (Borges-Andrade, 2006; Borges-Andrade, Zerbini, Abbad

Figura 4. Características da clientela (Meneses et al., 2006)

Figura 5. Modelo de Avaliação Integrado e Somativo - MAIS proposto por Borges-Andrade (2006)

Figura 6. Modelo de Avaliação do Impacto do Treinamento no Trabalho - IMPACT proposto por Abbad (1999)....

Figura 7. Modelo de avaliação e efetividade de treinamento (IMTEE) (Alvarez, Salas \& Garofano, 2004)

Figura 8. Modelo sistêmico Nikandrou et al. (2009)...............................................................26

Figura 9. Distribuição dos artigos por base de dados............................................................47

Figura 10. Gráfico de distribuição dos artigos por ano de publicação.....................................49

Figura 11. Gênero presentes nas áreas de formação superior (Inep, 2016).............................70 


\section{Lista de Tabelas}

Tabela 1. Enfoques teóricos referentes à aprendizagem e ao ensino.....................................6

Tabela 2. Classificação e definições das estratégias de aprendizagem (Warr \& Allan, 1998; Zerbini \& Pilati, 2012).

Tabela 3. Distribuição dos artigos de acordo com bases de dados

Tabela 4. Estudos nacionais e internacionais do período de 2015 e 2017

Tabela 5. Distribuição dos artigos por localização geográfica e idioma de publicação.

Tabela 6. Fatores e facetas do modelo Big Five (Manual NEO PI-R e NEO-FFI-R, MendonzaFlores, 2010).

Tabela 7. Dados de validação do NEO-FFI em diferentes culturas (Pedroso-Lima, et al., 2014).

Tabela 8. Distribuição dos artigos por localização geográfica

Tabela 9. Principais resultados de pesquisas rescentes sobre Traços de Personalidade em TD\&E.

Tabela 10. Resumo das hipóteses confirmadas e rejeitadas do estudo - adaptada (Lakhal, Sévigny \& Frenette, 2015)

Tabela 11. Características formais do treinamento "Gestão à Vista". .67

Tabela 12. Características da amostra......

Tabela 13 - Informações psicométricas do instrumento Estratégias de Aprendizagem adaptado por Martins (2016)

Tabela 14. Questionário Estratégias de Aprendizagem adaptado por Martins (2016).

Tabela 15 - Resumo das informações sobre o NEO-FFI-R (Paul \& McCrae, 2010). 73

Tabela 16: Estatísticas Descritivas do Instrumento de Estratégias de

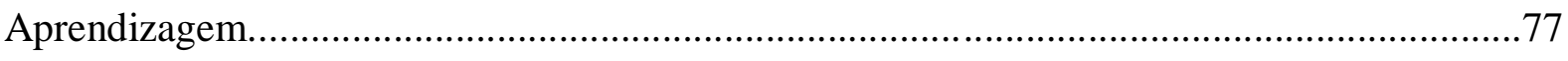

Tabela 17: Estatísticas dos Escores Médios dos Fatores do Questionário de Estratégias de Aprendizagem.

Tabela 18: Estatísticas Descritivas do Instrumento NEO-FFI R .80 
Tabela 19: Estatísticas das Médias dos Fatores do Questionário de Traços de

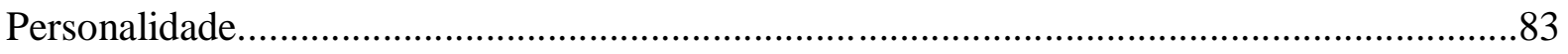

Tabela 20: Testes de Normalidade de Shapiro-Wilk dos Escores Fatoriais dos

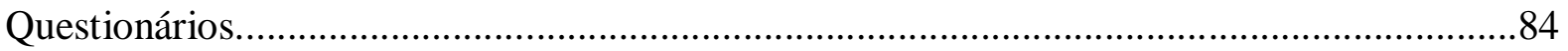

Tabela 21: Análises de Assimetria e Curtose dos Escores Fatoriais dos

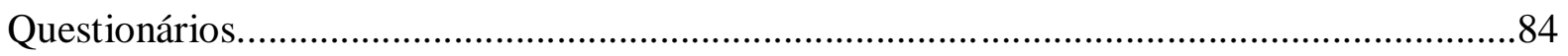

Tabela 22: Resultados dos Testes de Correlação de Pearson....................................................86 


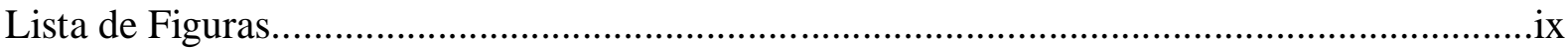

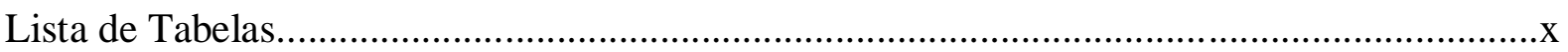

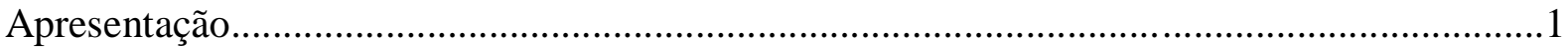

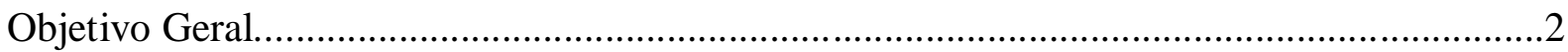

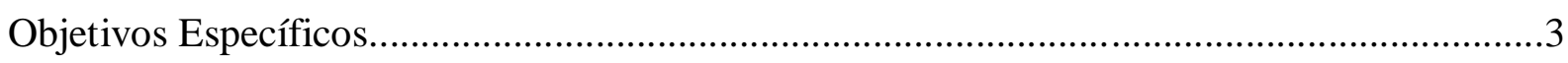

Capítulo 1. REVISÃO DA LIETERATURA EM TREINAMENTO, DESENVOLVIMENTO

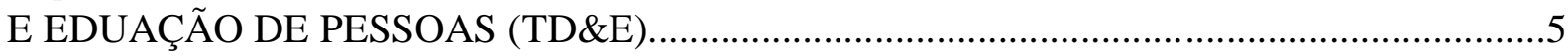

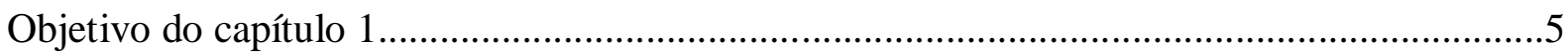

1.1. Aprendizagem Humana: teorias, conceitos e aplicações em contextos de organizações e

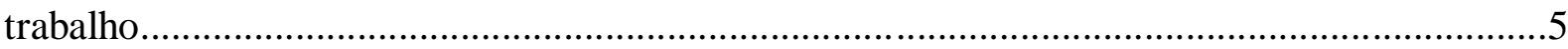

1.2. Treinamento, Desenvolvimento e Educação de pessoas: conceitos e subsistemas............10

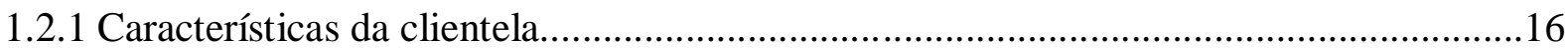

1.3. Modelos de avaliação de treinamentos presenciais........................................................19

Capítulo 2. REVISÃO DA LITERATURA: VARIÁVEIS DE INTERESSE........................28

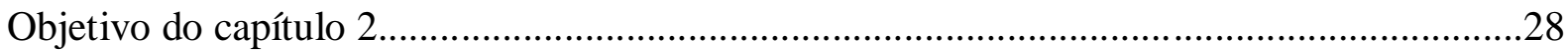

2.1. Estratégias de Aprendizagem: definições e conceitos .................................................28

2.1.1. Descrição do percurso metodológico para a revisão da literatura....................................31

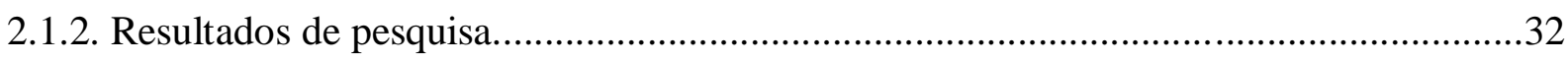

2.2 Traços de Personalidade: definições e conceitos..............................................................41

2.2.1 Descrição do percurso metodológico para a revisão sistemática da literatura..................46

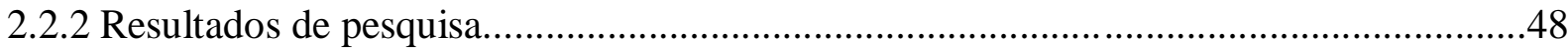

Capítulo 3. CARACTERÍSTICAS METODOLÓGICAS DA PESQUISA............................63

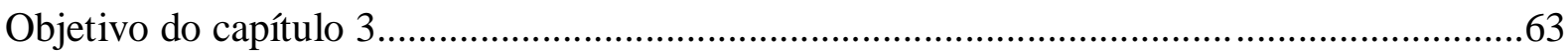

3.1. Delimitação do problema e objetivos de pesquisa..........................................................63

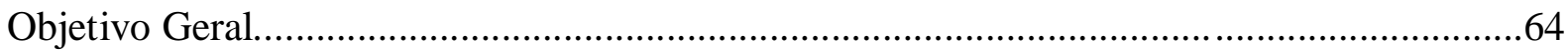

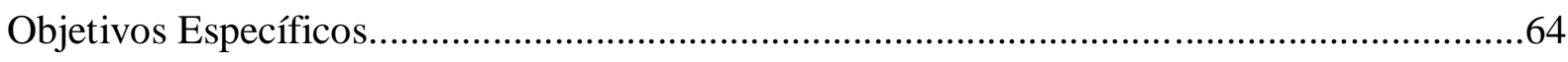

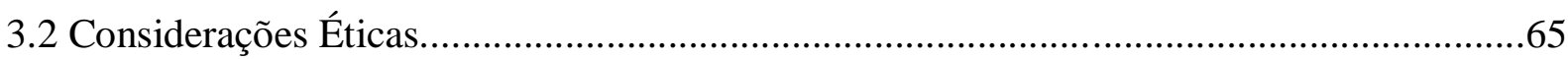

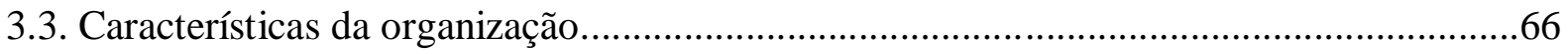




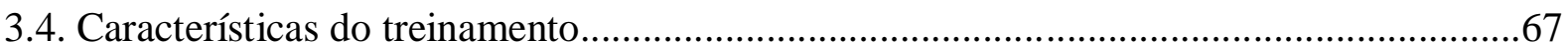

3.5. Características da população e amostra..........................................................................69

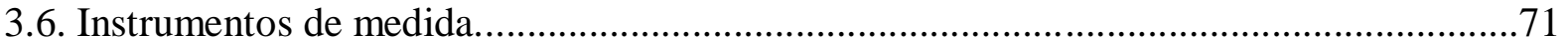

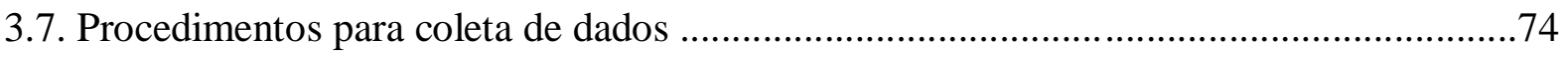

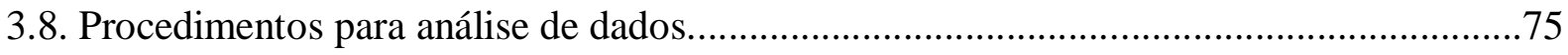

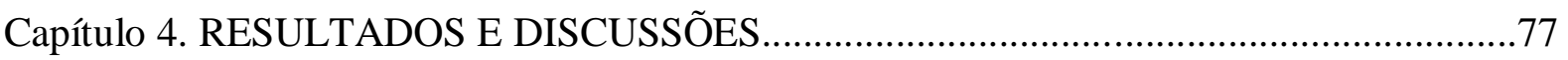

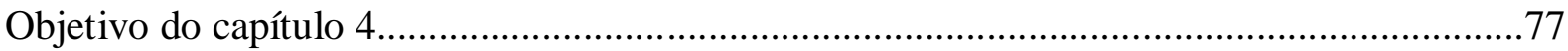

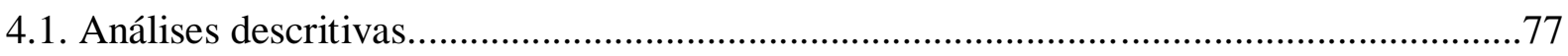

4.1.1. Questionário estratégias de aprendizagem..............................................................77

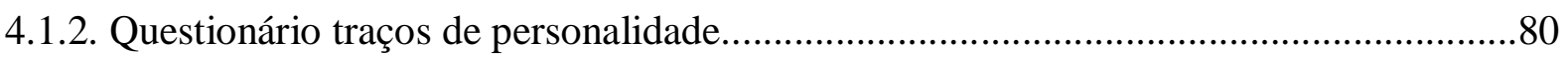

4.2. Testes de normalidade e análise de assimetria e curtose ................................................83

4.3. Testes de coeficiente de correlação Pearson...................................................................... 85

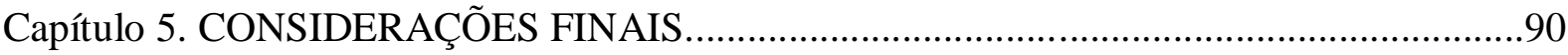

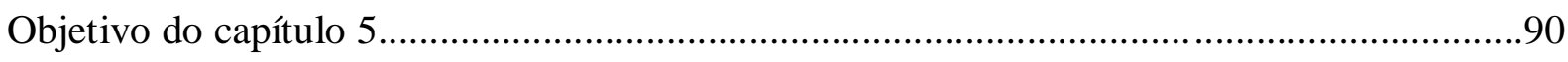

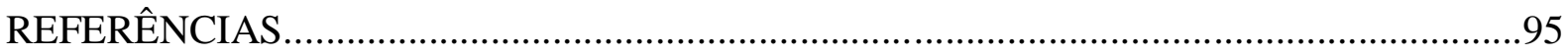

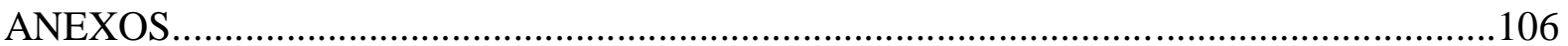




\section{APRESENTAÇÃO}

As rápidas transformações e a dinâmica do mercado de trabalho demandam das pessoas inseridas em ambientes corporativos constantes adaptações de suas habilidades e atualização de seus conhecimentos como diferencial competitivo. Neste cenário, Programas de Treinamento, Desenvolvimento e Educação (TD\&E) ocupam uma posição estratégica nas organizações, visto que auxiliam na promoção de aprendizagem contínua. Trata-se de um meio de desenvolvimento e consolidação de competências técnicas e comportamentais essenciais ao desempenho profissional de seus membros, melhorando a sua performance no trabalho (Salas, Tannenbaum, Kraiger, \& Smith-Jentsch, 2012).

Neste sentido, ao promover ação instrucional, uma organização espera que as novas competências adquiridas pelos colaboradores provoquem impactos nos processos de trabalho das equipes e resultados organizacionais (Aguinis \& Kraiger, 2009; Zerbini, Coelho, Abbad, Mourão, \& Loiola, 2012a), transpondo assim o nível individual, agregando valor também nos níveis meso e macro (Burke \& Hutchins, 2007). Assim, são consideradas ações educacionais bem-sucedidas aquelas em que as competências adquiridas ou aprofundadas em TD\&E são aplicadas e transferidas apropriadamente para o contexto de trabalho (Aguinis \& Kraiger, 2009; Borges-Andrade, 1997; Meneses, Zerbini, \& Abbad, 2010).

Para cumprir tais expectativas é imprescindível que se conheça os fatores que ajudam e os que prejudicam a efetividade de treinamentos, a fim de explicar a ocorrência dos resultados dessas ações e de sanar as lacunas teórico-metodológicas (Salas et al., 2012). Neste ponto, a área de TD\&E propõe modelos de avaliação de ações educacionais que visam investigar os componentes do processo.

A análise da literatura das últimas décadas apresenta importantes pesquisas que se dedicaram a investigar variáveis que podem influenciar os resultados de ações educacionais, principalmente presenciais. Tais pesquisas apontam que características individuais são preditoras de aprendizagem (Aguinis \& Kraiger, 2009; Bell, Tannenbaum, Ford, Noe, \& Kraiger, 2017; Salas et al., 2012). Neste prospecto, estratégias de aprendizagem é uma variável que têm despertado o interesse de pesquisadores por apresentar relações com diversas variáveis e por sua comprovada influência no processo de ensino-aprendizagem. Trata-se de uma variável referente às características da clientela, classificada na categoria cognitivo-comportamental, a qual é assim definida por mensurar determinados procedimentos concretos e observáveis utilizados pelos participantes para aprender e para modificar seu ambiente de trabalho (Pilati \& Borges-Andrade, 2012). 
A revisão da literatura realizada por Martins, Zerbini e Medina (2018) mostra que no Brasil há uma importante linha de pesquisa sobre estratégias de aprendizagem, com foco tanto nas estratégias aplicadas pelos indivíduos para aprender durante ações formais de treinamento, como nas práticas manifestas e encobertas utilizadas por profissionais para auxiliar a aquisição informal de conhecimentos e habilidades em seu ambiente de trabalho. Estes estudos têm mostrado ainda que estratégias de aprendizagem se correlacionam significativamente com outras variáveis envolvidas no processo de TD\&E, tais como desenvolvimento profissional, desempenho acadêmico e fatores motivacionais (Garrote Rojas, Garrote Rojas, \& Jiménez Fernández, 2016; Haeme, Borges-Andrade, \& Cassiano, 2017; Visbal-Cadavid, MendozaMendoza, \& Díaz Santana, 2017).

$\mathrm{Na}$ literatura internacional, estratégias de aprendizagem também tem apresentando correlações com uma variável - como mostra a revisão sistemática descrita no Capítulo 2 - não inserida em pesquisas nacionais da área de TD\&E: traços de personalidade (Kokkinos, Kargiotidis, \& Markos, 2015; Stumm \& Furnham, 2012). Aliás, cabe ressaltar que a literatura internacional tem contemplado tal variável como potencial preditora de desempenho acadêmico (Lakhal, Sévigny, \& Frenette, 2015; Furnham, Nuygards, \& Chamorro-Premuzic, 2013; Kappe, \& Der Flier, 2012; De Feyter, Caers, Vigna, \& Berings, 2012), satisfação com o treinamento (Yang, Jowett, \& Chan, 2014; Trógolo \& Medrano, 2012), e estilos de aprendizagem (Li \& Armstrong, 2015; Salahi, Hedjazi, Mahmood, \& Ebrahimi, 2014).

Diante de tais observações, a presente pesquisa pretende contribuir com a área de avaliação de sistemas instrucionais ao investigar as relações entre as variáveis estratégias de aprendizagem e traços de personalidade - segundo a teoria dos Cinco Grandes Fatores (Big Five) - em treinamentos corporativos presenciais. É importante dizer que as avaliações de personalidade sempre foram alvos de discussões éticas na psicologia por muitas vezes serem usadas para "rotular" os indivíduos. Neste trabalho, a inclusão de um instrumento que avalia traços de personalidade, contrário disso, visa acrescentar mais uma informação importante (não a única) ao processo de TD\&E, para que as ações educacionais sejam cada vez mais adequadas ao perfil de sua clientela. Para cumpir tal intenção, são propostos os seguintes objetivos:

\section{Objetivo Geral:}

Analisar as relações entre traços de personalidade e uso de determinadas estratégias de aprendizagem em treinamentos corporativos presenciais. 


\section{Objetivos Específicos:}

$>$ Descrever as estratégias de aprendizagem adotadas pelos participantes ao longo do treinamento, utilizando a Escala de Estratégias de Aprendizagem adaptada por Martins, Zerbini e Medina (2018).

$>$ Identificar e descrever os traços de personalidade dos participantes, segundo NEO-FFI-R (Mendonza-Flores, 2010).

$>$ Realizar correlações entre as variáveis traços de personalidade e estratégias de aprendizagem.

$>$ Identificar informações sobre características dos aprendizes que podem contribuir para o planejamento instrucional de treinamentos corporativos presenciais.

Para cumprir os objetivos, o Capítulo 1 desta pesquisa apresenta conceitos, teorias e abordagens relacionados ao processo de aprendizagem humana, bem como sua aplicação em contexto de organizações e trabalho. Além disso, são discutidos os conceitos, componentes e características dos processos formais que promovem a aprendizagem induzida no trabalho: ações de treinamento, desenvolvimento e educação de pessoas (TD\&E) presenciais, com foco nos métodos do subsistema de Avaliação em TD\&E.

O capítulo 2 apresenta definições, conceitos e a revisão de literatura, bem como discute os resultados de pesquisas nacionais e internacionais sobre as variáveis de interesse do estudo: Estratégias de Aprendizagem e Traços de Personalidade. O Capítulo 3 retrata a delimitação do problema, a justificativa e os objetivos da pesquisa, bem como descreve as características da organização-alvo, do curso avaliado, da população e amostra, dos instrumentos de medida. Neste também são apresentados os procedimentos de coleta e análise estatística dos dados.

O capítulo 4 evidencia e discute os resultados advindos das análises de dados, à luz da revisão da literatura. E, por fim, no capítulo 5 conclui o estudo, retomando os objetivos de pesquisa. Além disso, são relatadas contribuições e limitações da pesquisa e proposta uma agenda de estudos.

Visando facilitar o acompanhamento do texto, na página seguinte a Figura 1 ilustra a sequência dos capítulos e das seções do presente estudo. 
Figura 1. Estrutura geral do desenvolvimento do texto

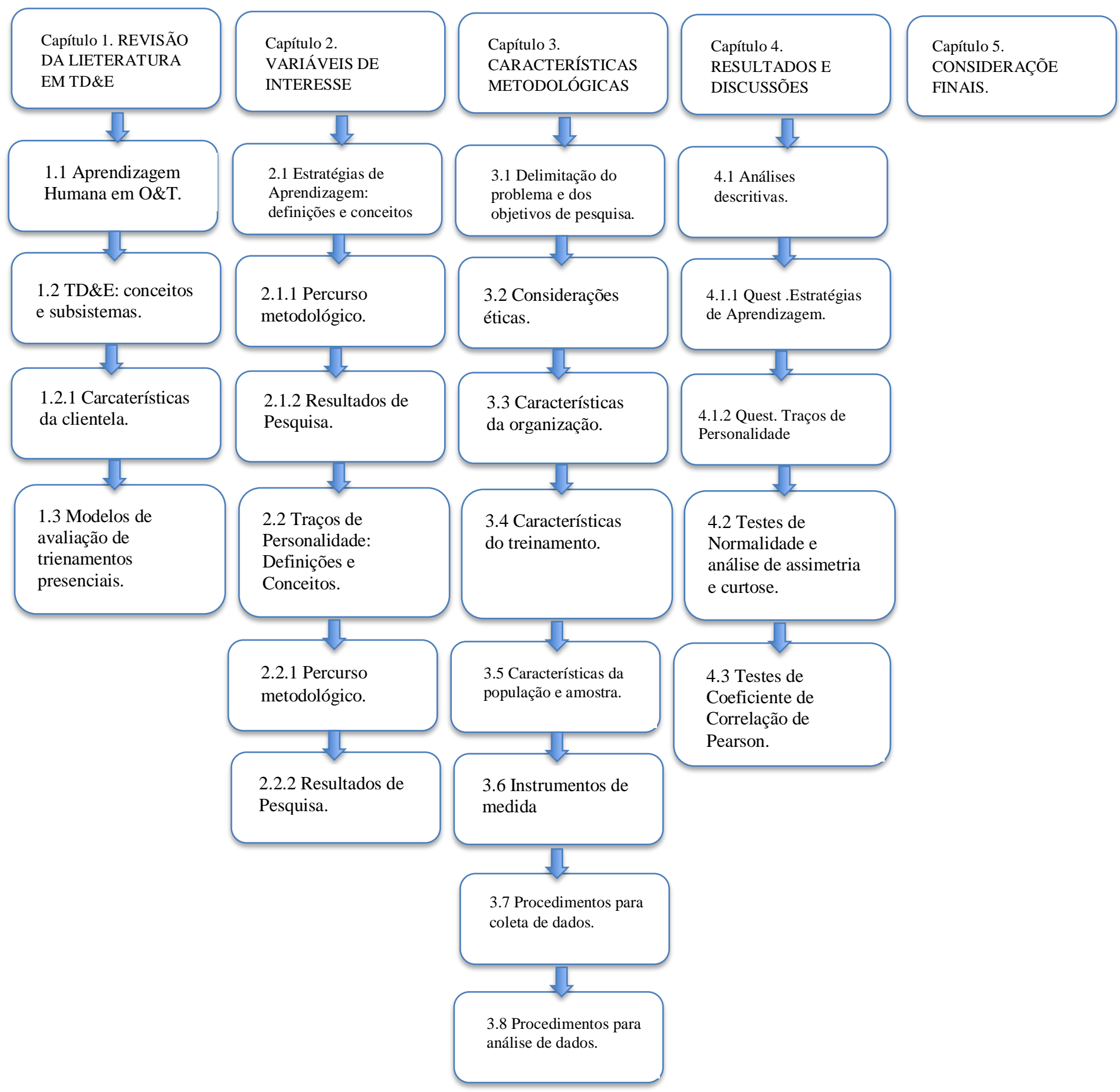

Fonte: Elaboração da autora. 


\section{Capítulo 1. Revisão da Literatura em Treinamento, Desenvolvimento E EduCAÇÃo de PeSsoas (TD\&E)}

\section{ObJetivo do Capítulo 1}

O objetivo deste capítulo é apresentar conceitos, teorias e abordagens relacionados ao processo de aprendizagem humana, bem como sua aplicação em contexto de organizações e trabalho. Além disso, são discutidos os conceitos, componentes e características dos processos formais que promovem a aprendizagem induzida no trabalho: ações de TD\&E presenciais, com foco nos métodos do subsistema de Avaliação.

\subsection{Aprendizagem Humana: teorias, Conceitos e Aplicação em ConteXto de OrganizaÇões E TrabalHo (O\&T)}

Antes de aprofundar nas variáveis de interesse deste estudo e buscar compreender como elas influenciam no processo de aprendizagem, se faz importante compreender o conceito de aprendizagem e as possibilidades de sua ocorrência em contextos de organizações e trabalho. A teoria da aprendizagem é uma construção humana para interpretar sistematicamente a área de conhecimento chamada de aprendizagem que, por sua vez, é uma maneira particular de ver as coisas, de explicar e prever observações, de resolver problemas (Moreira, 2011). Trata-se de um tema estudado há muitas décadas pela Psicologia Geral e Experimental, bem como por outras disciplinas, tais como a Pedagogia e Administração de Empresas. Tantos olhares diferenciados levam a uma falta de consenso acerca das concepções sobre aprendizagem.

Contudo, há um ponto de convergência que concebe a aprendizagem como uma mudança relativamente permanente no comportamento do indivíduo, resultante de sua interação com o meio, e não unicamente de sua maturação (Abbad \& Borges-Andrade, 2014; Illeris, 2013; Santrock, 2009). A Psicologia da Aprendizagem se vale das diferentes teorias que procuram explicar como os indivíduos aprendem, como se expressa seu desenvolvimento mental e como se estruturam os modelos institucionais, buscando nortear planejadores instrucionais a fim de que utilizem de forma adequada os métodos, técnicas e recursos de instrução e para que, consequentemente, melhorem a qualidade do ensino.

As principais teorias psicológicas que tem como objetivo explicar os mecanismos individuais envolvidos em processos de aprendizagem podem ser divididas em três: comportamentalistas, cognitivistas e humanistas (Meneses, Zerbini, \& Abbad, 2010). A Tabela 
1 apresenta, a partir do mapa elaborado por Moreira (2011), os principais enfoques teóricos relacionados à aprendizagem e ao ensino, bem como seus principais precursores, ideia principal e conceitos básicos.

Tabela 1. Enfoques teóricos referentes à aprendizagem e ao ensino

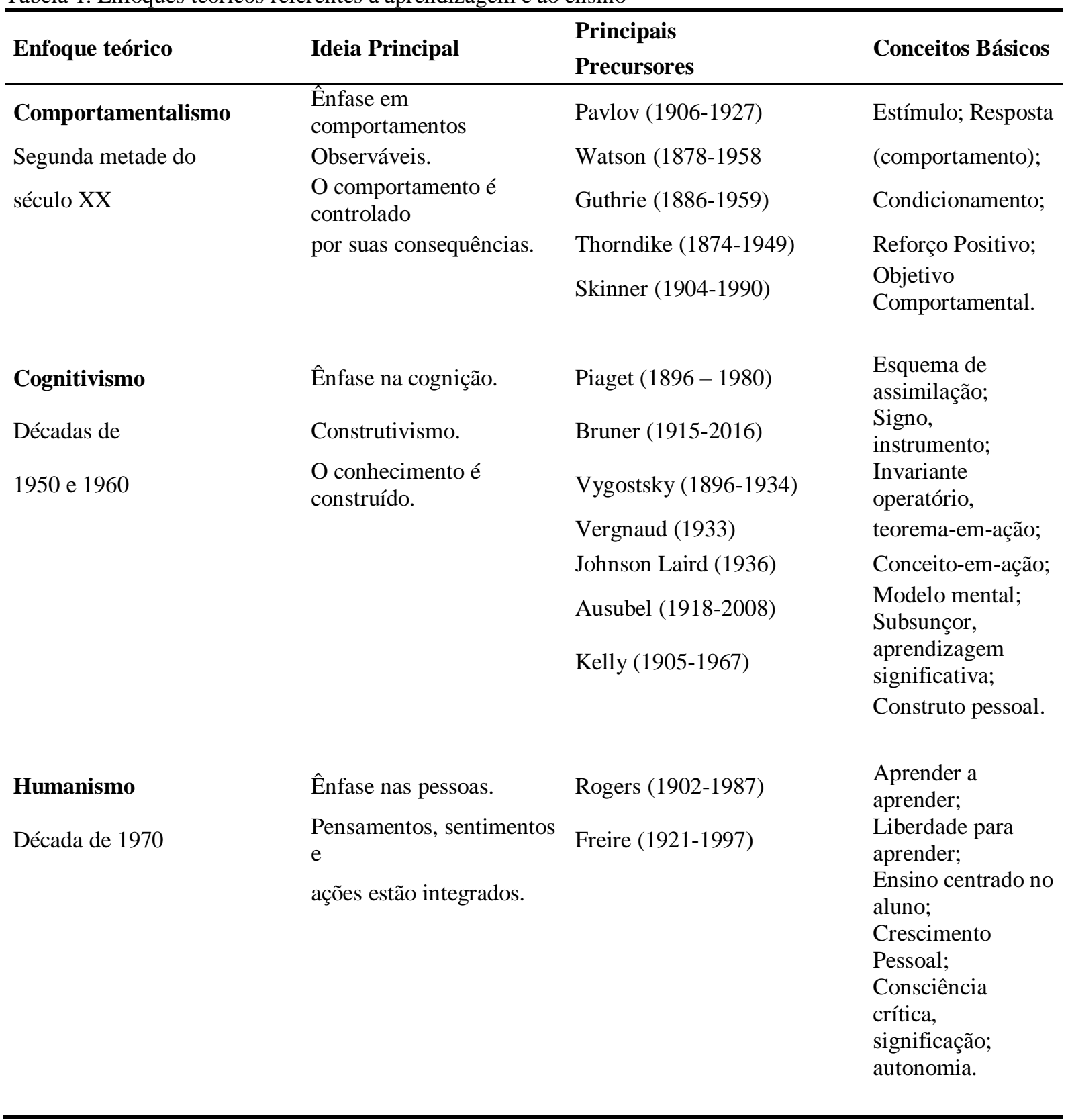

Fonte: Morerira (2011).

Na primeira metade do século XX surgiram teorias comportamentalistas (teorias $\mathrm{S}-\mathrm{R}$ ) Mayer (1992 como citado em Meneses et al., 2010). Nestas, o foco é a mudança duradoura de comportamento (R), resultante da interação do indivíduo com seu ambiente (S). A aprendizagem é compreendida como um processo de aquisição de respostas decorrente do contato com estímulos ambientais sistematicamente organizados, que se dá por meio de 
sucessivas associações entre os comportamentos emitidos pelos aprendizes e determinadas consequências (reforços e punições).

Nas teorias cognitivistas (teorias S-O-R), que marcam as décadas de 1950 e 1960, a mudança de comportamento $(\mathrm{R})$ como produto da interação com o ambiente (S), resultaria, antes, em processos mentais ou na aquisição de conhecimentos, habilidades e atitudes, ou "CHAs", que poderiam ser inferidos a partir daquelas mudanças (Abbad \& Borges-Andrade, 2004). Aqui, o indivíduo é considerado uma entidade ativa que adquire, armazena e recupera informações. Educar implica em provocar o desequilíbrio no organismo para que ele, em busca de um novo equilíbrio, reestruture-se cognitivamente e aprenda. Oriunda da década de 1970, a teoria humanista busca considerar o indivíduo em sua plenitude, assim, a aprendizagem, além de conhecimentos, depende também dos sentimentos, atitudes e escolhas do indivíduo, importando sua autorrealização e seu desenvolvimento integral (cognição e afetividade).

Como descrevem Abbad e Borges-Andrade (2014), as teorias cognitivistas consideram a influência dos processos mentais na aprendizagem, sendo a mais utilizada pela psicologia instrucional nas últimas décadas pelo seu caráter objetivista. Estas teorias também têm embasado grande parte do que já se produziu cientificamente em desenho instrucional.

No que se refere à Psicologia Instrucional, esta utiliza elementos descritivos (teoria instrucional) e prescritivos (desenho instrucional) no planejamento de ações educacionais, que envolvam um conjunto de fatores externos que podem apoiar e facilitar os processos de aprendizagem, sendo alguns dos mais importantes: 1) obter atenção do aprendiz; 2) informar o objetivo educacional; 3) lembrar pré-requisitos; 4) apresentar estímulo ao aprendiz; 5) fornecer guias de aprendizagem; 6) provocar o desempenho; 7) fornecer feedback; 8) avaliar o desempenho; 9) aumentar retenção e transferência (Gagné, 1988). Ressalta-se que as abordagens discutidas no presente estudo são guiadas pelas teorias cognitivistas.

Como visto, há muitas teorias e vertentes de estudo que produzem contribuições para a compreensão do processo de aprendizagem em contexto de O\&T. É importante ressaltar que ainda não há um método definitivo de ensino-aprendizagem, que se sobreponha a outros, ou que possa ser considerado completo. Abbad, Nogueira e Walter (2006) enfatizam a relevância de entender as teorias de aprendizagem em pesquisas de TD\&E como forma de fundamentar a prática profissional e a aprendizagem contínua no trabalho. Alguns autores destacam ainda que é possível utilizar elementos de teorias distintas em ações educacionais devido à complexidade do processo de aprendizagem (Pozo, 2002), principalmente no ambiente de trabalho, onde as mudanças são constantes, bem como as exigências técnicas para se adequar às demandas do mercado. 
A aprendizagem no local de trabalho pode ser definida como uma interação entre o indivíduo e o ambiente social que estimula o desenvolvimento de competências por meio de treinamento vocacional ou conjunto de prática, levando a uma mudança comportamental (Cairns \& Malloch, 2011). Estudos acerca da aprendizagem neste contexto têm aumentado nos últimos anos, especialmente aqueles relacionados a essas teorias e ferramentas que proporcionam meios para promover maior eficiência do processo de TD\&E. Porém, trata-se de um campo amplo e com muitas variáveis envolvidas. Assim, um dos primeiros passos é compreender os motivos pelos quais os indivíduos aprendem.

Camillis e Antonello (2010) defendem que há quatro motivos para os indivíduos aprendem em contexto de trabalho, sendo eles: execução de uma nova tarefa (mesmo a mais básica tarefa a ser realizada, exige que alguma orientação, procedimento ou regra sejam apresentados, portanto, remete à necessidade de serem aprendidos); resolução de problemas (em muitos casos, há necessidade de se aprender algo, seja a aquisição de um novo conhecimento ou o desenvolvimento de uma competência para se conseguir a solução desejada); necessidade de se obter autonomia (se refere a não precisar depender de outras pessoas no ambiente de trabalho, buscando-se aprender a executar com maestria as tarefas, conhecendo leis, regras e procedimentos); aumentar as chances de crescimento na empresa (indivíduos procuram medidas formais de aprendizagem como parte de uma estratégia de médio ou longo prazo para construção de carreira).

Há de se considerar ainda que a aprendizagem pode se dar por vias informais (aprendizagem natural) ou formais (aprendizagem induzida). Segundo Abbad e BorgesAndrade (2014), a aprendizagem natural não necessita de procedimentos sistemáticos para ocorrer. Kock e Ellström (2010) corroboram essa ideia dizendo que a aprendizagem informal é um processo no qual as pessoas melhoram seu desempenho realizando atividades por meio da interação com outras pessoas, ferramentas, matérias, de modo que, o aprendizado surge naturalmente como parte do processo. Assim, a combinação de efetividade da aprendizagem formal e informal é crucial, dado que ambas potencialmente contribuem para o desenvolvimento profissional do indivíduo (Malcolm, Hodkison, \& Colley, 2003; Moraes e Borges-Andrade, 2015b).

Pensando neste cenário, Illeris $(2004,2011)$ propõe um modelo de aprendizagem no local de trabalho que integra dois processos complementares de aprendizagem que podem promover o desenvolvimento de competências, sendo um processo psicológico interior e um processo interacional. O processo psicológico anterior refere-se à associação do indivíduo de conhecimentos recém adquiridos com experiências prévias e sua elaboração, considerando a 
definição cognitiva da aprendizagem e, assim, mais relacionados a eventos de aprendizagem formal. Já o processo interacional externo diz respeito a duas dimensões que podem aumentar ou inibir o processo de aprendizado interno. Mais especificamente, uma interação bidirecional entre novos conteúdos e atributos individuais como aprendizagem estratégias, motivação e emoções, chamadas dinâmicas, que podem afetar o treinando. Além disso, uma interação entre o processo interno e o processo técnico-organizacional (por exemplo, práticas, estrutura e recursos) e sociocultural (por exemplo, grupos sociais e comunidades) as dimensões do ambiente de trabalho podem ser determinantes. Tais processos interacionais dificilmente podem ser planejados ou estruturados anteriormente.

Nesta perspectiva, Kock e Ellström (2010) discutem a importância do ambiente de trabalho no processo de aprendizagem, considerando que este se constitui como uma conexão com o desenvolvimento do indivíduo e da empresa, onde a aprendizagem é baseada na experiência dos indivíduos, sendo o próprio local de trabalho um espaço para educação e treinamento. Já a aprendizagem induzida ou formal (Abbad et al., 2006), ocorre mediante planejamento sistemático de procedimentos e estratégias instrucionais visando o alcance de determinados CHA's, também previamente delineados.

Raymond, Clarke e Klein (2014) revelam que as organizações investem em grande parte em ações de treinamento, que estão associadas à aprendizagem formal. Porém, segundo os autores, cerca de $75 \%$ da aprendizagem no trabalho é informal. Neste sentido, a combinação de eficácia da aprendizagem formal e informal é crucial, uma vez que ambos contribuem para o desenvolvimento profissional do indivíduo (Moraes \& Borges-Andrade, 2015b).

Illeris (2004) acrescenta que a aprendizagem não ocorre somente em um local fixo no qual o indivíduo trabalha, mas também em outros pontos adjacentes como cursos, interações sociais, contato com clientes, fornecedores, sindicatos e em outros contextos relacionados ao trabalho. Assim, ele propõe um modelo holístico com elementos centrais, campos e processos que configuram a aprendizagem no trabalho. Segundo o autor, o aprendizado ocorre no encontro entre os ambientes de aprendizagem e os processos de aprendizagem dos empregados, sendo destacados três componentes: o ambiente de aprendizagem técnico organizacional, o ambiente de aprendizagem social e os processos de trabalho.

No Congresso de Psicologia Organizacional e do Trabalho (CBPOT) ocorrido em Goiânia, em junho de 2018, Gardênia Abbad discute, Doutora em Psicologia pela Universidade de Brasília e referência na área de TD\&E, em sua apresentação que um dos desafios das pesquisas em TD\&E está justamente em como integrar aprendizagem informal e formal, bem como em identificar efeitos de programas de TD\&E em todos os níveis: indivíduo, equipe, 
organização e sociedade. A pesquisadora coloca tais questões como um dos caminhos para aumentar a efetividade de programas de TD\&E. Destaca-se que, apesar de considerar de extrema importância tal integração, devido suas limitações a presente pesquisa tem como foco a aprendizagem induzida. Assim, a próxima seção aborda os componentes de ações formais de TD\&E.

\subsection{Treinamento, Desenvolvimento e Educação de Pessoas: Conceitos e SUBSISTEMAS}

Permeada pelas questões do processo de aprendizagem discutidas na seção anterior, na Psicologia Organizacional e do Trabalho (POT), a área de TD\&E investiga ações educacionais que utilizam tecnologias instrucionais e têm como objetivo superar lacunas de desempenho no trabalho, preparar os indivíduos para novas funções ou proporcionar o livre crescimento pessoal e profissional das pessoas de uma organização (Borges-Andrade, 2002). Neste sentido, exerce uma função estratégica e de sustentabilidade, tanto para as empresas quanto para os trabalhadores (Abbad \& Borges-Andrade, 2014).

Do ponto de vista científico, o TD\&E é uma área de conhecimento que auxilia na promoção de aprendizagem contínua, no desenvolvimento e consolidação de competências técnicas e comportamentais essenciais ao desempenho profissional de seus membros, melhorando a sua performance no trabalho (Salas et al., 2012). Ainda para estes autores, as atividades de TD\&E são fundamentais para a construção e a manutenção de uma força de trabalho efetiva. Elas permitem que as organizações se adaptem, compitam, inovem, produzam, mantenham-se seguras, melhorem o atendimento e atinjam metas. Trata-se de apreensão e transferência de novos conhecimentos, habilidades e atitudes (CHAs) para o ambiente de trabalho.

Cumpre ressaltar que para a área de TD\&E a aquisição de conhecimentos está relacionada à apreensão dos conhecimentos, habilidades ou atitudes (CHA) na memória de curto prazo, enquanto a retenção é o processo de armazenamento das informações na memória de longo prazo. A generalização acontece quando o indivíduo é capaz de demonstrar o que foi aprendido nas ações de TD\&E em situações diferentes das estabelecidas pelo curso. Os processos de aquisição, retenção e generalização são fundamentais para que ocorra a transferência do que foi aprendido para o desempenho do indivíduo no trabalho, mas não são suficientes. Para que os CHA aprendidos sejam utilizados no trabalho é preciso ocorrer o processo de transferência (Abbad \& Borges-Andrade, 2014). 
Ademais, para além de apreensão e transferência dos CHAs, ao promover uma ação instrucional, uma organização espera que as novas competências adquiridas pelos colaboradores possam provocar impactos nos processos de trabalho das equipes e resultados organizacionais (Aguinis \& Kraiger, 2009; Zerbini, Coelho, Abbad, Mourão, Alvim, \& Loiola, 2012a), transpondo assim o nível individual, agregando valor também nos níveis meso e macro (Burke \& Hutchins, 2007). Desta forma, são consideradas ações educacionais bem-sucedidas aquelas em que as competências adquiridas ou aprofundadas em TD\&E são aplicadas e transferidas apropriadamente para o contexto de trabalho (Aguinis \& Kraiger, 2009; BorgesAndrade, 1997; Meneses, Zerbini, \& Abbad, 2010).

Como visto, a aprendizagem formal ocorre por meio de ações estruturadas que induzem a aprendizagem. Vargas e Abbad (2006) propuseram um diagrama, representado pela Figura 2, que apresenta ações formais de TD\&E e a relação entre os conceitos e suas respectivas soluções educacionais.

Figura 2. Relação entre os conceitos e ações educacionais associadas

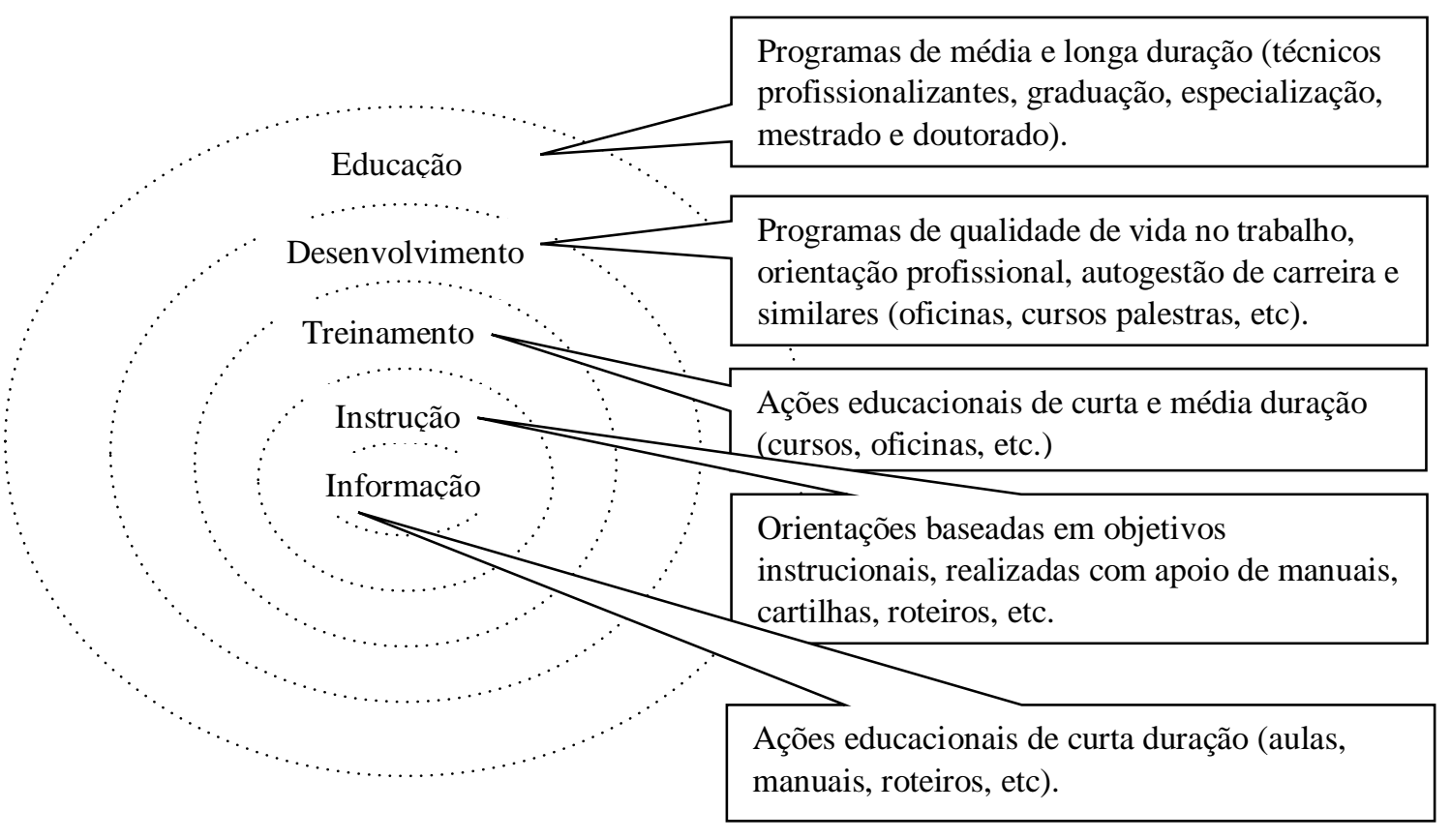

Fonte: Vargas \& Abbad, 2006.

Estes conceitos são sobrepostos, o que significa dizer que o conceito de educação engloba o de desenvolvimento, que engloba o de treinamento, e assim por diante (Vargas \& Abbad, 2006). Salas et al., (2012) apontam que treinamentos devidamente projetados 
funcionam e a maneira pela qual se dá sua entrega e implementação pode influenciar em sua efetividade. A fim de contemplar todas essas variáveis, as ações formais de TD\&E compõem um sistema integrado por três subsistemas basais, o qual segue representado na Figura 3 e descrito em seguida.

Figura 3. TD\&E: Sistema integrado

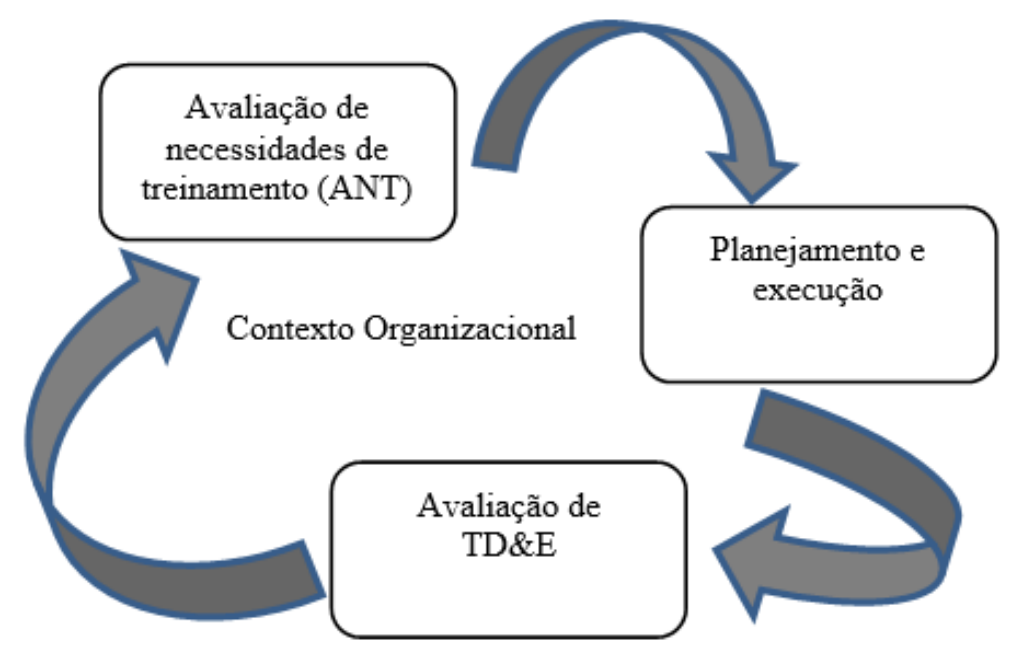

Fonte: Borges-Andrade (2006); Borges-Andrade, Zerbini, Abbad e Mourão (2013).

O subsistema de Avaliação de Necessidades de Ações Instrucionais (ANT) é responsável por determinar onde a ação instrucional é necessária, qual conteúdo deve ser treinado e quem são os agentes a participarem. Tais definições são realizadas a partir das análises: organizacional, de tarefas e individual (McGehee \& Thayer, 1961, citado em Meneses, Zerbini, \& Abbad, 2010).

A análise organizacional abrange a coleta de informações sobre o cenário (societal, organizacional, de grupos e equipes), os resultados e as variáveis contextuais, assumindo crucial importância para alinhar o treinamento à estratégia organizacional (Meneses et al., 2010; Tannenbaum \& Yukl, 1992). Para garantir o sucesso do programa de treinamento, deve-se considerar a sua congruência com as metas organizacionais, os recursos disponíveis, as restrições, os suportes à transferência, as condições de trabalho, a tecnologia circundante e o clima organizacional (Salas \& Cannon-Browers, 2001; Wexley, 1984). Contudo, estes autores mostram que a influência dessas variáveis organizacionais no treinamento tem sido negligenciada e até mesmo ignorada pelo campo de pesquisa, indicando a necessidade de se 
desenvolver ferramentas práticas e de diagnóstico para determinar o contexto organizacional onde ocorrerá o treinamento.

A análise de tarefas envolve o detalhamento das atribuições e responsabilidades ocupacionais; descrição dos CHA necessários ao desempenho das tarefas no trabalho; determinação da relevância dos CHA e das condições sob as quais o trabalho será desempenhado (Meneses et al., 2010). Por último, a análise individual identifica os indivíduos que precisam participar da ação educacional e se estes possuem certos pré-requisitos necessários ao efetivo aproveitamento dos conteúdos (Meneses et al., 2010). Uma análise individual inadequada pode resultar em um treinamento com um nível inapropriado e destinado às pessoas erradas (Tannenbaum \& Yukl, 1992).

É importante evidenciar ainda que existem algumas condições antecedentes ao treinamento passíveis de influenciá-lo, como variáveis relativas às características individuais dos participantes da ação instrucional e variáveis situacionais. Os eventos que ocorrem antes do treinamento podem ser tão importantes, ou em alguns casos, mais importantes do que aqueles que acontecem depois do treinamento (Salas \& Cannon-Bowers, 2001).

No que se refere às características individuais (condições internas antecedentes) que podem influenciar no sucesso do treinamento, os estudos têm abordado: treinabilidade capacidade cognitiva, autoeficácia, motivação, atitudes e expectativas. O conceito de treinabilidade, pesquisado desde Campbell (1971), diz da capacidade de uma pessoa em adquirir as habilidades, conhecimentos ou comportamentos necessários para desempenhar um trabalho em um determinado nível e alcançar resultados em um dado tempo. É um construto que abrange características pessoais como, por exemplo, auto eficácia, locus de controle e motivação.

Como visto, o subsistema de ANT abrange aspectos e oferece informações extremamente relevantes para a elaboração adequada de ações de TD\&E. Contudo, revisões de literatura sinalizam para uma quantidade limitada de estudos empíricos sobre este subsistema (Bell et al., 2017). Para os autores, a falta de objetivo instrucional dos programas de treinamento pode comprometer a motivação em aprender e transferir, posteriormente, acarretará em diminuição da eficácia do treinamento.

A partir dos insumos fornecidos pela ANT, a fase de Planejamento e Execução visa definir os objetivos e conteúdos instrucionais, escolher estratégias e métodos de ensino, e estabelecer critérios de avaliação apropriados para se atingir os objetivos do treinamento. As etapas aqui envolvidas consistem em: 1) definição de objetivos instrucionais; 2) seleção da modalidade de entrega; 3) análise, classificação e ordenação de objetivos instrucionais; 4) 
seleção ou desenvolvimento de estratégias e meios instrucionais; 5) definição de critérios de aprendizagem; 6) desenvolvimento e validação de materiais instrucionais; e 7) execução da ação educacional (Meneses et al., 2010).

$\mathrm{Na}$ definição dos objetivos instrucionais, especifica-se o desempenho esperado dos aprendizes ao final da ação educacional. Na etapa de análise, classificação e ordenação dos objetivos instrucionais, há uma distribuição destes de acordo com a lógica da execução da atividade, respeitando uma sequência que estimule e facilite a tarefa do aprendiz. Os objetivos são classificados de acordo com a natureza e os níveis dos resultados de aprendizagem baseados nas taxonomias de objetivos educacionais de Bloom, Engelhart, Furst, Hill e Krathwohl (1972a, 1972b).

A escolha da modalidade de ensino-aprendizagem deve ser feita com base nas informações sobre o perfil dos aprendizes: características sociodemográficas, funcionais e profissionais, além daquelas relacionadas às lacunas de CHA. Também é necessário analisar a disponibilidade de recursos financeiros, materiais e recursos tecnológicos disponíveis na organização necessários à implantação da modalidade de entrega da ação educacional escolhida.

$\mathrm{Na}$ etapa de seleção ou desenvolvimento de estratégias e meios instrucionais, são selecionadas as técnicas, os métodos e as abordagens mais adequadas a serem utilizadas durante a instrução para facilitar o processo de aprendizagem. Os recursos precisam estar de acordo com os objetivos elaborados e com o perfil da clientela, de modo a maximizar a execução dos desempenhos descritos nos objetivos educacionais ao final da ação. Posterior a isso, são definidos os critérios de aprendizagem, e no momento de desenvolvimento e validação de materiais instrucionais, eventuais ajustes devem ser realizados pela equipe de planejamento instrucional para que ação educacional seja executada.

Tannenbaum e Yukl (1992) enfatizam que o desenho do treinamento deve levar em conta os objetivos de aprendizagem, as características dos aprendizes, conhecimentos sobre os processos de aprendizagem, e considerações práticas, tais quais restrições e relação custobenefício. Ademais, estes autores argumentam que os processos instrucionais devem aumentar a autoeficácia dos treinandos e suas expectativas de que o treinamento será bem-sucedido e levará a resultados valorizados. Os métodos devem ser adaptados às diferenças de aptidões e conhecimento prévio dos aprendizes.

Após a implementação de sistemas instrucionais, a etapa de Avaliação de Treinamento, foco do presente estudo, fornece informações sobre a efetividade e possíveis falhas das ações realizadas, bem como sobre a aplicabilidade e a utilidade destas ações, e ainda sobre o 
desempenho dos participantes e dos instrutores. Este subsistema retroalimenta os demais com o objetivo de aperfeiçoar as ações de TD\&E. Assim, o objetivo de fazer avaliação não é apenas conhecer como funciona o sistema de TD\&E e que resultados ele gera, mas também intervir nesse sistema a fim de incrementar os efeitos positivos que ele possa gerar para todos os envolvidos (Abbad, Borges Andrade, \& Mourão, 2012). A realização de uma avaliação de resultados pode compreender três grandes níveis, sendo eles: reação, aprendizagem e impacto.

A avaliação da reação visa à opinião dos participantes do treinamento sobre a programação, apoio ao desenvolvimento do módulo, aplicabilidade e utilidade do treinamento, resultados, suporte organizacional e desempenho do instrutor. Nesse momento, os participantes devem julgar os aspectos relacionados à qualidade do plano instrucional ou de sua programação (objetivos, sequência, estratégias, meios, duração), à qualidade de sua execução (desempenho do tutor) e ao apoio oferecido à execução do treinamento (instalações e materiais didáticos).

O nível da aprendizagem refere-se ao grau de assimilação dos conteúdos ensinados no treinamento, medido em termos de escores obtidos pelo participante em testes ou provas aplicadas pelo instrutor no final do curso. Por fim, o nível impacto do treinamento no trabalho se refere à autoavaliação feita pelo próprio participante acerca dos efeitos imediatos produzidos pelo treinamento em seus níveis de desempenho, motivação, autoconfiança e abertura a mudanças nos processos de trabalho. Reconhece-se que essa avaliação também pode ser feita por outras pessoas, como o supervisor, colegas, ou clientes daquele participante (Abbad, 1999).

Compreendido os três subsistemas que envolvem ações formais de TD\&E, infere-se que condições antecedentes, bem como aspectos do ambiente de trabalho (clima para transferência, apoio gerencial e de pares, motivação e oportunidade para transferir, etc), comprovadamente apresentam forte ou moderado relacionamento com o impacto do treinamento (Burke \& Hutchins, 2007; Salas et al., 2012). Todavia, estudos retratam a predominância da perspectiva do indivíduo em detrimento dos aspectos contextuais que podem afetar o desempenho, ainda que as variáveis situacionais apresentem maior poder de predição de impacto do treinamento (Abbad, Mourão, Meneses, Zerbini, Borges Andrade, \& Vilas-Boas, 2012a; Aguinis \& Kraiger, 2009; D’netto, Bakas, \& Bordia, 2008; Salas \& Cannon-Bowers, 2001; Zerbini \& Abbad, 2010b). Assim, como perspectiva desta pesquisa, a próxima seção se destina a discorrer melhor sobre os aspectos individuais envolvidos no processo de TD\&E, designado como características da clientela. 


\subsubsection{Características da Clientela}

Segundo Abbad, Pilati e Pantoja (2003), pesquisas sobre características individuais investigam os aspectos motivacionais, atitudinais e afetivos, de personalidade, demográficos e funcionais dos participantes e seus efeitos sobre resultados de treinamento. De acordo com Burke \& Hutchins (2007), é amplamente aceito que as características dos treinandos possuem um poderoso papel no impacto do treinamento no trabalho, relacionando-se positivamente com os efeitos de programas instrucionais. Meneses, Abbad, Zerbini e Lacerda (2006) corroboram tal afirmação quando dizem que as características individuais dos aprendizes, os hábitos de vida, as expectativas, as estratégias utilizadas para alcançar aprendizagens, as motivações, os interesses e as metas podem influenciar na aquisição de competências durante um evento instrucional e na sua posterior aplicação em situações de trabalho. Assim sendo, conhecer o perfil dos participantes permite ajustar os programas instrucionais às suas características individuais e necessidades (Zerbini, 2007).

Warr e Allan (1998) e Warr e Downing (2000), orientam que a inserção e a análise das características individuais em pesquisas podem auxiliar na compreensão do processo de aprendizagem em adultos, identificar aquelas que podem melhorar o desempenho em atividades e contribuir para o desenvolvimento de modelos teóricos de treinamento e de avaliação. Para os mesmos autores, várias questões levantadas na área de TD\&E podem ser respondidas por meio do estudo das características da clientela, entre elas: a (in) satisfação com o curso, a aquisição ou não de aprendizagem, a possibilidade de transferir novos conhecimentos e habilidades, o fato de indivíduos apresentarem diferentes resultados ao final de um mesmo programa de TD\&E, e quais características influenciam de fato os resultados de um processo de aprendizagem.

As características individuais são denominadas características da clientela na área de TD\&E e são classificadas por Meneses, Abbad, Zerbini e Lacerda (2006), conforme organizador exposto na Figura 4. 
Figura 4. Organizador para características da clientela

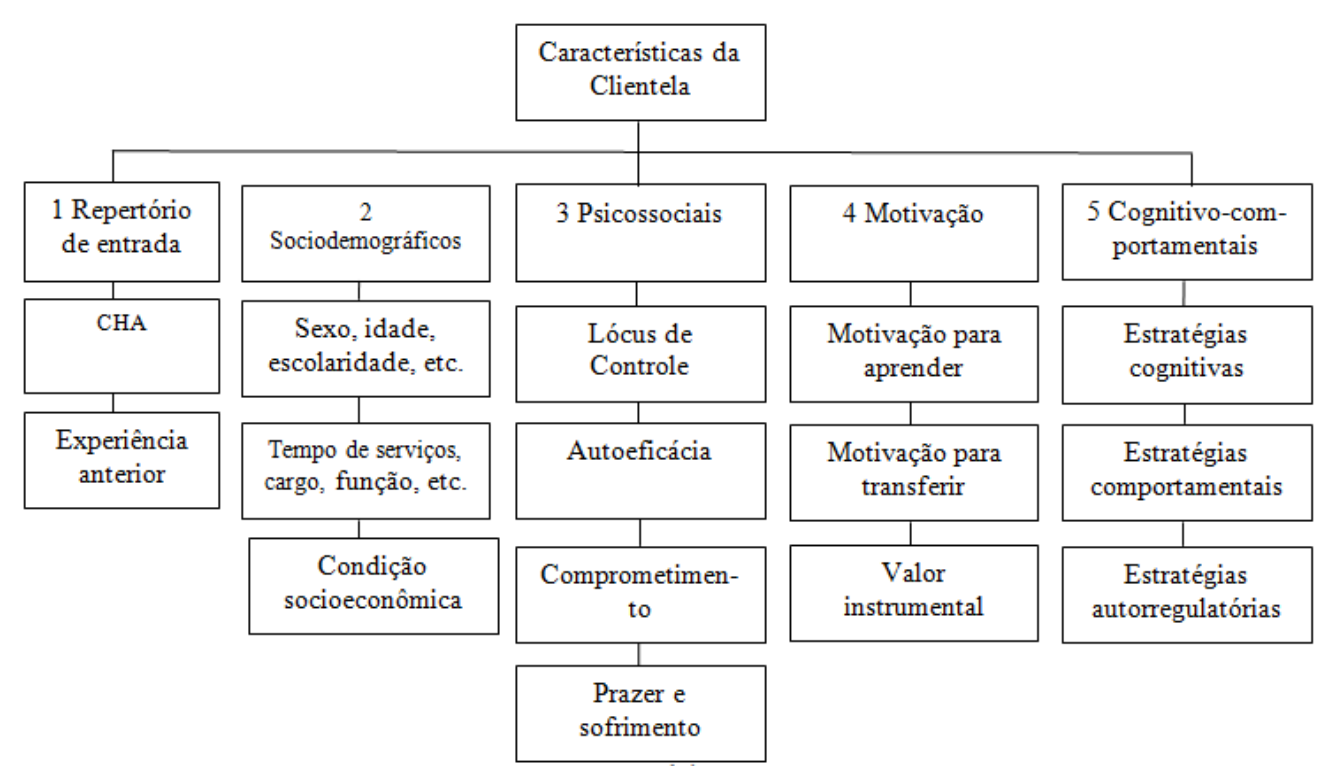

Fonte: Meneses et al. 2006.

Esta classificação está baseada no modelo IMPACT de avaliação do treinamento (Modelo Integrado de Avaliação do Impacto do Treinamento no Trabalho) proposto por Abbad em 1999, sendo as características definidas como: 1) Repertório de entrada - conjunto de conhecimentos, habilidades e atitudes, expectativas e experiências adquiridas pelos participantes antes do treinamento; 2) Sociodemográficas - relacionadas ao perfil fisionômico da clientela (sexo, idade, escolaridade, condição socioeconômica) e ao perfil profissional e funcional do participante (profissão, tempo de serviço, função, cargo, lotação); 3) Psicossociais - variáveis autorreferentes (lócus de controle, autoeficácia, comprometimento e prazer e sofrimento no trabalho); 4) Motivacionais - motivação para aprender e para transferir aprendizagem e valor instrucional da ação educacional; 5) Cognitivo-comportamentais estratégias cognitivas e comportamentais e autorregulatórias utilizados pelo participante para aprender (Meneses et al., 2006)

As características psicossociais ou autorreferentes, as quais mais se aproximam dos interesses desta pesquisa, abrange os lócus de controle, que é a maneira com que os indivíduos delegam as responsabilidades pelo fracasso ou sucesso de suas ações, podendo atribuir a ele mesmo (lócus internos) ou a outras fontes de controle (lócus externos). A autoeficácia referese a atitudes e crenças desenvolvidas por indivíduos em relação às próprias capacidades. $\mathrm{O}$ comprometimento também pertence a essa categoria e, apesar de ser um conceito amplo em psicologia organizacional, neste contexto, define-se como sentido de apego a uma organização 
de trabalho sendo uma atitude do indivíduo. Outra característica psicossocial apresentada pelo organizador é o prazer e sofrimento, sendo que, quanto maior o investimento em ações instrucionais, maior a pressão sobre os treinandos por melhores desempenhos (Meneses et al., 2006; Meneses \& Abbad, 2012; Wen \& Lin, 2014).

As revisões produzidas pela área de TD\&E têm mostrado uma pequena produção de artigos científicos sobre as variáveis autorreferentes (Abbad et al., 2003; Gonçalves \& Mourão, 2011; Ferreira \& Abbad, 2014). Zerbini (2007) alerta para o fato de que pesquisas em características da clientela são necessárias para entender a aprendizagem em adultos. Como mostra o estudo produzido por Bell et al. (2017), as características dos indivíduos podem ser amplamente definidas para incluir capacidades (e.g., habilidades cognitivas e aptidões específicas), traços de personalidade (e.g, Big Five, lócus de controle), construções motivacionais (e.g., autoeficácia, orientação para objetivos), valores e interesses (e.g, interesses profissionais e ocupacionais), atitudes e emoções (e.g., motivação para aprender) e percepções (e.g., apoio gerencial percebido, clima para treinamento, suporte).

Segundo Meneses et al., (2006), é necessário conhecer o perfil da clientela, mesmo antes de se iniciar o planejamento da ação educacional, para que certas questões sejam respondidas como, por exemplo:

1 - Até que ponto os indivíduos podem modificar seus repertórios de conhecimentos, habilidades e atitudes?;

2 - As ações de TD\&E são capazes de desenvolver competências profissionais, algumas vezes, não-coerentes com os traços de personalidade e características do indivíduo?;

3 - Por que indivíduos, sob as mesmas condições de aprendizagem, apresentam diferentes resultados ao final de um programa de TD\&E?;

4 - Por que alguns aprendem e outros não?;

5 - Por que uns são capazes de transferir aprendizagem e outros não?;

6 - As necessidades de TD\&E são influenciadas pelas características da clientela?

A resposta para essas e outras perguntas acerca da característica da clientela permitiriam a implementação bem-sucedida de ações educacionais, bem como a adoção de estratégias de ensino e aprendizagem capazes de beneficiar a todos os participantes de tais ações (Meneses, Zerbini \& Martins, 2012).

Um ponto de extrema relevância ao se estudar as características da clientela em treinamentos é a cautela quanto à compreensão dessas variáveis, pois, pode-se erroneamente diante dos escores obtidos, entender que o sucesso ou fracasso da ação se deve às pessoas que passaram por ações de treinamento. Ao contrário disso, o objetivo do levantamento das 
características da clientela é oferecer mais subsídios para direcionar o público para a ação certa ou modificar a ação instrucional de acordo com as características do público alvo (Warr \& Downing, 2000; Meneses et al., 2006; Martins \& Zerbini, 2015; Wen \& Lin, 2014).

No caso desta pesquisa que traz a variável traços de personalidade, essa cautela é importante para reforçar que a inclusão de medidas nesta natureza em avaliações de TD\&E não pretende tachar os sujeitos, mas sim contribuir para o objetivo de desenhos instrucionais mais adequados ao público a que se destina, bem como auxilía-los a se engajar em um processo de aprendizagem mais autorregulatório. A próxima seção aprofunda no subsistema de avaliação de treinamento, mais especificamente, os modelos de avaliação de treinamento presencial, foco deste estudo.

\subsection{Modelos de Avaliação de Treinamentos Presenciais}

Conforme visto na seção anterior, o subsistema de avaliação é importante para ações educacionais, pois retroalimenta todo o sistema com informações que contribuem para o seu aprimoramento. Assim, segundo Pineda (2010), a avaliação é uma ferramenta necessária para demonstrar resultados e dar respaldos na tomada de decisão das organizações, estando diretamente ligada à sistemas de qualidade da organização, uma vez que as informações fornecidas permitem identificar possíveis deficiências e melhorias a serem introduzidas para otimizar a função do treinamento como um todo.

Na revisão sobre o centenário da área, Bell et al., (2017) destacam que depois dos anos 2000 o desenvolvimento de novos modelos teóricos e a construção de ferramentas de relacionados à avaliação foram os artigos mais publicados. Assim, inúmeros modelos utilizados para avaliação de treinamento presencial estão disponíveis na literatura, sendo o modelo proposto por Kirkpatrick (1976) um marco na área. Este modelo é estruturado em quatro níveis de avaliação: reação, aprendizagem, comportamento e resultados. Estes níveis, de acordo com o autor, seriam sequenciais, lineares e fortemente correlacionados entre si. Porém, essa relação hierárquica e positiva entre os níveis foi questionada por outras pesquisas, surgindo modelos mais contemporâneos, considerados integrativos, os quais focalizam componentes capazes de explicar a ocorrência dos resultados dos eventos instrucionais.

Contudo, grande parte dos modelos de avaliação encontrados na literatura são geralmente baseados em noções dos quatro níveis originais, sendo o modelo ainda amplamente utilizado em cenários nacionais (principalmente pela área da Administração) e internacionais (Praslova, 2010; Martins, 2012; Reio, Rocco, Smith, \& Chang, 2017). Desta forma, Reio et al. 
(2016) listam outros modelos que surgiram a partir do proposto por Kirkpatrick (1976), dos quais os presenciais são apresentados a seguir.

$>$ Hamblin (1978): Modelo dos Cinco Níveis (Reação, aprendizagem, comportamento no cargo, organização.);

$>$ Brinkerhoff (1987): Modelo em Seis Estágios (Começa com a avaliação das necessidades e identifica os objetivos do treinamento. O estágio dois avalia o desenho do programa, o estágio três avalia a implementação do programa, o estágio quatro avalia o aprendizado, o estágio cinco avalia o comportamento e o estágio seis avalia quanto do aprendizado foi transferido para os resultados.);

> Stufflebeam (1988): Modelo CIPP - contexto (decisões para determinar objetivos e metas); entrada (estruturação e design do programa); processo (implementação do programa) e o produto (resultados);

$>$ Bushnell (1990): IPO Model - entrada, processo, saída (Similar a modelos sistemáticos de design instrucional. O estágio de entrada contém todos os elementos que podem afetar a eficácia do treinamento, como a competência do instrutor, materiais de treinamento, instalações e equipamentos. No estágio do processo, o treinador planeja, projeta, desenvolve e entrega o programa. O estágio de saída, ou benefícios de curto prazo, consiste nos três primeiros níveis de Kirkpatrick. O autor inclui o quarto nível de Kirkpatrick, identificandoo como benefícios de longo prazo para a linha de base da organização, incluindo lucratividade, satisfação do cliente, produtividade, etc.);

$>$ Kraiger, Ford e Salas (1993): Modelo integrado que sugere três categorias de aprendizagem de resultados (cognitivos, habilidades e afetivos);

$>$ Kaufman e Keller (1994): Propõe um modelo com 5 níveis, a saber: 1 (foi expandido para incluir capacitação e reação); 2 (aquisição); 3 (aplicação); 4 (resultados organizacionais) e 5 (transcede a organização e examina até que ponto os programas melhoram a sociedade e o ambiente em torno da organização);

$>$ Swanson (1994): (PLS) Performance - Aprendizagem - Satisfação. O modelo apresenta três níveis de análise (organização, processo e indivíduo) e cinco variáveis de desempenho em cada um dos três níveis (missão / objetivo, projeto de sistemas, capacidade, motivação e especialização). Os três domínios de avaliação são desempenho (P), aprendizado (L) e satisfação (S). O desempenho inclui a avaliação dos resultados financeiros ou comerciais da organização; a aprendizagem avalia o conhecimento do participante (domínio da informação e conceitos) e perícia (demonstração de comportamento especializado); e a satisfação é avaliada da perspectiva do participante, cliente e / ou supervisor; 
$>$ Holton (1996, 2005): HRD. Este modelo identifica três resultados de treinamento aprendizado, desempenho individual e resultados organizacionais. Ele mostra o resultado esperado do treinamento e as influências que os promovem ou inibem e identifica várias variáveis que afetam a eficácia de um programa de treinamento;

$>$ Phillips (1998): Aceita os primeiros três níveis de avaliação de Kirkpatrick, mas o quarto nível é expandido - qualidade do desempenho. O quinto nível foi acrescentado para determinar os benefícios organizacionais do treinamento convertendo os resultados do treinamento em valores monetários e comparando-os com o custo do treinamento para obter o retorno real do investimento em treinamento, ou ROI;

$>$ Swanson e Holton (1999): Revisão do modelo PLS para o modelo de avaliação da percepção de desempenho (PLP), que sustenta que o seu Sistema de Avaliação de Resultados orienta o estabelecimento de prioridades de desempenho, aprendizagem e percepção para atender a resultados desejáveis da organização;

> Moldovan (2016) O modelo de avaliação de resultados de treinamento eQvet-us, consiste em uma melhoria do modelo de Kirkpatrick ao associar ao nível de avaliação os objetivos correspondentes. O nível dos objetivos consiste no resultado, desempenho, conhecimento, motivação, que está associado ao nível de avaliação clássico composto de reação, aprendizagem, comportamento e avaliação de resultados

Ainda nesta linha dos modelos integrativos, Pilati (2004) os classificam como genéricos e específicos. Para o autor, os modelos genéricos são utilizados em avaliação de TD\&E como organizadores do campo de conhecimento e os específicos propõem os testes empíricos de relação entre variáveis, a maioria delas inspiradas pelos modelos genéricos. À medida que os testes empíricos dos modelos específicos confirmam ou não as relações mencionadas, a produção do conhecimento tem continuidade, aprimorando os modelos genéricos.

Dentre estes modelos genéricos, está o Modelo de Avaliação Integrado e Somativo (MAIS), proposto por Borges-Andrade (1982; 2006). Este é composto por cinco componentes: (1) insumo, (2) procedimentos, (3) processo, (4) resultados e (5) ambiente, incluindo assim variáveis do indivíduo, do curso e do ambiente, pois, considera que tais elementos também possam afetar os resultados de uma ação educacional (Borges-Andrade et al., 2006; Meneses et al., 2010; Abbad et al., 2012a). O modelo é apresentado no esquema da Figura 5. 
Figura 5. Modelo de Avaliação Integrado e Somativo - MAIS

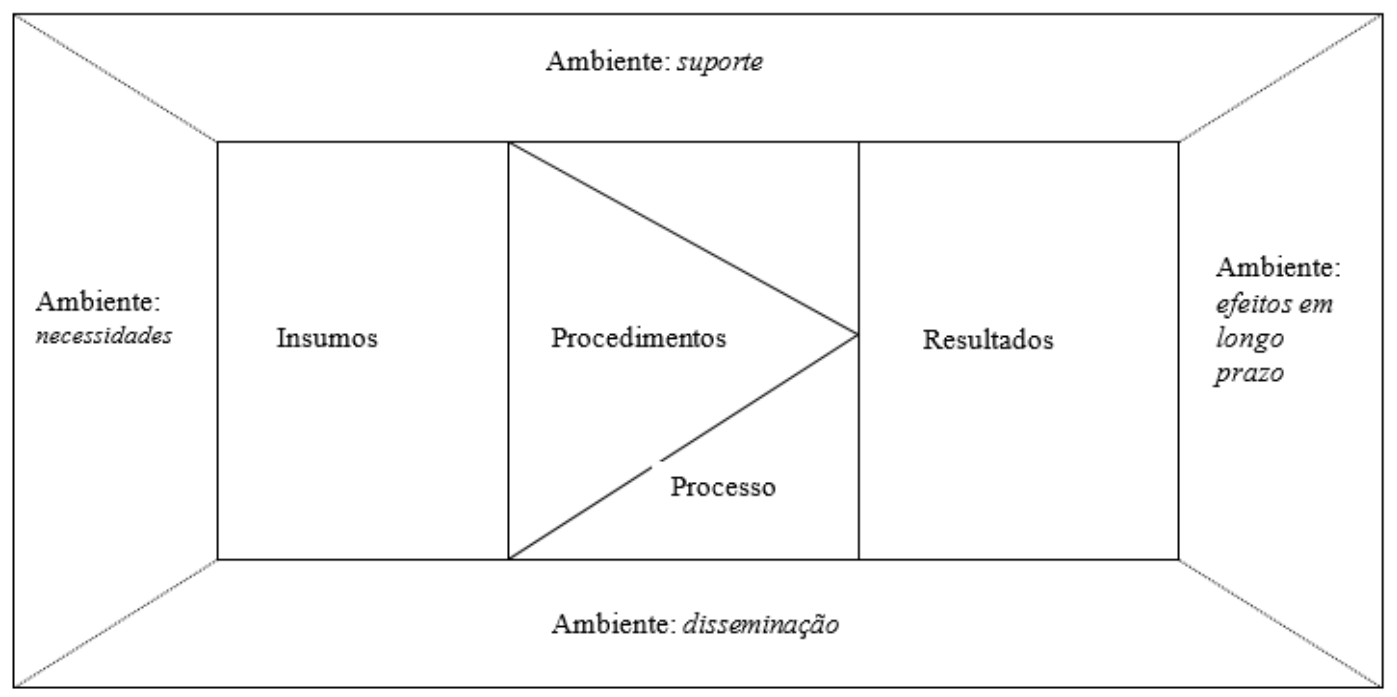

Fonte: Borges-Andrade (2006).

Conforme descreve Borges-Andrade (1982; 2006), o componente insumo refere-se a fatores anteriores à instrução - fatores físicos e sociais, e estados comportamentais e cognitivos - que podem influenciar os seus resultados (ex.: variáveis motivacionais, sociodemográficas, psicossociais, cognitivo-comportamentais). De acordo com o autor, este componente mede a capacidade do projeto de abordar as metas propostas e de planejar atividades para atingi-las.

Os procedimentos são operações necessárias para facilitar o processo de aprendizagem ou produzir resultados instrucionais como a clareza, precisão e sequência de objetivos, meios e estratégias instrucionais, exercícios propostos. Já o processo diz respeito aos resultados intermediários ou efeitos parciais do treinamento ocorridos no comportamento dos aprendizes à medida que os procedimentos são implantados (ex.: resultados em exercícios práticos, relações interpessoais estabelecidas entre pares e tutores).

O componente resultados refere-se aos efeitos produzidos pelo treinamento, ou seja, são os desempenhos finais imediatos decorrentes de TD\&E. Por último, o ambiente representa o contexto em que se insere a ação de TD\&E, e é dividido em quatro subcomponentes, sendo estes:

1 - Necessidades: são as lacunas importantes entre desempenhos esperados e realizados identifica os CHA não dominados pelos indivíduos, mas necessários para apresentarem desempenhos esperados no trabalho;

2 - Suporte: são os fatores ambientais que podem facilitar ou dificultar ações de treinamento, como: custos, recursos da organização, variáveis do lar, da comunidade ou da organização; 
3 - Disseminação: são as informações disponíveis na organização sobre o treinamento, como o programa, o material e a divulgação (natureza, método e canais);

4 - Efeitos em longo prazo: são as consequências ambientais das ações educacionais, como: comportamento no cargo ou impacto do treinamento no trabalho, mudança organizacional e valor final (Balarin, Zerbini, \& Martins, 2014; Borges-Andrade, 2006; Abbad et al., 2012a; Coelho Júnior \& Borges-Andrade, 2015).

Outros dois modelos de avaliação específicos têm destaque na área. O primeiro deles é o de Avaliação do Impacto do Treinamento no Trabalho - IMPACT, criado por Abbad (1999) e o segundo é o Modelo Integrado de Avaliação de Efetividade de treinamento - IMTEE, proposto por Alvarez, Salas e Garofono (2004). O IMPACT foi inspirado no modelo MAIS e propõe investigar o relacionamento entre variáveis relativas ao indivíduo, ao treinamento, ao contexto organizacional, aos resultados imediatos do treinamento (reação à aprendizagem) e à variável critério impacto do treinamento do trabalho (Abbad, 1999). O modelo pode ser visualizado na Figura 6.

Figura 6. Avaliação do Impacto do Treinamento no Trabalho - IMPACT

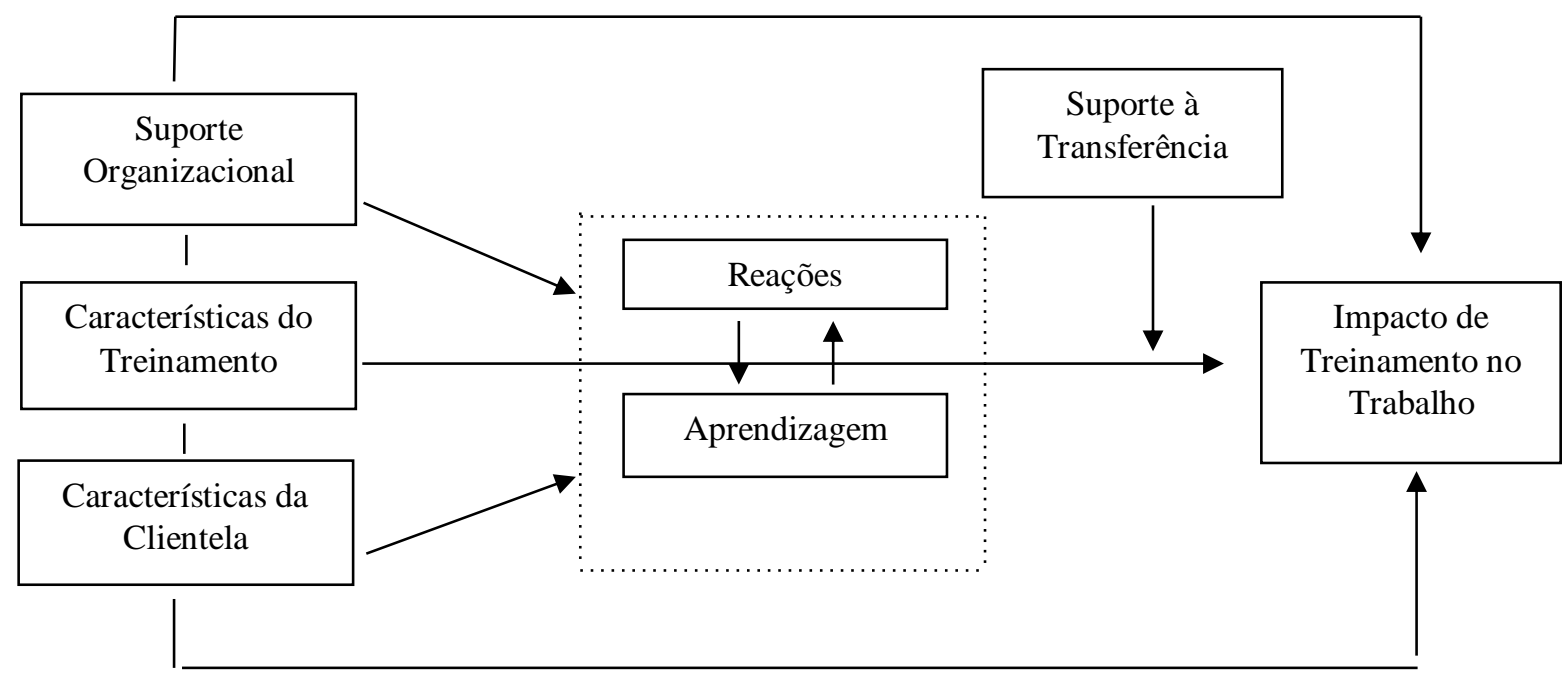

Fonte: Abbad (1999).

Como se observa na figura acima, este modelo foi testado empiricamente em termos de sete componentes, sendo estes:

1 - Percepção de suporte organizacional: envolve a opinião dos participantes sobre as práticas organizacionais de gestão de desempenho, de valorização do servidor e de apoio gerencial ao treinamento, relacionadas às condições do ambiente e nível de apoio fornecido ao treinando para participar do treinamento; 
2 - Características de treinamento: abarcam as variáveis próprias ao curso, como: área de conhecimento do curso, duração, natureza do objetivo principal do evento, origem institucional, escolaridade e desempenho do instrutor e qualidade do material didático;

3 - Características da clientela: são compostas por variáveis motivacionais, cognitivas, demográficas e funcionais dos participantes;

4 - Reação: refere-se à satisfação dos participantes com diversos aspectos da ação educacional (programação de atividades, apoio ao desenvolvimento do curso, aplicabilidade e utilidade das ações educacionais, resultados, expectativas de suporte organizacional e desempenho do instrutor);

5 - Aprendizagem: diz respeito ao grau de assimilação e retenção dos conteúdos ministrados no curso, medido em termos dos escores obtidos pelo participante em testes ou provas de conhecimentos parciais e finais;

6 - Suporte à transferência: compreende no suporte psicossocial - fatores situacionais de apoio e consequências associadas ao uso das novas habilidades no trabalho - e o suporte material à transferência, que são elementos de apoio ambiental oferecidos pela organização para que o treinando tenha a possibilidade de aplicar no trabalho;

7 - Impacto do treinamento no trabalho: abarca a auto e a heteroavaliação feita pelo próprio aprendiz acerca dos efeitos produzidos pelo treinamento em seus níveis de desempenho, motivação, autoconfiança e abertura a mudanças nos processos de trabalho (impacto em amplitude) ou pode ser definido como a aplicação (ou transferência) dos CHA apreendidos na ação educacional para o trabalho (impacto em amplitude).

O modelo IMPACT serviu para criação e validação de instrumentos de avaliação em cursos presenciais, a distância e híbridos (Borges-Andrade et al., 2012). Por sua vez, o modelo IMTEE (Modelo de Avaliação e Efetividade de Treinamento), propõe a mensuração de quatro níveis de avaliação: a) análise de necessidades, subdividida em conteúdo e projeto do treinamento, mudança nos participantes e demandas organizacionais; b) reações; c) transferência; d) resultados (Borges-Andrade et al., 2012). Este modelo segue exposto na Figura 7. 
Figura 7. Modelo de avaliação e efetividade de treinamento (IMTEE)

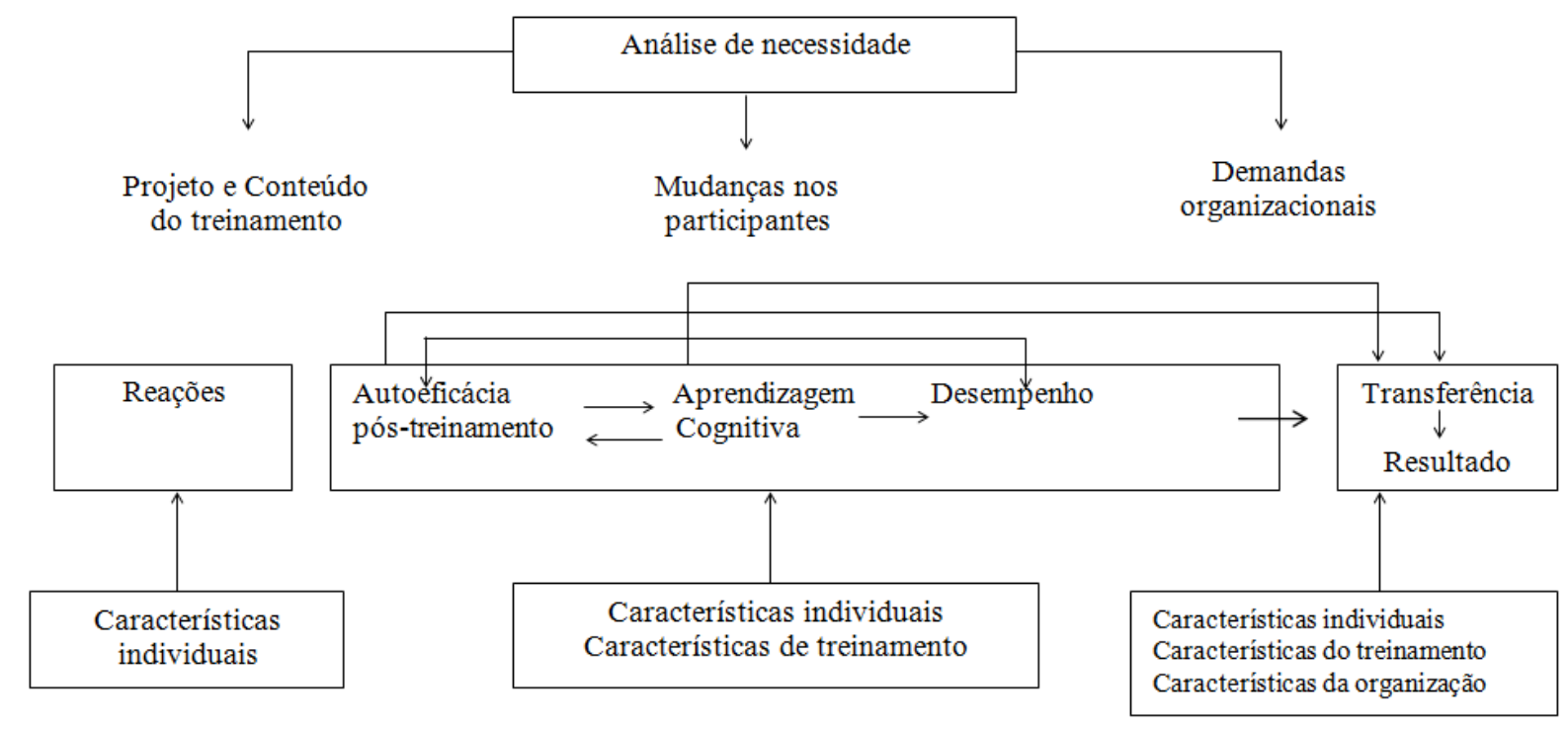

Fonte: Alvarez, Salas e Garofano (2004).

Segundo Borges-Andrade et al., (2012), existem similaridades entre o IMTEE e os modelos genéricos MAIS e de Kirkpatrick (1976) e Hamblin (1978). Os autores argumentam que os componentes e subcomponentes teoricamente previstos no MAIS aparecem com nomenclaturas mais específicas no IMTEE, que é um modelo advindo de resultados de pesquisa.

Outro modelo, criado por Nikandrou, Brinia e Bereri (2009), a partir de um estudo empírico, utilizou a abordagem sistêmica, com foco nas características do treinando, incluindo a personalidade, uma das variáveis desta pesquisa, não contemplada nos demais modelos de avaliação. 


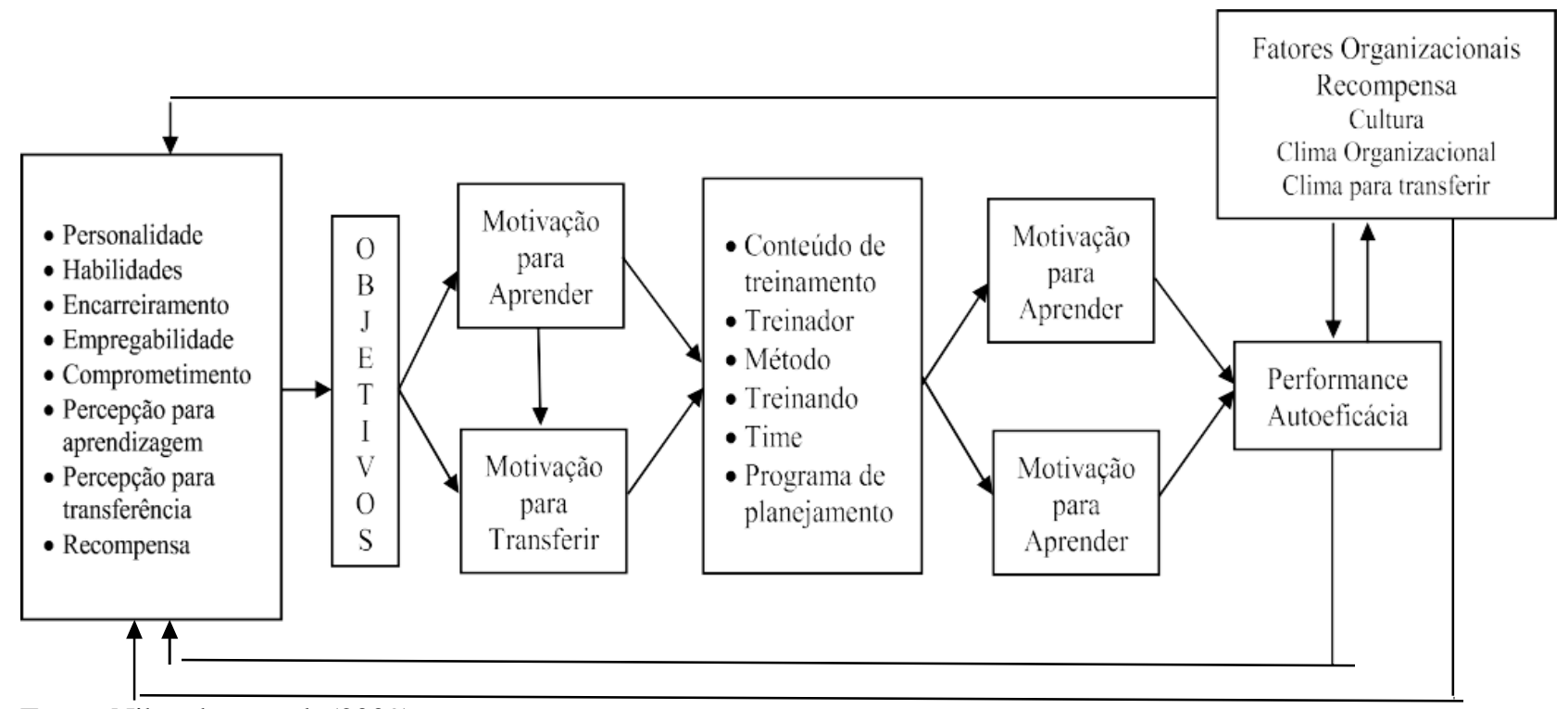

Fonte: Nikandrou et al. (2009).

Diante desta apresentação de alguns modelos de avaliação de treinamento existentes, é possível perceber que estudos realizados concentraram seus esforços no refinamento das metodologias e procedimentos aptos a analisar ações educativas, visando garantir a transferência e aplicação das competências adquiridas (Salas \& Cannon-Bowers, 2001). Através dos resultados apresentados pelas revisões clássicas, é possível constatar ainda progressos em relação ao subsistema em questão (Aguinis \& Kraiger, 2009; Raymond, Alena, Clarke, \& Klein, 2014; Salas \& Cannon-Bowers, 2001; Tannenbaum \& Yukl, 1992).

Pilati (2006) destacam que a partir da década de 90 os modelos integrados de avaliação criados possuem efetividade de avaliação suficiente para descrever um modelo geral que possa ser adaptado para cada realidade organizacional, porém, a ausência sistemática de avaliações de necessidades de treinamento e de processos efetivos de planejamento e execução instrucional torna-se uma limitação ainda marcada pelo campo da avaliação. Desta forma, estudos mais recentes da área passaram a se preocupar, de modo mais sistemático, com o planejamento e entrega de ações de TD\&E nos níveis de análise de grupos e equipes de trabalho, de forma que uma melhor compreensão desses níveis contribua para a área (Damasceno, Abbad \& Meneses, 2012).

Ademais, pesquisas nacionais e internacionais tem têm investido esforços para aprimorar seus modelos de avaliação de treinamento através de testes estatísticos robustos que propiciam melhor desenvolvimento e avaliação das variáveis propostas nas pesquisas realizadas. Como retratam Iglesias e Salgado (2012), há necessidade de transpor limitações que restringem a 
efetividade do sistema de TD\&E e comprometem o estado técnico-científico da área, tal como: restrições culturais e técnicas no uso de avaliações de aprendizagem; dificuldades de proceder a avaliações em níveis mais abrangentes; inadequações ou falta de manejo de resultados gerados por ações de TD\&E; carência de orientações teórico-metodológicas que embasam avaliações em termos de resultados organizacionais.

Como será visto nos próximos capítulos, a presente pesquisa ainda esbarra em grande parte destas limitações. Contudo, ao avaliar os traços de personalidade em conjunto com as estratégias de aparendizagem, sua inovação reside nas implicações teóricas e, principalmente, práticas nos treinamentos corporativos, uma vez que traz novos elementos, no que se refere a pesquisas nacionais, capazes de contribuir para o planejamento manejável das ações de TD\&E, bem como para a capacidade de autorregulação dos aprendizes. Assim, as variáveis supracitadas serão apresentadas e discutidas no próximo capítulo a luz de resultados de pesquisas. 


\section{CAPÍTULO 2. REVISÃo DA LITERATURA: VARIÁVEIS DE INTERESSE}

\section{ObJETIVo do CAPÍtulo 2}

O objetivo deste capítulo é apresentar definições, conceitos e a revisão de literatura, bem como discutir os resultados de pesquisas nacionais e internacionais sobre as variáveis de interesse do estudo: Estratégias de Aprendizagem e Traços de Personalidade.

Primeiramente cabe esclarecer os motivos das diferenças entre os percursos e estrutura da revisão das variáveis que serão observados neste capítulo. Para Estratégias de Aprendizagem, o objetivo foi complementar os achados de pesquisa de Martins (2016) sobre uma temática que vem sendo discutida em TD\&E, inclusive no contexto brasileiro e no próprio laboratório ao qual este estudo pertence.

No que refere à revisão sobre a variável Traços de Personalidade no contexto de TD\&E, como um dos primeiros passos desta pesquisa, foi procedida uma revisão sistemática da literatura. Primeiramente porque ao surgir o interesse pelo tema, a pesquisadora encontrou dificuldades de identificar trabalhos abrangentes e atuais, no que se refere às produções nacionais. Em segundo lugar, pretendeu-se identificar se a variável, ainda não incluída nos estudos brasileiros, sugere uma lacuna de pesquisa e se se incluí-la representaria contribuições para o avanço dos subsistemas de TD\&E, tomando como base resultados dos estudos.

\subsection{Estratégias de Aprendizagem: Definições e ConCeitos}

Estratégias de aprendizagem referem-se aos procedimentos e comportamentos que os aprendizes lançam mão no momento de estudo, visando facilitar o processo de aquisição, armazenamento e posterior aplicação dos conhecimentos aprendidos (Zerbini, 2007). Assim, por ser considerada um dos recursos para o processamento de informação, é uma variável que está positivamente associada com a aprendizagem bem-sucedida em estudos da área educacional e da psicologia organizacional que focam características pessoais do aprendiz (Oliveira, Boruchovitch \& Santos, 2009; Warr \& Downing, 2000).

Existem diferentes abordagens de estudos e de formas de classificar as estratégias de aprendizagem. Crouse, Doyle e Young (2011), por exemplo, definem estratégias de aprendizagem como maneiras pelas quais os indivíduos adquirem novos conhecimentos, habilidades e atitudes no ambiente de trabalho, como por exemplo: por meio de cursos e 
programas de treinamento, ao trabalhar com ou observar outras pessoas, tentativa e erro, lendo ou pesquisando, refletindo sobre ações, feedback e replicação.

No presente estudo, serão adotadas as definições e a classificação de estratégias de aprendizagem propostas por Warr e Allan (1998). Estes autores definem estratégias de aprendizagem como um conjunto de capacidades cognitivas, habilidades comportamentais e de autocontrole emocional (atenção, aquisição, memorização e transferência), utilizado pelo aprendiz para controlar os próprios processos psicológicos de aprendizagem. Zerbini e Pilati (2012) apresentam o sistema de classificação desenvolvido por Warr e Allan (1998), o qual propõe uma taxonomia constituída por três componentes principais que descrevem as estratégias de aprendizagem. Tal classificação é apresentada na Tabela 2.

Tabela 2. Classificação e definições das estratégias de aprendizagem

- Repetição: repetição mental da informação na forma em que foi apresentada.

Estratégias

Cognitivas
- Organização: identificação de ideias centrais do material e criação de esquemas mentais que agrupam e relacionam elementos que foram aprendidos.

- Elaboração: reflexão sobre implicações e conexões possíveis entre o material aprendido e o conhecimento já existente.

- Busca de ajuda interpessoal: obtenção de auxílio de outras pessoas, como pares e professores, para tirar dúvidas sobre o material (representa um comportamento proativo do indivíduo de solicitar ajuda ao invés de utilizar apenas as informações do próprio procedimento instrucional).

Estratégias

Comportamentais

- Busca de ajuda no material didático: obtenção de informações em documentos escritos, manuais de instruções, programas de computador e outras fontes que não envolvam contato social.

- Aplicação prática: aprimoramento do conhecimento por meio de aplicação prática do que foi aprendido.

Fonte: Warr e Allan (1998); Zerbini e Pilati (2012).

Warr e Allan (1998) sugerem que essas categorias podem ser definidas como primárias (cognitivas e comportamentais) e autorregulatórias. Os autores argumentam que as categorias primárias interferem sobre os processos de escolha, processamento, retenção e recuperação de informações, sendo usadas, portanto, na ocasião em que se dá o contato do aprendiz com os 
conteúdos a serem transmitidos. Já as categorias autorregulatórias estão relacionadas à motivação da pessoa para aprender, a autogestão de esforços, o automonitoramento do progresso durante aprendizagem e o controle da ansiedade frente a determinadas situações que estariam dissipando a atenção do aprendiz. A segunda categoria afetaria indiretamente o momento de interação do aprendiz com o objeto de conhecimento, interferindo na forma como ele mantém a motivação, gerenciamento, monitoramento do seu progresso e da ansiedade (Zerbini \& Abbad, 2008).

É importante ressaltar ainda que as estratégias de aprendizagem estão intimamente relacionadas ao conceito de autonomia. Este é um construto multidimensional que engloba os estilos de aprendizagem, as estratégias de aprendizagem, motivação, fatores afetivos, etc. (Magno \& Silva, 2008). Estes autores apresentam algumas definições sobre o conceito de autonomia e seus respectivos autores. Uma delas define autonomia como disposição para aprender a aprender, em outros termos, aprender como se aprende. Esta aposta no papel ativo do aprendiz, o qual assume uma verdadeira atitude de aprendizagem (Dickinson, 1994). Para Scharle e Szabó (2000) se trata de um processo composto por três fases: conscientização, mudança de atitude e transferência de papéis/funções. Para este autor, entender que aprender deve ser feito pelos próprios estudantes, deve causar uma mudança de atitude neles, que então, passam a assumir diferentes papéis no processo de aprendizagem, abandonando comportamentos passivos. Por último, a autonomia é definida por Benson (2001) como tomada de controle em um processo com três passos: controle sobre o manejo/gestão da aprendizagem, controle sobre os processos cognitivos e controle sobre os conteúdos da aprendizagem.

Pesquisas na área da Educação, principalmente em contexto escolar, têm demonstrado que o ensino de estratégias de aprendizagem aos alunos promove maior autonomia pessoal e aumenta sua consciência e responsabilidade sobre o próprio processo de aprendizagem (Santos, Boruchovitch, Primi, Zenorini, \& Bueno, 2004). Neste sentido, há necessidade de envolver os aprendizes em processos autorregulatórios, isto é, aqueles que promovam o monitoramento da compreensão e o controle da motivação, ansiedade e atenção no momento de estudo, para incentivá-los a refletir se estão aprendendo o que deveriam aprender e a ajustar a aquisição dos novos aprendizados, quando necessário (Salas et al., 2012).

Há de se considerar ainda o conceito de metacognição, o qual também está relacionado às estratégias de aprendizagem. Este se refere ao uso da capacidade de conhecer o funcionamento de alguns processos cognitivos como a memória, a atenção ou a compreensão (Flavell, 1970). Desta forma, enquanto as estratégias cognitivas estão voltadas para o cumprimento das tarefas, as estratégias metacognitivas relacionam-se à ordenação, regulação e 
monitoramento das primeiras, possibilitando verificar se a estratégia utilizada está gerando os resultados pretendidos (Souza, 2010) e refletir acerca das ações tomadas para o alcance do conhecimento, alterando e elaborando novos meios que permitam sanar dificuldades ou obstáculos (Oliveira, Boruchovitch, \& Santos, 2009).

Uma quantidade crescente de evidências empíricas sugere que os processos de autorregulação dos aprendizes mediam a relação treinamento aprendizagem (Aguinis \& Kraiger, 2009) e que estratégias de autogerenciamento são também relevantes para o impacto do treinamento no trabalho. Estas fornecem ao aprendiz habilidades que o auxiliam a transferir com sucesso quando volta ao local de trabalho (Burke \& Hutchins, 2007).

\subsubsection{Descrição do Percurso Metodológico Para a Revisão da literatura}

A revisão da literatura desta variável foi realizada a partir de Martins (2016), onde a autora fez um levantamento bibliográfico com o objetivo de apresentar resultados de pesquisas, bem como instrumentos nacionais e internacionais construídos para mensurar a estratégias de aprendizagem. Assim, após discorrer brevemente sobre suas principais conclusões, no intuito de identificar novos estudos, foi realizado um levantamento da produção acadêmica sobre a variável, compreendendo o período de 2015 a 2018. Para tanto, foi pesquisada a biblioteca eletrônica SciELO e as bases Proquest, PsycInfo e Web of Science, sendo estas escolhidas pela abrangência de disciplinas que comportam.

A SciELO - Scientific Electronic Library Online é uma biblioteca eletrônica que abrange uma coleção selecionada de periódicos científicos brasileiros e possui trabalhos publicados em países como: Brasil, Venezuela, Espanha, Cuba, Chile, Portugal. A base de dados ProQuest Academic Research Library concentra trabalhos nas áreas de Negócios, Artes, Educação, Saúde, Humanidades, Internacional, Direito, Psicologia, Ciência e Ciências Sociais. A PsycINFO abrange a literatura das ciências comportamentais e sociais, sendo uma das bibliotecas mais confiável e abrangente de ciência psicológica do mundo. Na Web of Science são encontrados estudos das áreas de Ciências, Ciências Sociais, Artes e Humanidades. As revistas ou journals que contêm os resumos são principalmente das áreas da Educação, Educação e Tecnologia, Saúde e Sociais.

Após testes, a busca dos artigos contemplou com os unitermos "Estratégias de Aprendizagem", "Treinamento", "Desenvolvimento" e "Educação" e "Aprendizagem". Estes também foram traduzidos para o inglês ("Leraning Strategies", "Training”, "human development", "education", "learning”) utilizando os operadores booleanos "AND" e "OR". 
Além disso, foram aplicados filtros nos campos de busca por ano de publicação, título e resumo. Os resultados do levantamento constam na Tabela 3.

Tabela 3. Distribuição dos artigos de acordo com bases de dados

\begin{tabular}{ccc}
\hline Base de dados & Levantamentos & Selecionados \\
\hline SciELO & 89 & 9 \\
ProQuest & 136 & 2 \\
PsycINFO & 35 & 0 \\
Web of Science & 187 & 2 \\
\hline
\end{tabular}

A primeira triagem constituiu-se da análise dos títulos, resumos e palavras-chave, sendo que, dos 447 artigos, 12 foram selecionados. Os artigos excluídos não abordavam a variável dentro do contexto presencial de educação superior ou corporativa, campos de interesse deste estudo. Além dos contextos mencionados, os demais critérios de inclusão adotados foram: artigos científicos publicados entre 2015 e 2018; artigos empíricos e teóricos; artigos nos idiomas inglês, espanhol e português. Na segunda etapa foi realizada a leitura detalhada dos artigos e a extração de dados, a saber: 1) Volume de publicações dos últimos 3 anos; 2) Contexto de realização das pesquisas; 3) Localização geográfica e idioma de publicação dos artigos; 4) Aspectos metodológicos; 5) principais resultados de pesquisas.

\subsubsection{Resultados de Pesquisas}

As estratégias de aprendizagem podem ser consideradas como um dos elementos decisivos à otimização dos processos de aprendizagem dos indivíduos em ambientes organizacionais (Pantoja \& Borges-Andrade, 2009). Nestes contextos há constantes demandas por resultados de aprendizagem (Moraes \& Borges-Andrade, 2010a), e ao mesmo tempo, oportunidades para promovê-la por meio de observações do comportamento dos outros, reflexão sobre a própria conduta, orientações recebidas de supervisores, etc. (Brandão \& Borges-Andrade, 2011).

Neste sentido, a revisão de literatura realizada por Martins (2016), mostra que no Brasil há uma importante linha de pesquisa sobre estratégias de aprendizagem, com foco tanto nas estratégias aplicadas pelos indivíduos para aprender durante ações formais de treinamento, como nas práticas, manifestas e encobertas utilizadas por profissionais para auxiliar a aquisição 
informal de conhecimentos e habilidades em seu ambiente de trabalho (Brandão \& BorgesAndrade, 2011; Brant, Pilati \& Borges-Andrade, 2015; Pantoja \& Borges-Andrade, 2009).

A autora evidencia ainda que estas pesquisas em andamento estão preocupadas com a validação de escalas que medem estratégias de aprendizagem no trabalho (e.g. Brandão \& Borges-Andrade, 2011; Brant, Pilati \& Borges-Andrade, 2015; Moraes \& Borges-Andrade, 2010b; Pilati \& Borges-Andrade, 2005), as quais se assemelham às dimensões de estratégias de aprendizagem propostas em outros contextos (Borges-Ferreira, 2005; Martins \& Zerbini, 2014b; Zerbini \& Abbad, 2008). Estas escalas buscam identificar as estratégias mais utilizadas para aprender no trabalho, sua influência na aquisição, retenção e aplicação das novas competências adquiridas, bem como detectar preditores do uso dessas estratégias empreendidas pelo trabalhador entre características do indivíduo, do posto de trabalho e dos contextos das organizações (Martins 2016).

Resultados do levantamento realizado por Martins (2016) - Anexo F - mostram que participantes de treinamentos com altos níveis de motivação anterior a aprendizagem, usam mais reflexão ativa, controle emocional e monitoramento da compreensão (Warr \& Downing, 2000) e que há diferenças significativas entre as estratégias de aprendizagem utilizadas no local de trabalho conforme a categoria profissional (Pantoja, 2004; Pantoja \& Borges-Andrade, 2009).

As estratégias de aprendizagem, por exemplo, mais utilizadas por gestores de um banco público foram busca de ajuda interpessoal e reflexão ativa (Brandão \& Borges-Andrade, 2011); em processos de aprendizagem informal, diferentes categorias profissionais usaram mais frequentemente as estratégias de aplicação prática e de busca de ajuda interpessoal (Pantoja \& Borges-Andrade, 2009); e as de busca de ajuda interpessoal, aplicação prática, reflexão intrínseca e extrínseca, busca de ajuda em material escrito foram preditoras da expressão de competências de liderança dentre gestores de equipes (Lins \& Borges-Andrade, 2014).

Martins (2016) atenta para o fato de que mesmo diante de todos os achados, o foco pesquisas recai sobre o processo de aprendizagem, indiretamente e em menos casos, sobre o impacto do treinamento no trabalho. Assim, há necessidade da evolução das perspectivas sobre as habilidades metacognitivas dos treinandos, isto é, da capacidade de automonitorar e autorregular as suas estratégias de aprendizagem para maximizar a aprendizagem (Burke \& Hutchins, 2007).

Neste sentido, pesquisas continuam em busca de identificar as estratégias mais utilizadas para aprender no trabalho, bem como de detectar preditores, entre características do indivíduo, do posto de trabalho e dos contextos das organizações, do uso dessas estratégias (Martins, 
2016). Logo, no intuito de identificar novos resultados advindos desses esforços de pesquisa, a Tabela 4 mostra o levantamento complementar, compreendendo o período de 2015 a 2018, a partir do de Martins (2016). Em seguida os resultados são apresentados e discutidos. 
Tabela 4. Estudos nacionais e internacionais do período de 2015 e 2017

\begin{tabular}{|c|c|c|c|c|c|}
\hline $\begin{array}{c}\text { Autores/Data/ } \\
\text { Local }\end{array}$ & Título Original & Objetivos & $\begin{array}{l}\text { Amostra/ } \\
\text { Contexto }\end{array}$ & $\begin{array}{l}\text { Procedimentos de análise } \\
\text { de dados }\end{array}$ & Principais Resultados \\
\hline $\begin{array}{l}\text { Boruchovitch \& } \\
\text { Santos (2015) } \\
\text { Brasil }\end{array}$ & $\begin{array}{l}\text { Psychometric } \\
\text { Studies of the } \\
\text { Learning } \\
\text { Strategies Scale } \\
\text { for University } \\
\text { Students }\end{array}$ & $\begin{array}{l}\text { Examinar as propriedades } \\
\text { psicométricas de uma } \\
\text { escala likert de estratégias } \\
\text { de aprendizagem composta } \\
\text { por } 49 \text { relacionados a } \\
\text { estratégias cognitivas e } \\
\text { metacognitivas para } \\
\text { estudantes universitários. }\end{array}$ & $\begin{array}{l}1.490 \\
\text { estudantes } \\
\text { universitários. }\end{array}$ & Análise fatorial. & $\begin{array}{l}35 \text { itens tiveram cargas aceitáveis e } \\
\text { identificaram três estruturas fatorial: } \\
\text { Fator } 1 \text { - Autorregulação Cognitiva e } \\
\text { Metacognitiva, Fator } 2 \text { - Regulação } \\
\text { Interna de Recurso e Contexto, e Fator } \\
3 \text { - Regulação social. Mais estudos são } \\
\text { sugeridos com base nas análises } \\
\text { fatoriais confrmatórias, de modo que a } \\
\text { escala possa ser usada na avaliação } \\
\text { psicoeducacional. }\end{array}$ \\
\hline $\begin{array}{l}\text { Ramírez- } \\
\text { Martínez, } \\
\text { Gallardo- } \\
\text { Matienzo, Mita- } \\
\text { Arancibia \& } \\
\text { Mita-Arancibia } \\
\text { (2015) } \\
\text { Bolívia }\end{array}$ & $\begin{array}{l}\text { Relación entre } \\
\text { prácticas } \\
\text { pedagógicas y } \\
\text { estrategias de } \\
\text { aprendizaje en } \\
\text { docentes } \\
\text { de carreras de la } \\
\text { salud }\end{array}$ & $\begin{array}{l}\text { Analisar o uso de } \\
\text { estratégias de } \\
\text { aprendizagem de acordo } \\
\text { com as abordagens de } \\
\text { aprendizagem em } \\
\text { estudantes do estágio } \\
\text { rotativo da Faculdade de } \\
\text { Medicina da Universidade } \\
\text { San Francisco Xavier de } \\
\text { Chuquisaca. }\end{array}$ & $\begin{array}{l}110 \text { estudantes } \\
\text { Universitários. }\end{array}$ & Corralção de Pearson. & $\begin{array}{l}\text { As abordagens estratégica e profunda } \\
\text { apresentam correlações significativas } \\
\text { com estratégias de aquisição, tais como } \\
\text { revisão mental, revisão repetida e } \\
\text { sublinhado linear, e codificação, com } \\
\text { questões próprias, aplicações e relações } \\
\text { intra-conteúdo. Nestas abordagens, há } \\
\text { correlação com todas as estratégias de } \\
\text { recuperação e com as de apoio, com } \\
\text { auto-instruções, planejamento de } \\
\text { autogestão e autogerenciamento. A } \\
\text { abordagem superficial não se } \\
\text { correlaciona sem estratégia de } \\
\text { codificação. }\end{array}$ \\
\hline $\begin{array}{l}\text { Akçãoglu (2016) } \\
\text { Turquia }\end{array}$ & $\begin{array}{l}\text { Teacher } \\
\text { Candidates' } \\
\text { Learning } \\
\text { Strategies and } \\
\text { Academic Self- } \\
\text { Efficacy Levels: } \\
\text { Is There a } \\
\text { Relation } \\
\text { Between the } \\
\text { Two? }\end{array}$ & $\begin{array}{l}\text { Identificar as estratégias } \\
\text { de aprendizagem dos } \\
\text { candidatos a professores e } \\
\text { os níveis acadêmicos de } \\
\text { autoeficácia. }\end{array}$ & $\begin{array}{l}256 \\
\text { candidatos a } \\
\text { professores } \\
\text { matriculados } \\
\text { em uma } \\
\text { faculdade de } \\
\text { educação. }\end{array}$ & $\begin{array}{l}\text { Correlações bivariada } \\
\text { multivariada e análise de } \\
\text { variâncias. }\end{array}$ & $\begin{array}{l}\text { Correlação significativa entre o ensaio } \\
\text { de estratégias de aprendizagem, } \\
\text { organização, auto-regulação } \\
\text { metacognitiva, associação, tempo / } \\
\text { estudo ambiental, aprendizagem entre } \\
\text { pares e busca de ajuda. Além disso, os } \\
\text { resultados indicaram que os candidatos } \\
\text { a professores tinham um nível geral de } \\
\text { alta auto-eficácia acadêmica. }\end{array}$ \\
\hline
\end{tabular}


Tabela 4. Estudos nacionais e internacionais do período de 2015 e 2017

\begin{tabular}{|c|c|c|c|c|c|}
\hline $\begin{array}{l}\text { Carrasco, Pérez, } \\
\text { Torres \& Fasce } \\
\text { (2016) } \\
\text { Chile }\end{array}$ & $\begin{array}{l}\text { Relación entre } \\
\text { prácticas } \\
\text { pedagógicas y } \\
\text { estrategias de } \\
\text { aprendizaje en } \\
\text { docentes } \\
\text { de carreras de la } \\
\text { salud }\end{array}$ & $\begin{array}{l}\text { Analisar a relação entre } \\
\text { práticas de ensino e } \\
\text { estratégias de } \\
\text { aprendizagem de } \\
\text { professores de carreiras de } \\
\text { saúde em universidades } \\
\text { chilenas. }\end{array}$ & $\begin{array}{l}200 \\
\text { professores. }\end{array}$ & $\begin{array}{l}\text { Análise de regressão } \\
\text { múltipla. }\end{array}$ & $\begin{array}{l}\text { As práticas de ensino e as estratégias de } \\
\text { aprendizagem dos professores estão } \\
\text { relacionadas. Professores } \\
\text { freqüentemente selecionam modelos } \\
\text { de estratégias construtivistas } \\
\text { estratégias, utilizando diferentes } \\
\text { práticas de ensino em seu trabalho. }\end{array}$ \\
\hline $\begin{array}{l}\text { Cunha \& } \\
\text { Boruchovitch } \\
(2016) \\
\text { Brasil }\end{array}$ & $\begin{array}{l}\text { Percepção e } \\
\text { conhecimento de } \\
\text { futuros } \\
\text { professores sobre } \\
\text { seus processos de } \\
\text { aprendizagem }\end{array}$ & $\begin{array}{l}\text { Levantar os } \\
\text { conhecimentos que os } \\
\text { futuros professores } \\
\text { tinham a respeito de suas } \\
\text { estratégias de } \\
\text { aprendizagem. }\end{array}$ & $\begin{array}{l}62 \text { estudantes } \\
\text { universitários. }\end{array}$ & Análise de conteúdo. & $\begin{array}{l}\text { Do total de participantes, } 70 \% \\
\text { declararam utilizar estratégias } \\
\text { cognitivas, enquanto somente } 30 \% \\
\text { mencionaram as metacognitivas. } \\
\text { Aventa-se que haja falta de instrução } \\
\text { adequada quanto ao uso de estratégias } \\
\text { de aprendizagem no contexto } \\
\text { educacional de formação do professor. }\end{array}$ \\
\hline $\begin{array}{l}\text { Pegalajar- } \\
\text { Palomino (2016) } \\
\text { Espanha }\end{array}$ & $\begin{array}{l}\text { Estrategias de } \\
\text { aprendizaje en } \\
\text { alumnado } \\
\text { universitario para } \\
\text { la formación } \\
\text { presencial y } \\
\text { semipresencial }\end{array}$ & $\begin{array}{l}\text { Determinar as estratégias } \\
\text { de aprendizagem de } \\
\text { Estudantes universitários } \\
\text { para sala de aula ou } \\
\text { aprendizado } \\
\text { semipresencial. }\end{array}$ & $\begin{array}{l}80 \text { estudantes } \\
\text { universitários. }\end{array}$ & $\begin{array}{l}\text { Análises descritivas dos } \\
\text { dados e Teste } t \text {. }\end{array}$ & $\begin{array}{l}\text { Existem diferenças estatisticamente } \\
\text { significantes em termos de estratégias } \\
\text { de planejamento (mais favoráveis para } \\
\text { alunos em aprendizado } \\
\text { semipresencial) e armazenamento de } \\
\text { informações (para os alunos que } \\
\text { aprendem em sala de aula). São } \\
\text { necessários ambientes de } \\
\text { aprendizagem que facilitem a inovação } \\
\text { e a participação dos estudantes no } \\
\text { processo de ensino-aprendizagem, que } \\
\text { deve ser criado para considerando } \\
\text { tanto o componente acadêmico do } \\
\text { ensino como a dimensão humana da } \\
\text { aprendizagem. }\end{array}$ \\
\hline
\end{tabular}


Tabela 4. Estudos nacionais e internacionais do período de 2015 e 2017 (continuação)

\begin{tabular}{|c|c|c|c|c|c|}
\hline $\begin{array}{l}\text { Garrote Rojas, } \\
\text { Garrote Rojas, \& } \\
\text { Jiménez } \\
\text { Fernández (2016) } \\
\text { Espanha }\end{array}$ & $\begin{array}{l}\text { Influential } \\
\text { Factors in } \\
\text { Motivation and } \\
\text { Learning } \\
\text { Strategies in } \\
\text { Grade Students }\end{array}$ & $\begin{array}{l}\text { Entender como como a } \\
\text { motivação e as estratégias } \\
\text { de aprendizagem } \\
\text { influenciam } \\
\text { desempenho acadêmico. }\end{array}$ & $\begin{array}{l}621 \text { estudantes } \\
\text { universitários. }\end{array}$ & $\begin{array}{l}\text { Análises descritivas das } \\
\text { médias. }\end{array}$ & $\begin{array}{l}\text { Os diferentes fatores motivacionais em } \\
\text { ordem decrescente idenficads foram: } \\
\text { metas intrínsecas }(6,07) \text {, valor da tarefa } \\
(5,91) \text {, autoeficácia }(5,57) \text {, metas } \\
\text { extrínsecas }(5,39) \text {, crenças de controle } \\
(5,27) \text { e ansiedade }(3,11) \text {. }\end{array}$ \\
\hline $\begin{array}{l}\text { Tezci, Sezer, } \\
\text { Aktan \& Gurgan } \\
\text { (2016) } \\
\text { Turquia }\end{array}$ & $\begin{array}{l}\text { Do Lifestyles } \\
\text { Shape Self- } \\
\text { Regulated } \\
\text { Learning } \\
\text { Strategies? }\end{array}$ & $\begin{array}{l}\text { Determinar se } \\
\text { existe uma correlação } \\
\text { entre os estilos de vida } \\
\text { adotados pelos indivíduos } \\
\text { suas vidas sociais e as } \\
\text { habilidades de } \\
\text { aprendizagem auto- } \\
\text { reguladas que eles usam } \\
\text { durante } \\
\text { o processo de } \\
\text { aprendizagem. }\end{array}$ & $\begin{array}{l}726 \text { estudantes } \\
\text { universitários. }\end{array}$ & Regressão linear múltipla. & $\begin{array}{l}\text { Correlações positivas entre estratégias } \\
\text { de aprendizagem auto-reguladas e } \\
\text { perfeição, valorização, expectativa, } \\
\text { controle e estilos de vida orientados } \\
\text { para o autorrespeito dos alunos. }\end{array}$ \\
\hline $\begin{array}{l}\text { Ushiro \& Bido } \\
(2016) \\
\text { Brasil }\end{array}$ & $\begin{array}{l}\text { Estratégias de } \\
\text { aprendizagem em } \\
\text { função da } \\
\text { finalidade para o } \\
\text { aprendizado: um } \\
\text { estudo com } \\
\text { trabalhadores da } \\
\text { linha de produção } \\
\text { de uma empresa } \\
\text { do ramo } \\
\text { automotivo }\end{array}$ & $\begin{array}{l}\text { Mensurar e compreender } \\
\text { quais estratégias de } \\
\text { aprendizagem são mais } \\
\text { utilizadas de acordo com } \\
\text { quatro motivos distintos } \\
\text { identificados no local de } \\
\text { trabalho. }\end{array}$ & $\begin{array}{l}463 \\
\text { profissionais } \\
\text { que atuam na } \\
\text { linha de } \\
\text { produção de } \\
\text { uma empresa } \\
\text { do ramo } \\
\text { automotivo. }\end{array}$ & $\begin{array}{l}\text { Análises fatoriais } \\
\text { confirmatórias e testes de } \\
\text { Kruskal-Wallis e } \\
\text { Wilcoxon. }\end{array}$ & $\begin{array}{l}\text { Resultados demonstraram que as } \\
\text { estratégias utilizadas não diferem } \\
\text { conforme as quatro finalidades } \\
\text { apresentadas. Dentre as estratégias } \\
\text { pesquisadas, a mais utilizada é a ajuda } \\
\text { interpessoal e as menos utilizadas são a } \\
\text { consulta a material escrito e a } \\
\text { participação em cursos e programas de } \\
\text { treinamento formais oferecidos pela } \\
\text { empresa. }\end{array}$ \\
\hline
\end{tabular}


Tabela 4. Estudos nacionais e internacionais do período de 2015 e 2017 (continuação)

\begin{tabular}{|c|c|c|c|c|c|}
\hline $\begin{array}{l}\text { Haeme, Borges- } \\
\text { Andrade \& } \\
\text { Cassiano (2017) } \\
\text { Brasil }\end{array}$ & $\begin{array}{l}\text { Learning } \\
\text { strategies at work } \\
\text { and } \\
\text { professional } \\
\text { development }\end{array}$ & $\begin{array}{l}\text { Investigar a previsão das } \\
\text { percepções atuais e } \\
\text { evolutivas do } \\
\text { desenvolvimento } \\
\text { profissional por meio de } \\
\text { cinco estratégias de } \\
\text { aprendizagem no trabalho } \\
\text { e por meio do treinamento } \\
\text { e como as características } \\
\text { individuais e de trabalho } \\
\text { predizem essas estratégias. }\end{array}$ & $\begin{array}{l}962 \\
\text { Indivíduos de } \\
\text { organizaçõe } \\
\text { privadas e } \\
\text { públicas. }\end{array}$ & $\begin{array}{l}\text { Análise de regressão linear } \\
\text { e modelagem de equações } \\
\text { estruturais. }\end{array}$ & $\begin{array}{l}\text { A variável critério desenvolvimento } \\
\text { profissional está positivamente } \\
\text { associada a três estratégias de } \\
\text { aprendizagem: reflexão intrínseca e } \\
\text { extrínseca, busca de ajuda dos outros e } \\
\text { tentativa e erro. Horas de treinamento } \\
\text { também predizem essa variável de } \\
\text { critério. Buscar ajuda de outras pessoas } \\
\text { e prever o nível educacional } \\
\text { desenvolvimento evolutivo percebido. } \\
\text { Variáveis socioculturais e técnico } \\
\text { organizacionais do ambiente de } \\
\text { trabalho prevêm essas cinco } \\
\text { estratégias. }\end{array}$ \\
\hline $\begin{array}{l}\text { Freiberg., } \\
\text { Ledesma \& } \\
\text { Fernández } \\
\text { (2017) } \\
\text { Buenos Aires }\end{array}$ & $\begin{array}{l}\text { Estilos y } \\
\text { estrategias de } \\
\text { aprendizaje en } \\
\text { estudiantes } \\
\text { universitarios de } \\
\text { Buenos Aires }\end{array}$ & $\begin{array}{l}\text { Conhecer a maneira em } \\
\text { que estilos e } \\
\text { estratégias de } \\
\text { aprendizagem são } \\
\text { apresentadas em } \\
\text { estudantes universitários, } \\
\text { para planejar ações em } \\
\text { diferentes níveis de ensino } \\
\text { - institucional, pedagógico, } \\
\text { discente, tutorial, entre } \\
\text { outros. }\end{array}$ & $\begin{array}{l}438 \text { estudantes } \\
\text { universitários. }\end{array}$ & Correlação de Peason. & $\begin{array}{l}\text { Os resultados mostram diferenças } \\
\text { significativas em algumas dimensões } \\
\text { de estilos e estratégias segundo } \\
\text { variáveis sociodemográficas e } \\
\text { acadêmicas bem como associações } \\
\text { significativas entre algumas estratégias } \\
\text { e a quantidade de recursos tecnologia } \\
\text { utilizada pelos alunos. }\end{array}$ \\
\hline $\begin{array}{l}\text { Visbal-Cadavid, } \\
\text { Mendoza } \\
\text { Mendoza \& Diáz } \\
\text { Santana (2017) } \\
\text { Colômbia }\end{array}$ & $\begin{array}{l}\text { Estrategias de } \\
\text { aprendizaje en la } \\
\text { educación } \\
\text { superior }\end{array}$ & $\begin{array}{l}\text { Identifcadar as estratégias } \\
\text { de aprendizagem e a sua } \\
\text { relação com as variáveis: } \\
\text { desempenho } \\
\text { acadêmico, gênero, nível } \\
\text { socioeconômico, tipo de } \\
\text { escola e tipo de engenharia } \\
\text { que estudam. }\end{array}$ & $\begin{array}{l}987 \text { estudantes } \\
\text { universitários. }\end{array}$ & $\begin{array}{l}\text { Análise descritiva, } \\
\text { regressão logística e } \\
\text { árvores de decisão. }\end{array}$ & $\begin{array}{l}\text { Na regressão logística, foi avaliada a } \\
\text { relação existente entre o desempenho } \\
\text { acadêmico dos estudantes e as outras } \\
\text { variáveis de estudo, evidenciano } 61,3 \% \\
\text { de predição dos casos. Nos resultados } \\
\text { obtidos com a árvore de decisão } \\
\text { observa-se uma coerência com os } \\
\text { resultados da regressão logística. }\end{array}$ \\
\hline
\end{tabular}


O novo levantamento mostrou que nos últimos três anos continuaram a ter publicações envolvendo a variável estratégias de aprendizagem, sendo que, 2016 foi o ano que apresentou o maior volume de publicações, assumindo 7 dos 12 artigos localizados neste estudo. Os anos de 2017 e 2015 também foram representados, respectivamente com 3 e 2 artigos. Este resultado mostra que apesar de oscilações no volume de publicações, a variável tem se mantido em evidência entre estudos da área de TD\&E, tanto nos nacionais, quanto nos internacionais, como mostra a Tabela 5.

Tabela 5. Distribuição dos artigos por localização geográfica e idioma de publicação

\begin{tabular}{|c|c|c|c|}
\hline & Países & $N$ & Idioma \\
\hline Europa & Espanha & 2 & Espanhol \\
\hline Ásia & Turquia & 2 & Inglês \\
\hline \multirow{5}{*}{ América do Sul } & Argentina & 1 & Espanhol \\
\hline & Brasil & 4 & 2 Inglês / 2 Português \\
\hline & Bolívia & 1 & Espanhol \\
\hline & Colômbia & 1 & Espanhol \\
\hline & Chile & 1 & Espanhol \\
\hline
\end{tabular}

Como observa-se, a América do Sul representou $67 \%$ das publicações deste levantamento, desta porcentagem, a metade está concentrada no Brasil. Tal dado corrobora Martins (2016) quando afirma que no Brasil há uma importante linha de pesquisa sobre estratégias de aprendizagem.

Quanto ao contexto de realização das pesquisas, a maioria foi realizada na educação (10 artigos), enquanto o corporativo apresentou apenas 2 estudos. Como se sabe, pesquisas no contexto corporativos ainda é um desafio devido a dificuldade de acesso e de parcerias para a realização de investigações. No que se refere aos aspectos metodológicos, as pesquisas, em sua maioria, se mostraram robustas em termos de coleta e análise de dados. Dentre outros tipos de análises estatísticas foi possível identificar regressão linear, modelagem de equações estruturais, análises fatoriais confirmatórias, correlações bivariadas e multivariadas.

Os resultados de pesquisa mostram que estratégias de aprendizagem têm evidenciado correlações significativas com muitas variáveis envolvidas no processo de TD\&E, tais como desenvolvimento profissional, desempenho acadêmico e fatores motivacionais (Garrote Rojas, Garrote Rojas, \& Jiménez Fernández, 2016; Haeme, Borges-Andrade \& Cassiano, 2017; Visbal-Cadavid, Mendoza-Mendoza, \& Díaz Santana, 2017). Estes dados apontam para a capacidade preditiva do comportamento de variáveis envolvidas em ações educacionais, ainda no nível da aprendizagem. 
Em contrapartida, neste levantamento ainda permaneceu o baixo volume de pesquisas centradas habilidades metacognitivas dos treinandos (Cunha \& Boruchovitch, 2016; Tezci, Sezer, Aktan \& Gurgan, 2016). Ademais, a pesquisa de Cunha \& Boruchovitch (2016), que contemplou a análise de conteúdo ao levantar os conhecimentos que os futuros professores tinham a respeito de suas estratégias de aprendizagem, mostrou que do total de participantes, $70 \%$ declararam utilizar estratégias cognitivas, enquanto somente $30 \%$ mencionaram as metacognitivas, indicando falta de instrução adequada quanto ao uso de estratégias de aprendizagem no contexto educacional de formação do professor. Assim, ainda há lacunas de pesquisas sobre a evolução de habilidades metacognitivas dos treinandos, conforme também identificado no levantamento de Martins (2016).

Tezci et al. (2016) mostram o quanto este enfoque nas habilidades metacognitivas podem trazer novos e importantes elementos do nível individual em ações de TD\&E. Os autores identificam que há correlações entre os estilos de vida adotados pelos indivíduos suas vidas sociais e as habilidades de aprendizagem auto-reguladas que eles usam durante o processo de aprendizagem. Salas et al. (2012) enfatizam que há necessidade de envolver os aprendizes em processos autoregulatórios durante o treinamento, para incentivá-los a refletir se estão aprendendo o que deveriam aprender e a ajustar a aquisição dos novos aprendizados.

Entender a competência das pessoas enquanto aprendizes e como elas podem aprender melhor como se aprende (Warr \& Allan, 1998) é fundamental ao considerar que o "aprender a aprender" é estratégico (Oliveira et al., 2009; Zabalza, 2005) no contexto atual que exige continuamente o gerenciamento da informação e a sua transformação em conhecimento. Pegalajar-Palomino (2016) recomenda ainda ambientes de aprendizagem que facilitem a inovação e a participação dos estudantes no processo de ensino-aprendizagem, que deve ser criado para considerando tanto o componente acadêmico do ensino como a dimensão humana da aprendizagem.

Nesta perspectiva, a proposta da presente pesquisa de avaliar os traços de personalidade em conjunto com as estratégias de aprendizagem cinde em oferecer mais elementos para essa capacidade de autorregulação dos aprendizes. Assim sendo, a próxima seção abarca a variável traços de personalidade no contexto de TD\&E. 


\subsection{Traços de PeRsonalidade: Definições E CONCEITOS}

Em uma das definições, Trentini, Hutz, Bandeira, Teixeira, Gonçalves e Thomazoni (2009) descrevem personalidade como características dos indivíduos, sendo única e o distinguindo dos demais a partir de padrões consistentes de sentimentos, pensamentos e comportamentos. Este construto sempre teve destaque no campo da psicologia, sendo fonte de numerosos estudos, debates teóricos e metodológicos, os quais evidenciam a implicação das dimensões afetivas, cognitivas e comportamentais deste construto.

Hansenne (2003) cita algumas algumas das perspectivas teóricas que abordam a personalidade e seus respectivos estudiosos: Psicanalítica (Freud); Neo-Analítica (Jung, Adler, Horney, Sullivan, Erikson e Fromm); Humanista (Rogers e Maslow); Aprendizagem (Skinner, Bandura e Rotter); Cognitiva (Kelly, Mischel e Beck); Psicobiológica (Gray, Tellegen, Zuckerman e o Modelo biossocial de Cloninger) e a perspectivas da Disposições (Allport, Cattell, Eysenck e o modelo Big Five, derivado de uma discussão de um grande número de psicólogos estudiosos da personalidade)

O modelo dos cinco fatores (Five Factor Model: FFM; McCrae \& Costa, 2004), que embasa a presente pesquisa, é uma teoria fatorial. Segundo Pervin e John (2004), as teorias fatoriais de personalidade são um delineamento matemático da estrutura da personalidade que reflete uma síntese de características básicas, considerando-se suas principais propriedades e as relações entre elas. O Big Five envolve uma representação dimensional das diferenças interpessoais ao nível da personalidade cuja validade, compreensividade, universalidade, hereditabilidade e estabilidade longitudinal tem sido recorrentemente sublinhada pela investigação empírica (McAdams \& Pals, 2006). Este modelo possibilita unir tendências comportamentais, emocionais e cognitivas dos indivíduos em cinco grandes categorias: Neuroticismo $(\mathrm{N})$, Extroversão $(\mathrm{E})$, Abertura à Experiência $(\mathrm{O})$, Amabilidade $(\mathrm{A})$ e Conscienciosidade (C).

Estas dimensões têm sido replicadas em auto e hetero-avaliações, em diferentes línguas e culturas e, com amostras clínicas e normativas (McCrae, Costa, del Pilar, Rolland, \& Parker, 1998; McCrae \& Terracciano, 2005). Assim, trata-se de um modelo de grande abrangência, concisão e muito replicado. Isso porque, nas palavras de Costa e McCrae (2010), é um modelo que aponta as dimensões sob as quais os indivíduos, independentemente de sua cultura ou nacionalidade, se reconhecem ou se diferenciam.

O Big Five avalia os cinco principais domínios da personalidade, bem como como um conjunto de facetas ou traços que definem cada um dos referidos domínios. Em conjuntos, 
os cinco domínios e as trinta escalas das facetas permitem uma avaliação compreensiva da personalidade adulta. Os cinco domínios e suas facetas são definidos conforme segue na Tabela 6:

Tabela 6 - Fatores e facetas do modelo Big Five

\begin{tabular}{|c|c|c|}
\hline Fatores & Características & Facetas \\
\hline Neuroticismo & $\begin{array}{l}\text { Diz respeito à instabilidade/estabilidade } \\
\text { emocional de um sujeito. Tendência geral } \\
\text { para experimentar afetos negativos, tais } \\
\text { como medo, tristeza, vergonha, raiva, culpa } \\
\text { e nojo. }\end{array}$ & $\begin{array}{l}\text { (N1) Ansiedade, (N2) Hostilidade, (N3) } \\
\text { Depressão, (N4) Constrangimento, (N5) } \\
\text { Impulsividade e (N6) Vulnerabilidade. }\end{array}$ \\
\hline Extroversão & $\begin{array}{l}\text { Corresponde ao nível de sociabilidade de } \\
\text { um indivíduo. Tendência a alegria e } \\
\text { disposição e está fortemente relacionado ao } \\
\text { interesse por atividades empreendedoras. }\end{array}$ & $\begin{array}{l}\text { (E1) Acolhimento, (E2) Gregarismo, (3) } \\
\text { Assertividade, (E4) Atividade, (E5) } \\
\text { Busca de sensações e (E6) Emoções } \\
\text { Positivas. }\end{array}$ \\
\hline $\begin{array}{l}\text { Abertura à } \\
\text { Experiência }\end{array}$ & $\begin{array}{l}\text { Caracteriza-se por um interesse intrínseco } \\
\text { por experiência em uma ampla variedade } \\
\text { de áreas. Tendência a imaginação ativa, } \\
\text { sensibilidade estética, atenção aos próprios } \\
\text { sentimentos, preferência pela variedade, } \\
\text { curiosidade intelectual e independência de } \\
\text { julgamento. }\end{array}$ & $\begin{array}{l}\text { (O1) Fantasia, (O2) Estética, (O3) } \\
\text { Sentimentos, (04) Ações Variadas, (05) } \\
\text { Ideias e (O6) Valores. }\end{array}$ \\
\hline Amabilidade & $\begin{array}{l}\text { Refere-se a traços que levam a atitudes e a } \\
\text { comportamentos pró-sociais. Trata-se da } \\
\text { predisposição a sensibilizar-se pela } \\
\text { situação dos outros e a colocar-se no lugar } \\
\text { deles, bem como a comportamentos de } \\
\text { complacência e cordialidade. }\end{array}$ & $\begin{array}{l}\text { (A1) Confiança, (2) Franqueza, (A3) } \\
\text { Altruísmo, (A4) Complacência, (A5) } \\
\text { Modéstia e (A6) Sensibilidade. }\end{array}$ \\
\hline Conscienciosidade & $\begin{array}{l}\text { Refere-se ao senso de contenção e sentido } \\
\text { prático, tendendo a processos mais ativos } \\
\text { de planejamento, organização e condução } \\
\text { das tarefas. }\end{array}$ & $\begin{array}{l}\text { (C1) Competência, (C2) Ordem, (C3) } \\
\text { Senso de dever, (C4) Esforço por } \\
\text { realizações, (C5), Autodisciplina e (C6) } \\
\text { Ponderação. }\end{array}$ \\
\hline
\end{tabular}

Fonte: Manual NEO PI-R e NEO-FFI-R (Mendonza-Flores, 2010).

De acordo com o Manual NEO PI-R e NEO-FFI-R (Mendonza-Flores, 2010), adaptação brasileira, as facetas se constituem fonte de interpretação dos construtos e formulação de teorias, sendo definidas conforme segue abaixo:

Facetas de Neuroticismo (N-Neuroticism)

N1: Ansiedade - Relacionada, como próprio nome sugere, à sensação de apreensão, medo, tensão, extrema preocupação.

N2: Raiva/Hostilidade - Representa a tendência a vivenciar raiva e estados relacionados, como a frustração e a amargura. 
N3: Depressão - Representa diferenças individuais normais na tendência a experimentar afeto negativo.

N4: Embaraço/Constrangimento - As emoções relacionadas a vergonha e embaraço formam o núcleo desta faceta de N. Embaraço/Constrangimento é semelhante a timidez e ansiedade social.

N5: Impulsividade - Refere-se à inabilidade de controle de anseios e ímpetos. O termo “impulsivo" do NEO PI-R não deve ser confundido com espontaneidade, ousadia ou rapidez na tomada de decisão.

N6: Vulnerabilidade - Refere-se à suscetibilidade ao estresse, às agressões psicológicas.

Facetas de Extroversão (E- Extraversion)

E1: Acolhimento (Acolhimento Caloroso) - Relaciona-se a afeto e amizade. No campo interpessoal esta é a faceta de E que está mais próxima de A.

E2: Gregarismo - Caracteriza-se a preferência pela companhia das outras pessoas, estimulação social.

E3: Assertividade - Relaciona-se à dominância, liderança e independência. Não se deve confundir essa faceta com agressividade verbal.

E4: Atividade - Representa agilidade, energia, vigor e necessidade de movimento.

E5: Busca de sensações - Caracteriza busca de excitação e estimulação.

E6: Emoções positivas - Tendência a experienciar emoções positivas tais como alegria, amor e animação. Diversos estudos têm mostrado que é a faceta mais relevante para predição de felicidade.

Facetas de Abertura $(\mathrm{O}-$ Openness)

O1: Fantasia - Relacionada a uma imaginação vívida e uma vida fantasiosa ativa.

O2: Estética - Apreciação profunda harmonia e gosto pelas diversas formas da arte e da beleza.

O3: Sentimentos - Receptividade dos próprios sentimentos e emoções. Avalia a emoção como parte importante da vida.

O4: Ações variadas - Disposição para atividades diferentes, conhecimento de novos lugares ou situações. Evita, sempre que pode, a rotina.

O5: Ideias - A curiosidade intelectual é um aspecto de O longamente reconhecido. Esse traço é visto não somente como uma busca ativa dos próprios interesses intelectuais, mas também uma abertura mental e uma disposição a considerar ideias novas e, talvez, até não convencionais.

O6: Valores - Prontidão para reexaminar valores sociais, familiares, políticos e/ou religiosos. Facetas de Amabilidade (A - Agreeableness) 
A1: Confiança - Disposição a acreditar que os outros são honestos e bem-intencionais.

A2: Franqueza - Relacionada à própria sinceridade, à lealdade para com a verdade.

A3: Altruísmo - Representa uma preocupação ativa com o bem-estar dos outros, demonstrando generosidade e disposição para assistir aqueles que precisam de ajuda.

A4: Complacência - Considera as reações aos conflitos interpessoais. Tendência a deferir em favor dos outros, a fim de evitar situações disruptivas.

A5: Modéstia - Relacionada à humildade, simplicidade e menor vaidade. Não se deve confundir com falta de auto-estima.

A6: Sensibilidade - Caracteriza atitudes de simpatia, compaixão e preocupação pelo lado humano das políticas sociais.

Facetas de Conscienciosidade (C-Conscientiouness)

$\mathrm{C} 1$ : Competência - Refere-se à preocupação da pessoa de que é capaz, sensível, prudente e efetiva. Das facetas de C, esta é a mais altamente associada com a auto-estima e controle interno.

C2: Ordem - Caracteriza atitudes de organização, preparação, metodismo.

C3: Senso do dever - Relacionada ao cumprimento das obrigações sociais, morais ou éticas.

C4: Esforço por realizações - Caracteriza a tendência a aspirar altos níveis e atitudes para alcançá-los.

C5: Autodisciplina - Representa a habilidade em começar tarefas e conduzi-las até o fim independentemente de tédio, fastio ou outras distrações. Essa faceta não deve ser confundida com a Impulsividade.

C6: Ponderação - Caracteriza a tendência a pensar, a deliberar cuidadosamente antes de agir.

O modelo tem sido operacionalizado através do NEO-PI-R (Neuroticism, Extraversion, Openness Personality Inventary Revised), elaborado por Costa \& McCrae (1992), sendo a última versão da revisão do NEO-PI. Ressalta-se que o primeiro instrumento a operacionalizar o modelo FFM começou a ser construído em 1978 através de uma combinação de métodos teóricos e de análise fatorial, sendo o instrumento atualmente utilizado alvo de uma extensa investigação (McAdams \& Olson, 2010). Uma vasta literatura permitiu compará-lo com dezenas de outros modelos, construtos e instrumentos de personalidade (e.g., EPQ, PFR, 16PF, MBTI, CPI e MMPI; Little \& Joseph, 2007), sendo suas qualidades psicométricas comprovadas em muitas populações, de diversos países (McCrae \& Costa, 2004).

Mesmo diante dessas vantagens, sua extensão (240 itens), o instrumento torna-se moroso e pouco versátil. Tal fato levou à construção de versões reduzidas deste instrumento, 
tipicamente designadas por NEO-FFI ou NEO-FFI-R (na versão revista). O NEO-FFI (NEOFive Factor Inventory; Costa \& McCrae, 1989) é assim uma versão reduzida do NEO-PI-R, constituída por 60 itens e que, no original, nos permite obter uma versão fiável dos domínios do modelo dos cinco fatores (com valores de consistência interna entre .68 e .86; Costa \& McCrae, 1989).

Várias adaptações têm sido desenvolvidas em diferentes países, sendo os valores de consistência interna entre culturas genericamente aceitáveis e similares, refletindo o potencial do presente instrumento para ser utilizado em diferentes contextos, conforme mostra a Tabela 7 de Pedroso-Lima, Magalhães, Salgueira, Gonzalez, Costa, Costa e Costa (2014).

Tabela 7. Dados de validação do NEO-FFI em diferentes culturas

\begin{tabular}{|c|c|c|c|c|c|c|c|}
\hline \multirow[t]{2}{*}{ País } & \multirow[t]{2}{*}{ Autores } & & \multicolumn{5}{|c|}{ Alfas } \\
\hline & & & $\mathbf{N}$ & $\mathbf{E}$ & $\mathbf{O}$ & $\mathbf{A}$ & $\mathbf{C}$ \\
\hline \multirow[t]{2}{*}{ USA } & \multirow{2}{*}{$\begin{array}{l}\text { Costa \& McCrae } \\
(1988 / 89 ; 1992)\end{array}$} & Amostra normativa & 0,86 & 0,77 & 0,51 & 0,69 & 0,83 \\
\hline & & $\begin{array}{l}\text { Amostras de estudantes universitários } \\
(\mathrm{N}=1959)\end{array}$ & 0,82 & 0,78 & 0,7 & 0,72 & 0,81 \\
\hline Canadá & $\begin{array}{l}\text { McCrae \& Costa } \\
(2004)\end{array}$ & $\begin{array}{l}\text { Amostra do estudo longitudinal sobre o } \\
\text { envelhecimento de Baltimore ( } N=1492)\end{array}$ & 0,86 & 0,8 & 0,75 & 0,69 & 0,79 \\
\hline & $\begin{array}{l}\text { Holden \& Fekken } \\
\text { (1992) }\end{array}$ & $\begin{array}{l}\text { Amostra de estudantes universitários } \\
(\mathrm{N}=243)\end{array}$ & 0,86 & & & 0,68 & \\
\hline França & $\begin{array}{l}\text { Rolland, Parker and } \\
\text { Stumpf (1998) }\end{array}$ & $\begin{array}{l}\text { Amostra de estudantes universitários } \\
(\mathrm{N}=447)\end{array}$ & 0,84 & 0,77 & 0,62 & 0,66 & 0,84 \\
\hline \multirow[t]{2}{*}{ UK } & \multirow[t]{2}{*}{ Egan et al. (2000) } & Amostra de militares $(\mathrm{N}=268)$ & 0,79 & 0,66 & 0,5 & 0,57 & 0,84 \\
\hline & & $\begin{array}{l}\text { Amostras de agricultores, médicos } \\
\text { e clínicos }(\mathrm{N}=1025)\end{array}$ & 0,65 & 0,58 & 0,3 & 0,62 & 0,83 \\
\hline \multirow[t]{2}{*}{ Alemanha } & $\begin{array}{l}\text { Borkenau \& } \\
\text { Ostendorf (1993) }\end{array}$ & Amostra de adultos $(\mathrm{N}=2112)$ & 0,85 & 0,8 & 0,71 & 0,71 & 0,71 \\
\hline & Schmitz et al. (2001) & $\mathrm{N}=300$ & 0,84 & 0,79 & 0,66 & 0,68 & 0,79 \\
\hline Suiça & $\begin{array}{l}\text { Aluja Garcia, Rossier } \\
\text { e } \\
\text { Garcia }(2005 ; 2007)\end{array}$ & $\begin{array}{l}\text { Amostra de adultos voluntários } \\
(\mathrm{N}=1090)\end{array}$ & 0,85 & 0,74 & 0,71 & 0,71 & 0,83 \\
\hline Espanha & $\begin{array}{l}\text { Aluja, Garcia, Rossier } \\
\text { e Garcia (2004) }\end{array}$ & $\begin{array}{l}\text { Amostra de estudantes não graduados } \\
(\mathrm{N}=1006)\end{array}$ & 0,82 & 0,78 & 0,71 & 0,71 & 0,83 \\
\hline $\begin{array}{l}\text { Polónia; } \\
\text { República }\end{array}$ & $\begin{array}{l}\text { Hrebícková et al. } \\
(1991,2002)\end{array}$ & $\mathrm{N}=350$ & & & 0,69 & & 0,84 \\
\hline $\begin{array}{l}\text { da } \\
\text { Eslováquia }\end{array}$ & & $\mathrm{N}=516$ & & & 0,66 & & 0,83 \\
\hline
\end{tabular}


Tabela 7. Dados de validação do NEO-FFI em diferentes culturas

\begin{tabular}{|c|c|c|c|c|c|c|c|}
\hline $\begin{array}{l}\text { República } \\
\text { Checa }\end{array}$ & & $\mathrm{N}=945$ & & & 0,6 & & 0,84 \\
\hline Japão & $\begin{array}{l}\text { Yoshimura et al. } \\
(2001)\end{array}$ & Amostra rural $(\mathrm{N}=1664)$ & 0,6 & & & & 0,77 \\
\hline Austrália & $\begin{array}{l}\text { Lucas \& Donnellan } \\
\text { (2009) }\end{array}$ & $\mathrm{N}=12.618(15$ a 84 anos $)$ & 0,85 & & 0,74 & & \\
\hline Grécia & $\begin{array}{l}\text { Panayiotou, Kokkinos } \\
\text { e Spanoudis (2004) }\end{array}$ & $\mathrm{N}=1204$ & 0,78 & 0,7 & 0,51 & 0,69 & 0,83 \\
\hline Noruega & Nordvik et al. (2003) & $\begin{array}{l}\mathrm{N}=1717 \text { (mulheres) } \\
\mathrm{N}=1751 \text { (homens) }\end{array}$ & 0,92 & & & 0,86 & \\
\hline
\end{tabular}

Fonte: Pedroso-Lima et al., 2014.

Diante desse panorama, no contexto de TD\&E, O NEO-FFI tem sido utilizado extensivamente para estudar as relações entre as cinco dimensões da personalidade e outros construtos como, por exemplo, estilos de aprendizagem (Chamorro-Premuziac \& Furnham, 2009) e sucesso académico (Chamorro-Premuzic, Quiroga \& Colom, 2009). Assim sendo, foi o instrumento escolhido para compor a revisão de literatura e coleta de dados da presente pesquisa, como será verificado a seguir.

\subsubsection{Descrição do Percurso Metodológico Para a Revisão Sistemática da LITERATURA}

Com base na leitura sobre os aspectos anteriormente citados e algumas reflexões, nesta revisão sistemática sobre a variável Traços de Personalidade, o objetivo foi mapear a produção acadêmica nacional e internacional na área de TD\&E, compreendida no período de 2006 a 2018, que abordou a variável traços de personalidade, segundo o Modelo dos Cinco Grandes Fatores (Big Five) em ações direcionadas para a qualificação profissional. Foram utilizadas as bases de dados Proquest, PsycInfo Scielo e Web of Science, sendo as escolhidas pela abrangência de disciplinas que comportam.

A revisão foi realizada em três etapas. Na primeira, após testes nas bases de dados, a busca dos artigos contemplou com os unitermos "Cinco Grandes Fatores da Personalidade", "NEO-PI-R", "treinamento", “desenvolvimento" e "educação" e "aprendizagem”. Estes também foram traduzidos para o inglês ("Big Five”, "NEO-PI-R", "Training”, "human development", “education", "learning”) utilizando os operadores booleanos "AND" e "OR". Além disso, foram aplicados filtros nos campos de busca por ano de publicação, idioma, título e resumo. 
A seleção dos artigos foi feita a partir da análise dos títulos e das palavras-chave, com base nos critérios de inclusão: a) estudos na área de TD\&E que utilizaram a variável traços de personalidade, segundo a teoria Big Five; b) publicações compreendidas no período de 2006 a 2018; c) estudos realizados em ações de TD\&E direcionadas para a qualificação profissional: (graduação, pós graduação, cursos técnicos e corporativos); d) estudos nos idiomas português, inglês e espanhol; e) artigos científicos; f) pesquisas empíricas e teóricas; g) estudos que utilizaram o instrumento NEO (Versões NEO-PI-R e NEO-FFI-R). Foram encontrados 851 artigos, dos quais 96 eram duplicados, restando 755. Na primeira seleção, 91 estudos atenderam aos critérios de inclusão.

Na segunda etapa, a seleção inicial foi refinada a partir da leitura dos resumos, a fim de verificar a adequação do conteúdo dos artigos aos objetivos da revisão. Como procedimento complementar, também foi realizada a checagem cruzada dos artigos escolhidos pelas pesquisadoras. Assim, cada pesquisadora validou os artigos selecionados pela outra para compor a revisão final.

Uma terceira pesquisadora foi consultada para avaliar a pertinência do compilado final dos artigos selecionados. Desta forma, ao final, 39 artigos tiveram o consenso das três pesquisadoras e preencheram todos os critérios de inclusão. Os motivos de exclusão dos outros 52 artigos nesta etapa foram: a) estudos realizados em ações de TD\&E não direcionadas para a qualificação profissional (41); b) estudos não disponíveis para download (9); c) estudos sobre TD\&E que não contemplaram a teoria big five (1); d) estudos em idiomas diferentes português, inglês e espanhol (1). A distribuição dos artigos por base de dados pode ser melhor visualizada na Figura 9.

Figura 9. Distribuição dos artigos por base de dados

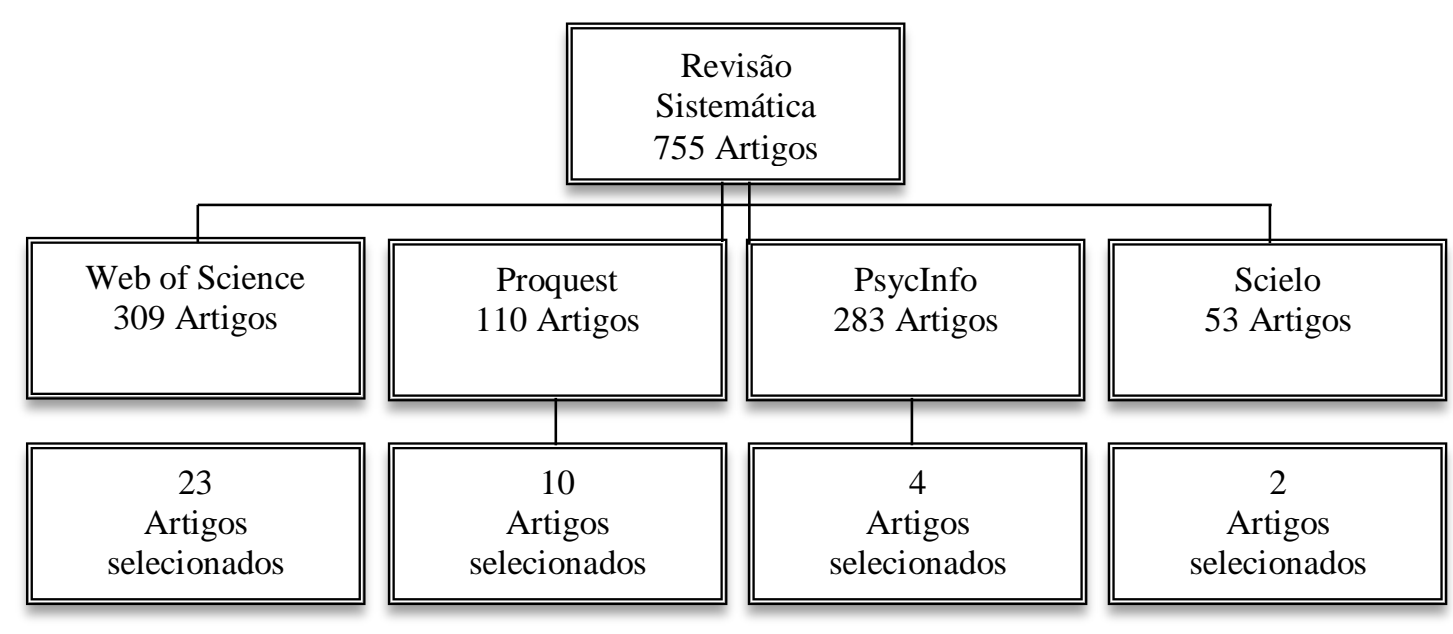

Fonte: Elaboração da autora. 
Na última etapa, foi realizado um exame aprofundado dos artigos a partir de sua leitura na íntegra, sendo os dados compilados e analisados por meio de um protocolo elaborado com a finalidade de mapear informações sobre: 1) Volume de publicações por periódico e por ano; 2) Área de conhecimento da vinculação dos artigos e contexto de realização das pesquisas; 3 ) Localização geográfica e idioma de publicação dos artigos; 4) Aspectos metodológicos e versão mais utilizada no instrumento NEO-PI-R; 5) Principais resultados de pesquisa, tomando como referência os cinco grandes fatores e seus impactos/influências sobre outras variáveis no contexto de TD\&E. Ressalta-se que a opção por investigar o instrumento NEO foi, primeiramente pelo leque de instrumentos existentes, e, principalmente, pelo fato da literatura indicá-lo como um dos instrumentos mais frequentemente utilizado no mundo para medir a variável em questão em virtude de suas vantagens e comprovada qualidade psicométrica em diferentes contextos.

Para auxiliar no planejamento, na execução e na análise final dos estudos encontrados, foi utilizado o software State of Art through Systematc Review (StArt), versão 3.03-64, desenvolvido pelo Laboratório de Pesquisa em Engenharia de Software (Lapes) da Universidade de São Carlos. Esta ferramenta torna a revisão sistemática mais ágil, precisa e replicável.

\subsubsection{Resultados De Pesquisa}

Conforme detalhadamente descrito no percurso metodológico, diante da identificação da escassez de pesquisas nacionais que abordassem a variável estratégias na área de TD\&E, foi feito um mapeamento a fim de analisar o estado da arte desta temática. Retomando, o mapeamento abrange informações de volume de publicações por ano, área de conhecimento da vinculação dos artigos e contexto de realização das pesquisas, localização geográfica e idioma de publicação dos artigos, aspectos metodológicos e versão mais utilizada no instrumento NEOPI-R e principais resultados de pesquisa, tomando como referência os cinco grandes fatores e seus impactos/influências sobre outras variáveis no contexto de TD\&E. Estas serão divididas em tópicos para facilitar a apresentação dos resultados da revisão, bem como a leitura.

\section{1) Volume de publicações por ano}

Ao analisar de volume de publicações por ano constata-se que o investimento científico que abordou a variável traços de personalidade em pesquisas em TD\&E teve um declínio nos cinco últimos anos quando comparado ao mesmo período anterior. 
Figura 10. Gráfico de distribuição dos artigos por ano de publicação

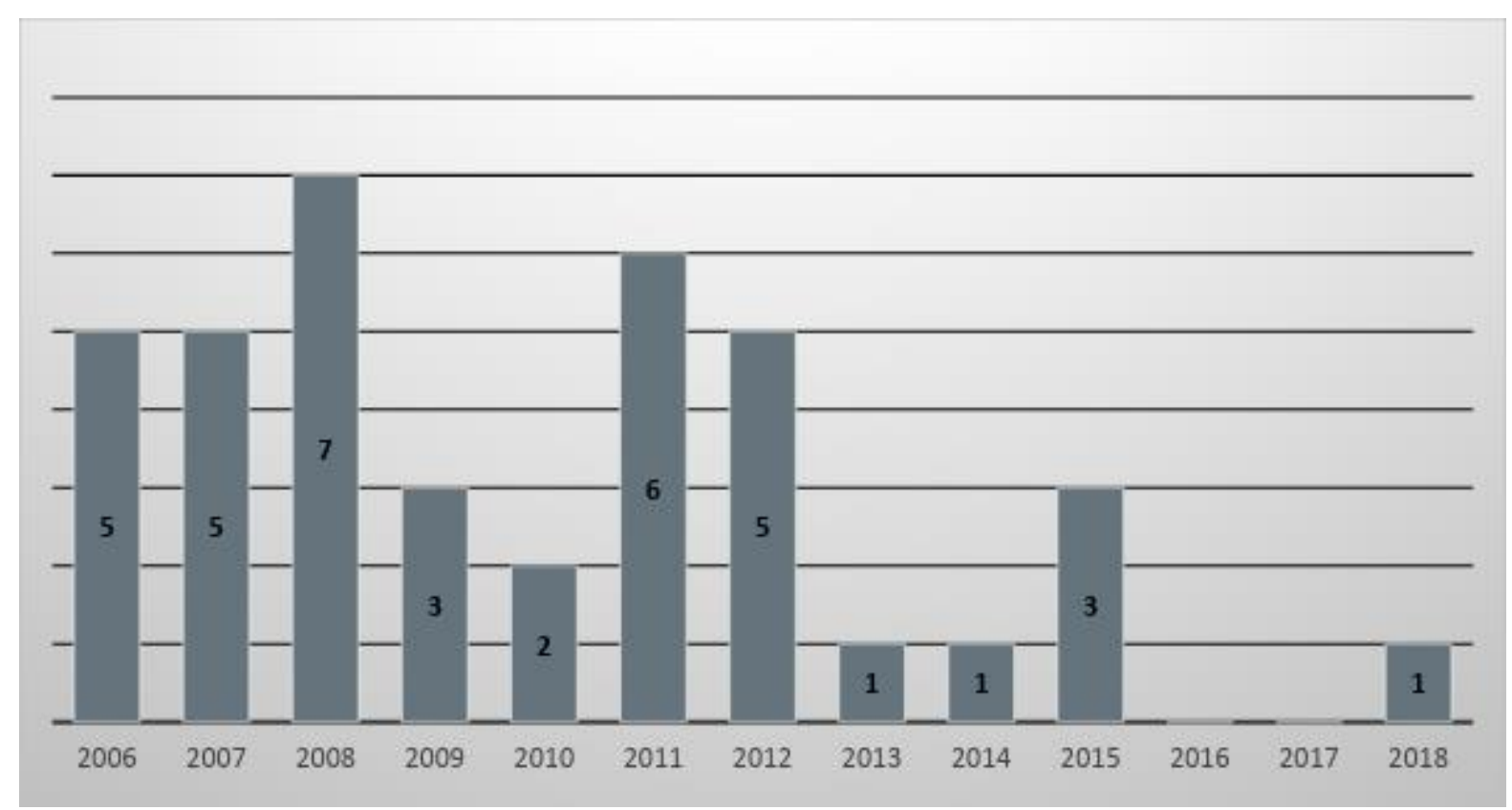

Fonte: Elaboração da autora.

Os motivos para o declínio no número de publicações identificado neste estudo não são óbvios, uma vez que as investigações até então realizadas abriram novas agendas de pesquisas, além de apontarem para a importância do reconhecimento dos traços de personalidade em ações educacionais como fornecedores de feedbacks para o desenho do treinamento mais adequado ao perfil da clientela. Além disso, muitos países, como veremos adiante, ainda não abordaram a variável em questão, bem como sua extensão para o contexto corporativo, que é um potente investidor em ações de TD\&E, ainda é pequena. Portanto, conclui-se que se trata de uma variável que ainda pode ser explorada em novas culturas e no contexto corporativo.

\section{2) Área de conhecimento da vinculação dos artigos e contexto de realização das pesquisas}

Em sua maioria estão vinculados à periódicos da área da educação, representada por 23 artigos. Em seguida está a psicologia, com 12 artigos. Periódicos da área de saúde tiveram pouca representatividade, com 2 artigos apenas, bem como a antropologia e saúde mental, com frequência de vinculação 1 para cada uma. Quanto aos contextos de realização das pesquisas, há uma disparidade dos resultados, sendo que a área da educação assumiu 37 artigos, ficando o corporativo com apenas 2 .

A predominância das publicações em periódicos da área da educação é compreensível, visto que a área de TD\&E contempla a aprendizagem e os modos como ela acontece. Ademais, 
uma hipótese é a receptividade dos periódicos em relação à temática. Contudo, estudiosos da psicologia, envolvidos na área de TD\&E, há bastante tempo investem esforços de pesquisas a fim de explicar os mecanismos individuais envolvidos no processo de aprendizagem, como Bell et al. (2017) mostram no artigo sobre os 100 anos de pesquisas em treinamento e desenvolvimento. Nos próprios estudos deste levantamento, a maioria dos pesquisadores é oriunda da psicologia. Então, mais publicações em periódicos da própria psicologia poderiam resultar em maior visibilidade desta disciplina enquanto ciência aplicada, sendo um ponto de alerta para os profissionais da área.

No que se refere ao contexto de realização das pesquisas, como visto, a maioria foi realizada no contexto da educação. A inserção dos traços de personalidade como mais um elemento para aprofundar nas características da clientela, evidenciou contribuições para o aprimoramento do processo de TD\&E. Furnham, Nuygards e Chamorro-Premuzic (2013), ressaltam que o reconhecimento desta variável pode indicar, por exemplo, até que ponto os métodos de avaliação podem influenciar a escolha de um aluno por um determinado curso, bem como pode apontar caminhos para que professores escolham os meios mais adequados de examinar seus alunos.

Já no contexto corporativo não foi identificado um volume de publicações significativo, o que pode ser considerado uma lacuna. Como retratam Bell et.al (2017), organizações privadas e públicas investem grandes quantias em treinamento e desenvolvimento e quase todos os adultos que trabalham passam horas de suas vidas participando de experiências de aprendizado. Um estudo realizado pela Associação Brasileira de Treinamento e Desenvolvimento (ABTD) registrou o crescimento da área de TD\&E no ano de 2016. O volume de horas de treinamento por colaborador no Brasil foi $33 \%$ superior ao registrado no ano anterior, passando de 16,6 horas para 22 horas, em média. O valor investido por funcionário foi de R\$ 624 - crescimento de $24 \%$ em relação ao ano de 2015.

A média brasileira está abaixo da norte-americana, que registrou 32 horas de treinamento e um investimento de U\$ 1.252 por colaborador (ABTD, 2016; Ho, 2016). Contudo, é possível observar que em ambos casos há uma preocupação das organizações em qualificar suas equipes e de torná-las mais competitivas. Neste sentido, um dos caminhos para cumprir a tais expectativas é compreender como os humanos aprendem no trabalho e como melhor projetar, implementar, e apoiar atividades de TD\&E (Bell et.al, 2017). Neste sentido, investigar como os traços de personalidade influenciam em ações instrucionais poderia ser mais um elemento importante no mapeamento das características da clientela especificamente no contexto organizacional, assim como vem acontecendo no contexto da educação. 
Meneses et al. (2006) corroboram tal análise quando dizem que as características individuais dos aprendizes, os hábitos de vida, as expectativas, as estratégias utilizadas para alcançar aprendizagens, as motivações, os interesses e as metas podem influenciar na aquisição de competências durante um evento instrucional e na sua posterior aplicação em situações de trabalho. Apesar dos resultados advindos de pesquisas do contexto de educação também oferecerem, em alguma medida, contribuições para o âmbito corporativo, estender as pesquisas a este pode gerar resultados mais eficientes, haja vista as particularidades de cada ambiente, conforme sugerem Lakhal, Sévigny e Frenette (2015).

\section{3) Localização geográfica e idioma de publicação dos artigos}

$\mathrm{Na}$ análise da localização geográfica em que os artigos foram produzidos, a Europa e a América do Norte apareceram como importantes centros de produção de conhecimento acerca da temática, representadas prioritariamente pelo Reino Unido e Estados Unidos. Já a América do Sul foi representada apenas pela Argentina, ficando o Brasil fora da lista. O levantamento retratou ainda que os 39 artigos foram publicados no idioma inglês. A Tabela 8 apresenta o comportamento de tais dados.

Tabela 8. Distribuição dos artigos por localização geográfica

\begin{tabular}{|c|c|c|c|}
\hline & Países & $N$ & Idioma \\
\hline \multirow{6}{*}{ Europa } & Reino Unido & 17 & Inglês \\
\hline & Alemanha & 1 & Inglês \\
\hline & Holanda & 2 & Inglês \\
\hline & Bélgica & 1 & Inglês \\
\hline & Grécia & 1 & Inglês \\
\hline & Total & 22 & \\
\hline \multirow{4}{*}{ América do Norte } & Estados Unidos & 8 & Inglês \\
\hline & Canadá & 1 & Inglês \\
\hline & México & 1 & Inglês \\
\hline & Total & 10 & \\
\hline \multirow{4}{*}{ Ásia } & China & 3 & Inglês \\
\hline & Iran & 2 & Inglês \\
\hline & Singapura & 1 & Inglês \\
\hline & Total & 6 & \\
\hline América do Sul & Argentina & 1 & Inglês \\
\hline
\end{tabular}

A concentração dos estudos na Europa e na América do Norte não surpreende, uma vez que estes são, reconhecidamente, polos de investimento em pesquisas científicas nas diversas áreas do conhecimento. $\mathrm{O}$ fato destes estudos apresentarem contribuições para o sistema de 
TD\&E nestas culturas, sugere a possibilidade de inserção da variável em outros países, como no Brasil, fazendo avançar esse sistema.

\section{4) Aspectos metodológicos e versão mais utilizada no instrumento NEO-PI-R}

Quanto aos aspectos metodológicos, foi constatado o domínio dos estudos correlacionais, com delineamento quantitativo (39). Destaca-se ainda que o tipo de pesquisa predominante foi a empírica (37), restando apenas 2 artigos teóricos. Para análise dos dados as pesquisas utilizaram principalmente combinações entre as técnicas estatísticas de análises de regressão simples múltipla, linear, hierárquica e logística, além da modelagem de equação estrutural, demonstrando preocupação com a adoção de metodologias bem planejadas e análises robustas dos dados, conforme pode ser verificado na Tabela 9, que segue no próximo tópico.

Análises de dados mais robustas e rigorosas para o teste de relações entre variáveis de TD\&E, como a Análise Fatorial Combinatória e Modelagem de Equação Estrutural, auxiliam no desenvolvimento teórico do campo (Pilati \& Borges-Andrade, 2006; Zerbini, 2007). Segundo estes autores, no Brasil, por exemplo, estes procedimentos ainda são recomendados em agendas de pesquisa da área de avaliação instrucional, indicando que as pesquisas nacionais devem progredir neste quesito para que sejam testadas teorias e modelos no campo de variáveis de interesse em TD\&E.

A versão curta do NEO-PI-R, denominada NEO-FFI-R, adaptada em diferentes países, foi utilizada com mais frequência (24). Trata-se de uma variação do NEO-PI-R, composta por 60 afirmações auto descritivas. A preferência pela utilização da versão reduzida do NEO-PI-R identificada neste estudo, pode ser explicada pela extensão da versão original, composta por 240 itens. McAdams e Olson (2010) apontam que construções de versões reduzidas deste instrumento (60 itens) têm sido desenvolvidas em diferentes países, sendo os valores de consistência interna, entre culturas, genericamente aceitáveis e similares, refletindo o potencial do instrumento para ser utilizado em diferentes contextos, conforme verificado na apresentação dos resultados deste estudo.

Pesquisas dos cinco últimos anos da amostra de artigos analisada nesta revisão evidenciam que os coeficientes de consistência interna (Alfas de Cronbach) do NEO-FFI têm se mostrado bem próximos aos obtidos na versão americana (McCrae \& Costa, 2004), na qual a amplitude dos fatores se situada entre .75 e .82 (Li \& Armstrong, 2015; Lakhal, Sévigny \& Frenette, 2015; Salahi, Hedjazi, Mahmood, \& Ebrahimi, 2014; Kappe \& Der Flier, 2012). Estes achados corroboram as bases da teoria na qual este instrumento se ancora (big five), um modelo 
que aponta as dimensões da personalidade sob as quais os indivíduos, independentemente de sua cultura ou nacionalidade, se reconhecem ou se diferenciam (Costa \& McCrae, 2010).

5) Principais resultados de pesquisa: os cinco grandes fatores e seus impactos/influências sobre outras variáveis no contexto de TD\&E

As pesquisas dos últimos anos, levantadas nesta revisão, seguem compiladas na Tabela 9, sendo os principais resultados discutidos na sequência. 
Tabela 9. Principais resultados de pesquisas rescentes sobre traços de personalidade em TD\&E

\begin{tabular}{|c|c|c|c|c|c|c|}
\hline $\begin{array}{l}\text { Autores/Data/ } \\
\text { Local }\end{array}$ & Título Original & Objetivos & $\begin{array}{l}\text { Amostra/ } \\
\text { Contexto }\end{array}$ & $\begin{array}{l}\text { Versão do NEO } \\
\text { utilizada }\end{array}$ & $\begin{array}{l}\text { Procedimentos de } \\
\text { análise de dados }\end{array}$ & Principais Resultados \\
\hline $\begin{array}{l}\text { De Feyter, } \\
\text { Caers, Vigna, } \\
\& \text { Berings } \\
(2012) \\
\text { Bélgica }\end{array}$ & $\begin{array}{l}\text { Unraveling the impact of } \\
\text { the Big Five personality } \\
\text { traits on academic } \\
\text { performance: } \\
\text { The moderating and } \\
\text { mediating effects of self- } \\
\text { efficacy and academic } \\
\text { motivation }\end{array}$ & $\begin{array}{l}\text { Desvendar o impacto } \\
\text { dos fatores de } \\
\text { personalidade do Big } \\
\text { Five no desempenho } \\
\text { acadêmico. }\end{array}$ & $\begin{array}{l}375 \\
\text { estudantes/gra } \\
\text { duação. }\end{array}$ & $\begin{array}{l}\text { NEO-FFI (Costa } \\
\text { \& McCrae, 1992; } \\
\text { Hoekstra, Ormel, } \\
\text { \& De Fruyt, } \\
\text { 1996). }\end{array}$ & $\begin{array}{l}\text { Análises de regressão } \\
\text { simples, múltipla e } \\
\text { hierárquica. }\end{array}$ & $\begin{array}{l}\text { a) Achados revelaram um efeito indireto positivo do } \\
\text { neuroticismo no desempenho acadêmico em níveis } \\
\text { superiores de auto-eficácia, e efeito direto positivo do } \\
\text { neuroticismo em níveis inferiores de autoeficácia; b) } \\
\text { a conscienciosidade apresentou efeito indireto } \\
\text { positivo com o desempenho acadêmico, através da } \\
\text { motivação acadêmica, bem como na extroversão, } \\
\text { neuroticismo e conscienciosidade. }\end{array}$ \\
\hline $\begin{array}{l}\text { Kappe \& Der } \\
\text { Flier (2012) } \\
\text { Holanda }\end{array}$ & $\begin{array}{l}\text { Predicting academic } \\
\text { success in higher } \\
\text { education: } \\
\text { what's more important } \\
\text { than being smart? }\end{array}$ & $\begin{array}{l}\text { Investigar a validade } \\
\text { preditiva combinada } \\
\text { da inteligência e } \\
\text { fatores de } \\
\text { personalidade em } \\
\text { múltiplas medidas de } \\
\text { desempenho } \\
\text { acadêmico. }\end{array}$ & $\begin{array}{l}137 \\
\text { estudantes / } \\
\text { graduação. }\end{array}$ & $\begin{array}{l}\text { NEO-FFI } \\
\text { (Hoekstra et al., } \\
\text { 1996). }\end{array}$ & $\begin{array}{l}\text { Análises de regressão } \\
\text { múltipla. }\end{array}$ & $\begin{array}{l}\text { a) } 33 \% \text { da variação média de pontuação e } 30 \% \text { da } \\
\text { variância no tempo até a graduação podem ser } \\
\text { explicados pela combinação de inteligência, } \\
\text { personalidade e preditores motivacionais; b) a } \\
\text { conscienciosidade é o melhor preditor em um amplo } \\
\text { espectro de medidas de realização acadêmica e } \\
\text { explica cinco vezes mais variância média de } \\
\text { pontuação do que a inteligência. }\end{array}$ \\
\hline $\begin{array}{l}\text { Stumm \& } \\
\text { Furnham } \\
(2012) \\
\text { Reino Unido }\end{array}$ & $\begin{array}{l}\text { Learning approaches: } \\
\text { Associations with Typical } \\
\text { Intellectual Engagement, } \\
\text { intelligence and the Big } \\
\text { Five }\end{array}$ & $\begin{array}{l}\text { Investigar até que } \\
\text { ponto as abordagens } \\
\text { de aprendizagem são } \\
\text { explicadas por Traços } \\
\text { de personalidade e }\end{array}$ & $\begin{array}{l}579 \\
\text { estudantes / } \\
\text { graduação. }\end{array}$ & $\begin{array}{l}\text { (NEO-FFI; Costa } \\
\text { \& McCrae, } \\
\text { 1992). }\end{array}$ & $\begin{array}{l}\text { Modelagem de equação } \\
\text { estrutural. }\end{array}$ & $\begin{array}{l}\text { a) A inteligência foi associada de maneira } \\
\text { insignificante com as abordagens de aprendizagem; } \\
\text { b) alcançar a aprendizagem foi melhor explicado pela } \\
\text { extroversão, abertura à experiência e } \\
\text { consienciosidade. }\end{array}$ \\
\hline
\end{tabular}


Tabela 9. Principais resultados de pesquisas rescentes sobre traços de personalidade em TD\&E (continuação)

\begin{tabular}{|c|c|c|c|c|c|c|}
\hline $\begin{array}{l}\text { Trógolo \& } \\
\text { Medrano } \\
\text { (2012) }\end{array}$ & $\begin{array}{l}\text { Personality traits, } \\
\text { difficulties in } \\
\text { emotion } \\
\text { regulation and } \\
\text { academic } \\
\text { satisfaction in a } \\
\text { sample of } \\
\text { argentine college } \\
\text { students }\end{array}$ & $\begin{array}{l}\text { Examinar as } \\
\text { contribuições de } \\
\text { traços de } \\
\text { personalidade, usando } \\
\text { o Big Five, e } \\
\text { dificuldades na } \\
\text { regulação emocional } \\
\text { para prever satisfação } \\
\text { acadêmica. }\end{array}$ & $\begin{array}{l}230 \\
\text { estudantes / } \\
\text { graduação. }\end{array}$ & $\begin{array}{l}\text { IPIP-NEO } 120 \\
\text { personality } \\
\text { inventory } \\
\text { (Cupani, } \\
\text { 2012). }\end{array}$ & $\begin{array}{l}\text { Regressão } \\
\text { hierárquica. }\end{array}$ & $\begin{array}{l}\text { Os traços do Big Five nem as dificuldades na regulação } \\
\text { emocional contribuíram significativamente para a } \\
\text { previsão da satisfação acadêmica. }\end{array}$ \\
\hline $\begin{array}{l}\text { Furnham, Nuygards, } \\
\text { \& Chamorro- } \\
\text { Premuzic (2013) } \\
\text { Reino Unido }\end{array}$ & $\begin{array}{l}\text { Personality, } \\
\text { assessment } \\
\text { methods and } \\
\text { academic } \\
\text { performance }\end{array}$ & $\begin{array}{l}\text { Examinar se a relação } \\
\text { entre traços e métodos } \\
\text { de avaliação eram } \\
\text { consistentes em } \\
\text { resultados de exames } \\
\text { auto-relatados versus } \\
\text { documentados, em } \\
\text { duas técnicas de } \\
\text { avaliação diferentes e } \\
\text { em diferentes } \\
\text { faculdades. }\end{array}$ & $\begin{array}{l}1013 \\
\text { estudantes / } \\
\text { graduação. }\end{array}$ & $\begin{array}{l}\text { NEO-FFI (Costa } \\
\& \text { McCrae 1992), }\end{array}$ & $\begin{array}{l}\text { Modelagem de } \\
\text { equaço estrutural. }\end{array}$ & $\begin{array}{l}\text { a) Conscinciosidade e amabilidade foram os preditores de } \\
\text { personalidade mais fortes na avaliação de desempenho } \\
\text { acadêmico; b) os efeitos do sexo e da personalidade na } \\
\text { avaliação de desempenho acadêmico eram invariantes em } \\
\text { diferentes áreas de estudo ou tipos de licenciatura; c) as } \\
\text { variáveis de personalidade são correlatos estáveis, } \\
\text { robustos e previsíveis e determinantes da avaliação de } \\
\text { desempenho acadêmico; d) a Conscinciosidade, a abertura } \\
\text { e a amabilidade foram preditores positivos, conforme } \\
\text { medido por boas notas, enquanto o neuroticismo e } \\
\text { extroversão foram correlacionados com desempenho mais } \\
\text { fraco. }\end{array}$ \\
\hline $\begin{array}{l}\text { Salahi, Hedjazi, } \\
\text { Mahmood, \& } \\
\text { Ebrahimi (2014) } \\
\text { Iran }\end{array}$ & $\begin{array}{l}\text { The Effect of } \\
\text { Personality Types } \\
\text { on the } \\
\text { Learning Styles of } \\
\text { Agricultural } \\
\text { Students } \\
\text { (A case study in } \\
\text { Iran) }\end{array}$ & $\begin{array}{l}\text { Investigar o efeito das } \\
\text { características da } \\
\text { personalidade nos } \\
\text { estilos de } \\
\text { aprendizagem dos } \\
\text { estudantes. }\end{array}$ & $\begin{array}{l}260 \\
\text { estudantes / } \\
\text { graduação. }\end{array}$ & $\begin{array}{l}\text { NEO-FFI (Costa } \\
\& \text { McCrea 1992). }\end{array}$ & $\begin{array}{l}\text { Análise } \\
\text { discriminante. }\end{array}$ & $\begin{array}{l}\text { a) A maioria dos alunos tinha estilo de aprendizagem } \\
\text { assimilador; b) para os cinco fatores de personalidade, } \\
\text { exceto neuroticismo, foi encontrada uma associação } \\
\text { consistente e positiva com os estilos de aprendizagem; c) a } \\
\text { conscienciosidade apresenta importante distinção entre o } \\
\text { estilo de aprendizado convergente e outros três estilos de } \\
\text { aprendizagem; d) a extroversão se mostrou importante para } \\
\text { a distinção entre aprendizagem convergente e outros dois } \\
\text { estilos de aprendizagem. }\end{array}$ \\
\hline
\end{tabular}


Tabela 9. Principais resultados de pesquisas rescentes sobre traços de personalidade em TD\&E (continuação)

\begin{tabular}{|c|c|c|c|c|c|c|}
\hline $\begin{array}{l}\text { Yang, Jowett, } \\
\text { \& Chan (2014) } \\
\text { China }\end{array}$ & $\begin{array}{l}\text { Effects of big-five } \\
\text { personality traits on the } \\
\text { quality of relationship } \\
\text { and satisfaction in } \\
\text { Chinese coach-athlete } \\
\text { dyads }\end{array}$ & $\begin{array}{l}\text { Examinar a influência } \\
\text { dos traços de } \\
\text { personalidade sobre a } \\
\text { qualidade do } \\
\text { relacionamento } \\
\text { treinador-atleta chinês } \\
\text { e satisfação com o } \\
\text { treinamento. }\end{array}$ & $\begin{array}{l}350 \text { díades } \\
\text { treinador- } \\
\text { treinando / } \\
\text { Trabalho de } \\
\text { treinamento } \\
\text { de atletas. }\end{array}$ & $\begin{array}{l}\text { NEO-FFI (Yang } \\
\text { et al., 1999). }\end{array}$ & $\begin{array}{l}\text { Modelagem de } \\
\text { equação estrutural; } \\
\text { Testes de APIM. }\end{array}$ & $\begin{array}{l}\text { a) A característica de personalidade de cada } \\
\text { membro do relacionamento contribuiu de forma } \\
\text { independente para a qualidade da relação; b) os } \\
\text { efeitos das características de personalidade sobre } \\
\text { qualidade do relacionamento do ator e parceiro e } \\
\text { na satisfação com o treinamento foram } \\
\text { considerados significativos. }\end{array}$ \\
\hline $\begin{array}{l}\text { Kokkinos, } \\
\text { Kargiotidis, \& } \\
\text { Markos (2015) } \\
\text { Grécia }\end{array}$ & $\begin{array}{l}\text { The relationship between } \\
\text { learning and study } \\
\text { strategies and big five } \\
\text { personality traits among } \\
\text { junior university student } \\
\text { teachers }\end{array}$ & $\begin{array}{l}\text { Examinar a associação } \\
\text { preditiva entre os } \\
\text { cinco principais traços } \\
\text { de personalidade e as } \\
\text { estratégias de } \\
\text { aprendizagem e estudo }\end{array}$ & $\begin{array}{l}521 \\
\text { estudantes / } \\
\text { pós-graduação }\end{array}$ & $\begin{array}{l}\text { NEO-FFI (Costa } \\
\& \text { McCrae, } \\
\text { 1992; } \\
\text { Panayiotou, } \\
\text { Kokkinos, \& } \\
\text { Spanoudis, 2004) }\end{array}$ & $\begin{array}{l}\text { Análises de } \\
\text { regressão múltipla e } \\
\text { linear }\end{array}$ & $\begin{array}{l}\text { a) Altas pontuações de extroversão e neuroticismo } \\
\text { baixaram o uso das estratégias de aprendizagem e } \\
\text { de estudo, enquanto a conscienciosidade, a } \\
\text { abertura para a experiência e a amabilidade } \\
\text { apresentaram resultados mistos; b) necessidade de } \\
\text { levar em consideração os traços de personalidade } \\
\text { dos estudantes universitários para a } \\
\text { implementação de intervenções educacionais } \\
\text { mais individualizadas. }\end{array}$ \\
\hline $\begin{array}{l}\text { Lakhal, } \\
\text { Sévigny, \& } \\
\text { Frenette. } \\
\text { (2015) } \\
\text { Estados } \\
\text { Unidos. }\end{array}$ & $\begin{array}{l}\text { Personality and student } \\
\text { performance on } \\
\text { evaluation methods used } \\
\text { in business administration } \\
\text { courses. }\end{array}$ & $\begin{array}{l}\text { Verificar se a } \\
\text { personalidade (modelo } \\
\text { Big Five) influencia o } \\
\text { desempenho nos } \\
\text { métodos de avaliação } \\
\text { utilizados nos cursos } \\
\text { de administração de } \\
\text { empresas. }\end{array}$ & $\begin{array}{l}169 \\
\text { estudantes / } \\
\text { graduação. }\end{array}$ & $\begin{array}{l}\text { NEO-FFI (Costa } \\
\& \text { McCrea 1992). }\end{array}$ & $\begin{array}{l}\text { Análises de } \\
\text { regressão linear e } \\
\text { hierárquica. }\end{array}$ & $\begin{array}{l}\text { Os fatores do Big Five explicam } 6 \text { a } 13 \% \text { da } \\
\text { variabilidade no desempenho em trabalhos } \\
\text { grupais, exames orais, exames escritos, testes de } \\
\text { escolha múltipla e trabalho prático. }\end{array}$ \\
\hline $\begin{array}{l}\text { Li \& } \\
\text { Armstrong } \\
\text { (2015) } \\
\text { Reino Unido }\end{array}$ & $\begin{array}{l}\text { The relationship between } \\
\text { Kolb's experiential } \\
\text { learning styles and Big } \\
\text { Five } \\
\text { personality traits in } \\
\text { international managers }\end{array}$ & $\begin{array}{l}\text { Investigar a relação } \\
\text { entre estilo de } \\
\text { aprendizagem } \\
\text { experiencial e traços } \\
\text { de personalidade em } \\
\text { gerentes } \\
\text { internacionais. }\end{array}$ & $\begin{array}{l}269 \text { gerentes } \\
\text { /corporativo } \\
\text { (curso in } \\
\text { company) }\end{array}$ & $\begin{array}{l}\text { NEO-FFI (Costa } \\
\& \text { McCrea 1992) }\end{array}$ & $\begin{array}{l}\text { Análises de } \\
\text { regressão múltipla e } \\
\text { logística }\end{array}$ & $\begin{array}{l}\text { a) O traços de extroversão está associado ao estilo } \\
\text { de aprendizagem experiencial; b) os gerentes } \\
\text { extravertidos compreendem melhor ao se } \\
\text { envolverem em experiências concretas e } \\
\text { experimentação ativa em vez de observação } \\
\text { reflexiva e tendem a ter um estilo de } \\
\text { aprendizagem acomodativo. }\end{array}$ \\
\hline
\end{tabular}


Tabela 9. Principais resultados de pesquisas rescentes sobre traços de personalidade em TD\&E (Continuação)

\begin{tabular}{|c|c|c|c|c|c|c|}
\hline $\begin{array}{l}\text { Osmon, Santos, } \\
\text { Kazakov, Kassel, } \\
\text { Mano, \& Morth } \\
\text { (2018) }\end{array}$ & $\begin{array}{l}\text { Big Five } \\
\text { personality } \\
\text { relationships with } \\
\text { general } \\
\text { intelligence and } \\
\text { specific Cattell- } \\
\text { Horn-Carroll } \\
\text { factors of } \\
\text { intelligence }\end{array}$ & $\begin{array}{l}\text { Examinar relações } \\
\text { entre os Cinco } \\
\text { Grandes traços de } \\
\text { personalidade no } \\
\text { Inventário de } \\
\text { Personalidade } \\
\text { e os escores g- } \\
\text { residualizados dos sete } \\
\text { fatores do modelo de } \\
\text { Cattell-Horn-Carroll } \\
\text { (CHC) } \\
\text { o Woodcock-Johnson- } \\
\text { III (WJ-III; Mather \& } \\
\text { Woodcock, 2001). }\end{array}$ & $\begin{array}{l}140 \\
\text { estudantes } \\
\text { universitários } \\
\text {. }\end{array}$ & $\begin{array}{l}\text { NEO - Revisado } \\
\text { (NEO-PI-R; } \\
\text { Costa \& } \\
\text { McCrae, } \\
\text { 1992). }\end{array}$ & $\begin{array}{l}\text { Análises de } \\
\text { regresão } \\
\text { hierárquica. }\end{array}$ & $\begin{array}{l}\text { a) Maior capacidade intelectual foi associada com } \\
\text { níveis mais altos de abertura à experiência e } \\
\text { neuroticismo, enquanto correlações negativas } \\
\text { indicaram que maior função intelectual estava } \\
\text { associada com menor amabilidade e } \\
\text { conscienciosidade. }\end{array}$ \\
\hline
\end{tabular}


As pesquisas mostraram que altas pontuações no fator Neuroticismo foram correlatas de desempenho acadêmico mais fraco, dificuldade de aprendizagem, de níveis inferiores de autoeficácia, além de baixar as pontuações no uso de estratégias de aprendizagem (Furnham, Nuygard \& Chamorro-Premuzic, 2013; Kokkinos, Kargiotidis \& Markos, 2015; Stumm \& Furnham, 2012; De Feyter, Caers, Vigna, \& Berings,2012; Kokkinos, Kargiotidis, \& Markos, 2015).

Corroborando estes resultados, estudos anteriores identificaram que estudantes com características de personalidade neurótica mostram ansiedade elevada e baixa autoconfiança, o que dificulta a participação no processo de aprendizagem (ChamorroPremuzic, Furnham, \& Lewis, 2007). Além da ansiedade e da baixa autoconfiança, estudantes com esse perfil tendem a experimentar outras emoções negativas como medo, tristeza, constrangimento, raiva, depressão, hostilidade e culpa. Ainda segundo os autores, alunos com predomínio deste traço de personalidade muitas vezes têm ideias irracionais e têm mais dificuldade em gerenciar situações estressantes como exames orais, provas escritas e testes de múltipla escolha.

Chamorro-Premuzic (2006) relata que os alunos com uma pontuação menor no traço de neuroticismo têm melhor desempenho nos exames escritos, provavelmente porque experimentam menos estresse do que os outros alunos. Diante de tais fatos, apesar dos esforços substanciais para se destacarem, seus altos níveis de ansiedade e falta de estratégias efetivas de aprendizagem, geralmente os impedem de alcançar seus objetivos.

Níveis mais altos no fator Extroversão também foram correlatos foram relacionadas de desempenho acadêmico mais fraco. Indivíduos com altas pontuações neste fator aprendem melhor ao se envolverem em experiências concretas durante o treinamento, diminuindo as pontuações do uso de estratégias de aprendizagem não-práticas. Este fator também se relaciona negativamente com a velocidade no processamento das informações, tomando como base avaliações de QI (Furnham et Al., 2013; Li \& Armstrong, 2015; Kargiotidis et al., 2015; Osmon, Santos, Kazakov, Kassel, Mano, \& Morth, 2018).

Alunos com predomínio neste traço são sociáveis, ativos, comunicativos e orientados para as pessoas. Eles gostam de interações com os outros e são capazes de manter relações interpessoais. Assim, enquanto alunos introvertidos passam mais tempo estudando, os estudantes extrovertidos gastam mais tempo socializando e se distraindo (Furnham et al. 2003). Estes colocam grande ênfase nas interações (O'Connor \& Paunonen, 2007) e nas atividades sociais. Komarraju e Karau (2005) mostraram ainda que a extroversão foi 
associada a uma atitude de evitação em relação à aprendizagem. Assim, para os autores, embora estudantes extravertidos possam usar várias estratégias de aprendizagem, provavelmente serão facilmente distraídos quando perceberem sem sentido o que estão estudando.

As pesquisas desta revisão não evidenciaram influências significativas do fator Amabilidade sobre outras variáveis. Por exemplo, a pesquisa de Chamorro-Premuzic et al. (2007), na investigação sobre traços de personalidade e estratégias de aprendizagem, no que se refere a este traço os resultados não foram conclusivos. Contudo, McCrae (1992) dizem que no contexto da educação, alunos com ênfase neste perfil são basicamente altruístas. Eles gostam de cooperar com os outros e estão sempre dispostos a ajudar as pessoas. Além disso, costumam causar uma boa impressão em seus professores. Assim, os autores inferem que, uma vez que os alunos são caracterizados pela simpatia, confiabilidade e cooperação, podese assumir que eles preferem o trabalho em grupo, além de estarem dispostos a pedir ajuda sempre que precisarem, levando a melhores resultados acadêmicos.

Já a Conscienciosidade foi o fator que mais se comportou como preditor de desempenho acadêmico, quando medido, por exemplo, por notas. Indivíduos com altas pontuações em conscienciosidade apresentaram bom desempenho acadêmico, alcance da aprendizagem nas atividades propostas e motivação para aprender. O fator mostrou ainda relação positiva com o uso de diferentes estratégias de aprendizagem (Lakhal, Sévigny \& Frenette, 2015; Furnham et al., 2013; Kappe \& Der Flier, 2012; De Feyter et al., 2012).

O perfil de conscienciosidade é organizado, escrupuloso, pontual, confiável autodisciplinado e determinado. No ambiente corporativo e de estudos este perfil é conhecido pelo bom desempenho em suas atividades, incluindo aquelas que exigem muito esforço em um longo período de tempo, como trabalhos práticos e projetos (ChamorroPremuzic, 2006).

Altas pontuações no traço de Abertura à Experiência também foram correlatas de alcance da aprendizagem e de relação positiva com o uso de diferentes estratégias de aprendizagem, tais como afetivas, objetivas e de processamento de informação (Furnham, 2012; Kargiotidis \& Markos, 2015). Este domínio tem sido ainda freqüentemente associada à inteligência (Chamorro-Premuzic e Furnham, 2005) e à criatividade (Chamorro-Premuzic, 2006), visto que sugere se tratar de indivíduos que gostam de variedade e são intelectualmente curiosos. Eles são capazes de apreciar novas experiências, tolerar a incerteza e explorar. Não são convencionais em suas ideias, seus valores e suas crenças. 
Desta forma, para Chamorro-Premuzic et al. (2007), a conscienciosidade e a abertura à experiência são precursores nas estratégias de aprendizagem que promovem bom desempenho acadêmico e aprendizagem, devido às suas características de empenho, curiosidade intelectual, imaginação e criatividade. Ainda nesta perspectiva, Komarraju, Karau e Schmeck (2009), descobriram que estudantes com altos índices de abertura à experiência são muitas vezes motivados intrinsecamente em relação a aprender.

Como é possível notar, os estudos sobre a temática têm notório foco no desempenho acadêmico, medido por diferentes relações entre variáveis. Lakhal et al. (2015) propuseram verificar, através da formulação de algumas hipóteses baseadas em estudos anteriores, se a personalidade (segundo o modelo Big Five) influencia o desempenho nos métodos de avaliação utilizados em contexto acadêmico, considerando preferência por métodos e notas de avaliação geralmente obtidos em cada um desses métodos. Na pesquisa foram considerados métodos como exames orais, provas escritas, testes de múltipla escolha, trabalhos práticos, estudos de caso, simulações, trabalho em grupo e projetos. As hipóteses levantadas no estudo, bem como as confirmações ou rejeições destas seguem na Tabela 10.

Tabela 10. Resumo das hipóteses confirmadas e rejeitadas do estudo

\section{Hipóteses}

Principais resultados

H1. Ao controlar o sexo e a idade, a personalidade, definida pelo modelo Big Five, afeta o desempenho em métodos de avaliação dos alunos.

H2. O neuroticismo tem um efeito negativo no desempenho em exames orais, exames escritos e testes de múltipla escolha.

H3. A extroversão tem um efeito positivo no desempenho em simulações, trabalho em grupo e exames orais.

H4. A extroversão tem um efeito negativo no desempenho em exames escritos.

H5. Abertura à experiência tem um efeito positivo no desempenho em exames orais, provas escritas e projetos.

H6. Aberto à experiência tem um efeito negativo no Confirmada. desempenho em testes de múltipla escolha.

Confirmada para trabalho em grupo, exames orais, provas escritas, testes de múltipla escolha e trabalhos práticos. Rejeitado por estudos de caso, simulações e projetos

Rejeitada.

Rejeitada.

Rejeitada.

Confirmada para exames orais. Rejeitada para exames escritos e projetos.

H7. A amabilidade tem um efeito positivo sobre o desempenho no trabalho de grupo e nas provas orais. 
Tabela 10. Resumo das hipóteses confirmadas e rejeitadas do estudo (continuação)

\begin{tabular}{ll}
\hline $\begin{array}{l}\text { H8. A amabilidade tem um efeito negativo no } \\
\text { desempenho em exames escritos e testes de múltipla } \\
\text { escolha. }\end{array}$ & $\begin{array}{l}\text { Confirmada para exames escritos. Rejeitado para } \\
\text { testes de múltipla escolha. }\end{array}$ \\
$\begin{array}{ll}\text { H.9 Conscienciosidade tem um efeito positivo sobre } \\
\text { o desempenho em todos os métodos de avaliação } \\
\text { considerados no estudo. }\end{array}$ & $\begin{array}{l}\text { Confirmada para exames orais, provas escritas, } \\
\text { testes de múltipla escolha e trabalhos práticos. }\end{array}$ \\
& $\begin{array}{l}\text { Rejeitada para estudos de caso, simulações, } \\
\text { trabalho em grupo e projetos. }\end{array}$
\end{tabular}

Fonte: Adaptada de Lakhal et al. (2015).

Para as hipóteses rejeitadas os autores chamam a atenção para o fato de que um único modelo não é o suficiente para para descrever esses relacionamentos, pois nem sempre são os mesmos fatores de personalidade que são determinantes de um dado método. As divergências encontradas podem dizer, por exemplo, do nível acadêmico do aluno. Lakhal, Sévigny e Frenette (2015), ressaltam ainda a importância de pesquisas futuras incorporarem, por exemplo, outros contextos como o da educação corporativa.

Nota-se que os principais resultados de pesquisa demonstram que os traços de personalidade se comportaram como correlatos estáveis, robustos, previsíveis e determinantes de outras variáveis envolvidas no processo de TD\&E como, por exemplo, de desempenho acadêmico, motivação e estratégias de aprendizagem. Neste sentido, essa variável pode ser mais um elemento relevante que ajude na otimização, formação e seleção em programas de TD\&E mais próximos da realidade das características dos estudantes (Salahi, Hedjazi, Mahmood, \& Ebrahimi, 2014).

É importante dizer que essa revisão de sistemática de literatura possui limitações, dentre elas o recorte de um número limitado de bases de dados. Considerando a diversidade de periódicos disponíveis hoje, futuras pesquisas que tenham como objetivo mapear a temática, podem ampliar as bases de dados a fim de abranger mais estudos. Além disso, a extração de informações acerca de outros instrumentos que mensuram os cinco grandes fatores de personalidade e comparação entre os interesses de pesquisas por localização geográfica, podem trazer informações para aprofundar o conhecimento sobre a variável.

Todavia, mesmo diante de suas limitações, esta revisão contribui com a área de TD\&E e com essa pesquisa, na medida em que consolida as descobertas de estudos sobre a influência dos traços de personalidade sobre ações instrucionais e sobre a sua relação com a variável estratégias de aprendizagem, que por diversas vezes apareceu nas pesquisas. Além disso, evidencia a importância da temática na produção do conhecimento em TD\&E, o que 
é relevante principalmente para os países onde não foram identificadas pesquisas, incluindo o Brasil.

Como visto, os investimentos em produções científicas na área de TD\&E que abordam os cinco grandes fatores da personalidade diminuíram nos últimos anos. Como pesquisas nacionais não foram identificadas e, diante das evidências das contribuições apresentadas pelos artigos analisados nesta revisão, investigar a influência desta variável sobre outras se constitui como uma agenda de pesquisa para o campo de TD\&E no Brasil. 


\section{Capítulo 3. Características Metodológicas da Pesquisa}

\section{ObJetivo do CAPítulo 3}

Este capítulo visa apresentar a delimitação do problema, a justificativa e os objetivos da pesquisa, descrever as características da organização-alvo, do curso avaliado, da população e amostra, dos instrumentos de medida, bem como do procedimento de coleta e análise estatística dos dados.

\subsection{Delimitação do Problema e ObJetivos de Pesquisa}

A delimitação do problema de pesquisa foi realizada a partir da análise das questões empíricas identificadas na literatura nacional e internacional em TD\&E, considerando as lacunas no que se refere às características individuais e ao subsistema de avaliação. Como visto na revisão de literatura, o subsistema de avaliação treinamentos ofertados presencialmente já passou por muitos avanços, mas ainda há necessidade de transpor limitações que restringem a efetividade do sistema de TD\&E (Iglesias \& Salgado, 2012). Neste sentido, as características da clientela têm oferecido importantes feedbacks para este subsistema, auxiliando na elaboração de eventos instrucionais mais adequados aos aprendizes, que possibilitem a aprendizagem.

Ao analisar a literatura internacional, diferentemente da literatura nacional, identifica-se a inclusão da variável traços de personalidade como preditora do comportamento de outras variáveis, dentre elas, com certa frequência, das estratégias de aprendizagem. Como mostra o estudo de Martins (2016), estratégias de aprendizagem tem se mostrado uma variável de importância influência sobre o processo de ensinoaprendizagem, sendo relacionada nas pesquisas com muitas outras variáveis, tais como motivação para estudar, aquisição e retenção de conteúdo, autoconfiança e variáveis individuais - idade, gênero, anos de estudo, etc., mas sem o aparecimento dos traços de personalidade em pesquisas nacionais.

A literatura internacional vem mostrando a sua importância no processo ensinoaprendizagem, visto que se trata de características dos indivíduos, sendo única e o distinguindo dos demais a partir de padrões consistentes de sentimentos, pensamentos e comportamentos (Trentini et al., 2009). Ademais, a personalidade sempre teve destaque no 
campo da psicologia, sendo fonte de numerosos estudos, debates teóricos, metodológicos e éticos, os quais evidenciam a implicação das dimensões afetivas, cognitivas e comportamentais desta variável.

A avaliação de traços de personalidade é amplamente utilizada pelos psicólogos em diversos fazeres da psicologia. Então, como uma variável de tal familiaridade dos psicólogos, com longos estudos e desenvolvimentos de ótimos instrumentos de medidas, investigá-la em pesquisas nacionais na área de TD\&E podem trazer novas contribuições para o sistema, como têm mostrado as pesquisas internacionais. Em função da apreciação de tais questões, são propostos os seguintes problemas de pesquisa:

1. Existe relação entre traços de personalidade com uso de determinadas estratégias de aprendizagem?

2. De que forma o reconhecimento dessa relação entre traços de personalidade e uso de estratégias podem contribuir para o planejamento instrucional de treinamentos corporativos mais adequados às características dos aprendizes?

O presente trabalho de Mestrado, portanto, pretende levantar a possibilidade da inclusão de uma nova variável relacionada às características da clientela e contribuir com a área de avaliação de sistemas instrucionais. Com a finalidade de responder às duas questões empíricas descritas anteriormente, foram traçados os seguintes objetivos para essa pesquisa:

\section{OBJETIVO GERAL:}

Analisar as relações entre traços de personalidade e uso de determinadas estratégias de aprendizagem em treinamentos corporativos presenciais.

\section{OBJETIVOS ESPECÍFICOS:}

$>$ Descrever as estratégias de aprendizagem adotadas pelos participantes ao longo do treinamento, utilizando a Escala de Estratégias de Aprendizagem adaptada por Martins, Zerbini e Medina (2018).

$>$ Identificar e descrever os traços de personalidade dos participantes, segundo NEO-FFI-R (Mendonza-Flores, 2010).

$>$ Realizar correlações entre as variáveis traços de personalidade e estratégias de 
aprendizagem.

$>$ Identificar informações sobre características dos aprendizes que podem contribuir para o planejamento instrucional de treinamentos corporativos presenciais.

\subsection{CONSIDERAÇões Éticas}

A presente pesquisa seguiu as diretrizes da Resolução 466/12, do Conselho Nacional de Saúde, e contemplou em seu planejamento os princípios da autonomia, beneficência, nãomaleficência e justiça. A pesquisa também está de acordo com a Resolução 002/2003, do Conselho Federal de Psicologia, com Código de Ética do Psicólogo e foi aprovado pelo Comitê de Ética em Pesquisa da Faculdade de Filosofia, Ciências e Letras de Ribeirão Preto - USP (CAAE nº 60834516.4.0000.5407).

Os potenciais riscos aos participantes estão relacionados ao sigilo das informações fornecidas pela instituição (dados pessoais dos funcionários fornecidos durante a realização do questionário de personalidade). Contudo, nas etapas de análise e divulgação dos dados será assegurada a manutenção de sigilo e anonimato acerca da identidade dos participantes. Após a aprovação do projeto pelo Comitê de Ética em Pesquisa, os objetivos da pesquisa e os procedimentos utilizados foram esclarecidos aos responsáveis da organização participante.

Previamente à aplicação dos questionários, os participantes receberam esclarecimentos quanto aos objetivos da pesquisa e seus procedimentos. Conforme descrito, o Termo de Consentimento Livre e Esclarecido (Anexo A) foi disponibilizado a todos os funcionários convidados a participar da pesquisa. Somente o participante que autorizou a sua participação foi direcionado para a página seguinte para responder aos questionários.

Ademais, reforça-se que a utilização da medida de personalidade nesta pesquisa não tem como objetivo "rotular" os indivíduos como capazes de adotar estratégias de aprendizagem ou não. Pelo contrário, o reconhecimento desta variável pretende ser mais um elemento que possibilita projetar ações educacionais mais adequadas ao perfil de sua clientela. 


\subsection{CARACTERístiCas da ORganizaÇão}

A organização participante é considerada de médio porte, tem 22 anos de mercado e está localizada no Estado de Minas Gerais, com sede em Belo Horizonte. A mesma atua no segmento de telecomunicações, oferecendo inovação tecnológica em serviços de voz, infraestrutura de rede de dados, contact center e videoconferência. A organização tem em sua carteira grandes clientes e trabalha com projetos complexos. Por isso, tem como missão superar as expectativas de seus clientes, com foco em resultados sustentáveis.

Para cumprir esta missão conta com seus colaboradores, que estão sempre à frente das operações e em contato com o cliente final. Por isso, são profissionais que precisam, em sua maioria, de formação, experiência prática e conhecimentos técnicos, além de habilidades interpessoais. Desta forma, a organização se preocupa muito com boas práticas de gestão de pessoas, sendo um dos focos do setor de Recursos Humanos o investimento as ações de TD\&E, tanto técnicas, quanto comportamentais.

Até 2016 os treinamentos eram realizados, a priori, de acordo com demandas aleatórias que surgiam nos setores. Mas, a partir de então a empresa iniciou um projeto de aperfeiçoamento de seu sistema de treinamento, começando pela implantação do ANT. Assim, ao serem convidados a participar deste estudo, os gestores demonstraram abertura e satisfação em cooperar, além de interesse pelo tema abordado nesta pesquisa por acreditarem nos avanços que os resultados podem oferecer para a área de TD\&E no contexto corporativo. Ademais, a empresa tem a cultura de utilizar a avaliação psicológica e os indicadores dos testes de personalidade como uma das formas de auxiliar na gestão de seus funcionários, acreditando assim na aplicabilidade do presente estudo.

A parceria com esta organização foi viabilizada pelo fato da pesquisadora já ter sido uma de suas prestadoras de serviços de recrutamento, seleção e avaliação psicológica, e por ter mantido um bom relacionamento e contato com o setor de Recursos Humanos desde então. Ressalta-se que essa situação se difere da realidade da maioria das pesquisas que buscam parcerias no contexto corporativo, visto que as organizações quase sempre são de difícil acesso. Talvez este seja um dos motivos para o baixo número de pesquisas realizadas no contexto corporativo identificado na revisão da literatura sobre traços de personalidade e ações de TD\&E realizada neste estudo.

Inicialmente foi firmado, entre a pesquisadora e responsável pelo o setor de Recursos Humanos um Termo de Autorização Institucional para a realização dos trabalhos 
acadêmicos. Tal documento teve como objetivos: a) esclarecer os objetivos da pesquisa, bem como suas etapas; b) informar sobre a preservação do anonimato e sigilo dos participantes e assegurar-lhes a participação voluntária no estudo; c) firmar que os objetivos e procedimentos metodológicos estabelecidos no projeto de pesquisa previamente apresentado serão seguidos.

\subsection{Características do Treinamento}

O treinamento avaliado foi intitulado como "Gestão à Vista", desenvolvido e oferecido pela organização participante. O mesmo tem duração de duas horas e trinta minutos e visa alinhar as estratégias e políticas organizacionais e comportamentos esperados no ambiente de trabalho. Ressalta-se que este treinamento começou a ser ministrado no ano de 2016, quando a empresa parceira passou a investir fortemente no aprimoramento dos seus processos internos, com foco em melhorias da qualidade e agilidade no atendimento de seus clientes internos e externos.

Trata-se de um treinamento corporativo, obrigatório, destinado a todos os colaboradores. Em outubro de 2016, quando o treinamento foi implantado, a equipe foi dividida em turmas, e todos participaram. Posteriormente, os novos funcionários foram agrupados nas contrações mensais e receberam o mesmo treinamento.

O treinamento é ministrado presencialmente pelo gestor do setor de Recursos Humanos, durante a jornada de trabalho, em um ambiente de treinamentos dentro da própria organização. O desenho do treinamento é o mesmo, independente da hierarquia do cargo. Na Tabela 11 são apresentadas as características formais do treinamento.

Tabela 11. Características formais do treinamento Gestão à Vista.

\begin{tabular}{ll}
\hline & - Presencial \\
Características & - Instrucional \\
& - Ofertado presencialmente para todos os colaboradores da organização \\
& - Público-alvo (potencial a ser atingido): 115 colaboradores \\
\hline - Alinhar a estratégia e política organizacional e comportamentos esperados no \\
Objetivos de & - Ambiente de trabalho \\
Aprendizagem & melhorias da qualidade e agilidade da prestação de serviços aos clientes internos e \\
& externos \\
\hline \multirow{2}{*}{ Duração } & - 2 h e 30m (carga horária total) \\
& - Colaboradores já pertencentes ao quadro da empresa: $2^{\circ}$ semestre/2016: 10/10/16 \\
& a 03/11/16 \\
\hline
\end{tabular}


Tabela 11. Características formais do treinamento Gestão à Vista (Continuação).

\begin{tabular}{ll}
\hline Estrutura & $\begin{array}{l}\text { 6 Unidades } \\
\text { - Avaliação: atividade ao final do curso sobre o domínio, conhecimento e } \\
\text { compreensão do conteúdo. }\end{array}$ \\
\hline Conteúdos & $\begin{array}{l}\text { 1) Introdução; 2) Mapa da Estratégia Organizacional; 3) Atitudes e } \\
\text { Comportamentos Organizacionais e Estratégia Organizacional; 4) Políticas } \\
\text { Internas; 5) Ética e Conduta no Atendimento ao Cliente Interno e Externo. }\end{array}$ \\
\hline $\begin{array}{l}\text { Análise dos } \\
\text { objetivos }\end{array}$ & Não havia a descrição de objetivos educacionais no material instrucional do curso. \\
\hline
\end{tabular}

Esta é uma ação educacional de curta duração e de baixa complexidade, onde o instrutor, além de apresentação oral e visual, disponibiliza o material impresso para que os colaboradores utilizem durante e após o treinamento. Os objetivos educacionais não constavam na introdução do material instrucional. Assim, em reunião com o gestor de Recursos Humanos da organização, foram identificadas e listadas as competências a serem observadas em desempenhos específicos no trabalho a partir da realização do treinamento, sendo estas:

> Aprender sobre a cultura organizacional e sobre os resultados esperados;

$>$ Conduzir as atividades de trabalho de forma consciente, minimizando o consumo de recursos da organização e ampliando os resultados esperados;

> Agir de forma ética e comprometida com a organização, com os colegas de trabalho e com o cliente interno;

> Compartilhar com os colegas ações que podem ser implementadas para promoção da eficiência operacional;

> Vivenciar a organização do trabalho de forma integrada, levando em consideração a importância de todos os setores que compõem o negócio, bem como os elementos financeiros, comerciais e de eficiência operacionais envolvidos.

$>$ Acompanhar os indicadores de gestão a fim de contribuir para a sua melhoria.

Apesar de não descritos no material instrucional, nota-se que grande parte dos objetivos instrucionais foram descritos pelo gestor de recursos humanos em termos de desempenhos observáveis, demonstrando definição clara das condições para a realização dos comportamentos esperados. As estratégias instrucionais parecem aquém das características de clientela (em sua maioria de nível superior de escolaridade) e incompatível com o nível de complexidade dos objetivos instrucionais.

O treinamento poderia, por exemplo, propor exercícios práticos ou simular situações 
reais que tivessem relação com a rotina de trabalho, aumentando a complexidade das atividades propostas, abrangendo outros domínios da aprendizagem, além do cognitivo. Para tanto, talvez o tempo atualmente definido para o treinamento também não seja adequado.

Os conteúdos estão sequenciados e bem articulados entre as unidades. A confecção do material apresenta muitos conteúdos de elaboração própria da organização e, portanto, pouco respaldo e fontes bibliográficas. Ademais, fontes alternativas de informações sobre os temas do curso não são indicadas. Contudo, de modo geral, o material possui boa apresentação e organização, facilitando sua usabilidade pelos participantes do treinamento. Além disso, orientações e instruções sobre o seu uso são fornecidas aos colaboradores ao início do treinamento.

\subsection{Características da População e Amostra}

A população da pesquisa foi composta por 115 colaboradores da organização parceira, os quais participaram do treinamento de Gestão à Vista. Dentre estes haviam pessoas dos sexos feminino e masculino, com diferentes níveis de escolaridade, ocupando cargos com diferentes hierarquias dentro da organização. Desta população, uma amostra composta por 86 colaboradores aceitou participar da pesquisa, sendo o seu perfil detalhado na Tabela 12.

Tabela 12. Características da amostra.

\begin{tabular}{clcc}
\hline \multirow{3}{*}{ Idade } & & Frequência & $(\boldsymbol{\%})$ \\
\cline { 2 - 3 } & De 31 a 40 anos & 46 & $\mathbf{5 3 , 5}$ \\
& De 19 a 30 anos & 24 & 27,9 \\
& De 41 a 50 anos & 11 & 12,8 \\
& De 51 a 60 anos & 5 & 5,8 \\
\multirow{5}{*}{ Gênero } & Masculino & 68 & $\mathbf{7 9 , 1}$ \\
& Feminino & 18 & 20,9 \\
\multirow{3}{*}{ Escolaridade } & Ensino Superior & 53 & $\mathbf{6 2}$ \\
& Especialização & 17 & 20 \\
& Ensino Médio Completo & 12 & 15 \\
& Técnico & 4 & 5 \\
Hierarquias dos Cargos & & $\mathbf{7 7}$ \\
& Técnico/Operacional & 66 & 23 \\
\hline
\end{tabular}


A Tabela 12 apresenta a frequência das variáveis idade, gênero, escolaridade e hierarquia dos cargos presente na amostra. Observamos que mais de 50\% estão na maior faixa etária, mostrando que a maioria dos funcionários tem mais que 31 anos. Tal dado vai de encontro às exigências da organização, dentre as quais estão formação, experiência prática e conhecimentos técnicos, além de habilidades interpessoais.

Observamos ainda que $79 \%$ (68) dos participantes são do gênero masculino e $21 \%$ (18) são do gênero feminino. Estes resultados podem estar relacionados com o fato das atividades dominantes da organização serem de natureza mais técnicas/operacionais, ligadas a cursos técnicos e graduações, como, por exemplo, eletrônica, engenharias elétrica e de telecomunicações, onde ainda se observa maior prevalência do sexo masculino. O Censo da Educação Superior de 2016, divulgado pelo INEP (Instituto Nacional de Estudos e Pesquisas Educacionais Anísio Teixeira Legislação e Documentos) mostra essa maior concentração do sexo masculino nestas áreas do conhecimento, conforme mostra a Figura 11.

Figura 11. Gênero presentes nas áreas de formação superior

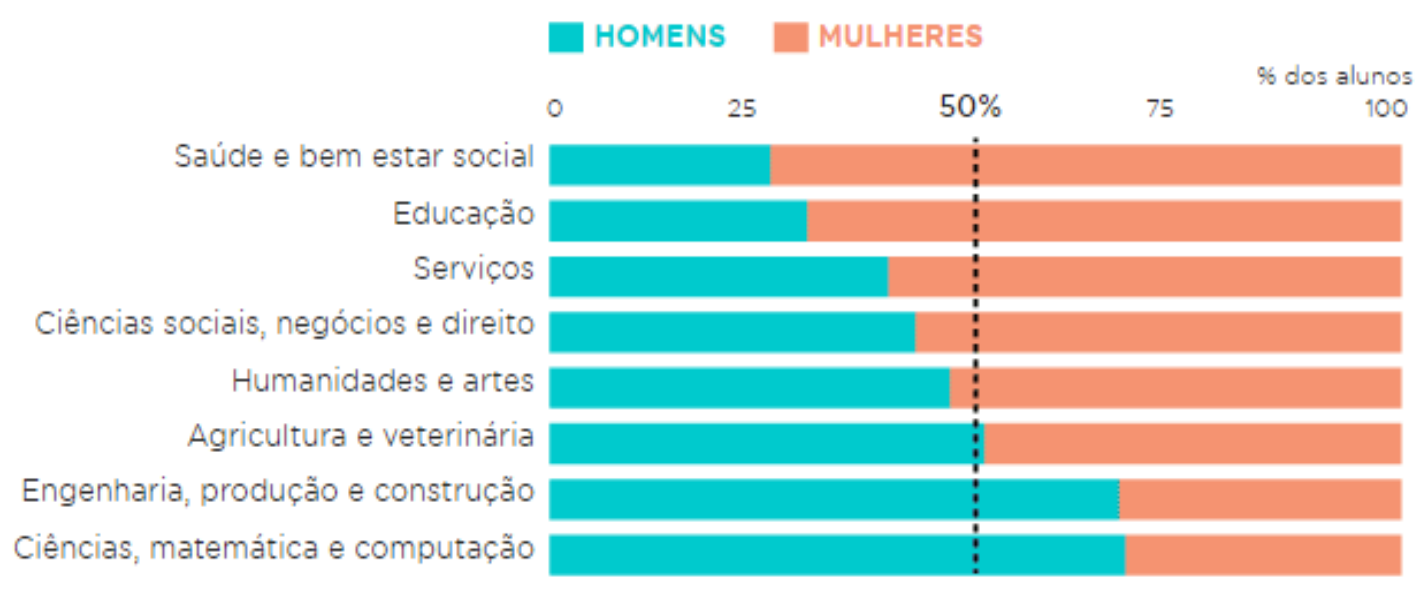

Fonte: Inep (2016).

A Tabela 12 retrata ainda que a maioria dos participantes (82\%) possuem pelo menos ensino superior, o que está em consenso com o nível de complexidade e exigências dos cargos, conforme verbalizado pelo gestor de recursos humanos da empresa. Fica evidenciado também que a maioria dos cargos na empresa é técnico/operacional, o que tem a ver com natureza de suas prestações de serviços. 


\subsection{INSTRUMENTOS DE MEDIDA}

Os instrumentos utilizados neste estudo foram a Escala de Estratégias de Aprendizagem (Martins et al., 2018) e o Inventário de Personalidade NEO, na versão NEOFFI (Mendoza-Flores, 2010). Estes não foram submetidos a adaptações ou validações semânticas, visto que o primeiro havia sido validado muito próximo a coleta de dados desta pesquisa e o segundo instrumento foi adaptado em diferentes em todo mundo, sendo a versão utilizada neste trabalho fruto de um grande trabalho de adaptação para o contexto brasileiro.

Cabe esclarecer ainda que o instrumento de Estratégias de Aprendizagem foi adaptado e utilizado por Martins et al. (2018) para investigar uma amostra de funcionários que participou de cursos corporativos à distância. Contudo, sua natureza generalista também permite a sua utilização em treinamentos corporativos presenciais. $\mathrm{O}$ instrumento demonstra ser psicometricamente válido e confiável, com índices de consistência interna considerados bons, conforme mostra a Tabela 13.

Tabela 13 - Informações psicométricas do instrumento estratégias de aprendizagem

\begin{tabular}{llcccc}
\hline \multirow{2}{*}{ Instrumento } & Escalas Obtidas & \multicolumn{4}{c}{ Cargas Fatoriais } \\
\cline { 3 - 6 } & & $\begin{array}{l}\mathbf{N}^{\mathbf{0}} \text { de } \\
\text { Itens }\end{array}$ & Alfa & Mín. & Máx. \\
\hline Estratégias de Aprendizagem & Cognitivas/Busca de Ajuda & 07 & 0,85 & 0,35 & 0,76 \\
(Martins et al., 2018) & Controle de Emoção & 03 & 0,80 & 0,69 & 0,85 \\
(Anexo B) & Elaboração/Aplicação Prática & 05 & 0,84 & $-0,30$ & 0,83 \\
& Controle da Motivação & 03 & 0,81 & 0,50 & $-0,88$ \\
\hline
\end{tabular}

Fonte: Martins, et al., 2018.

O instrumento mensura a frequência de uso de capacidade cognitivas, habilidades comportamentais e autocontrole emocional utilizados pelo aprendiz para controlar os próprios processos psicológicos de aprendizagem, sendo que, a escala de frequência de comportamento varia de 1 ("Nunca") a 5 ("Sempre"). Os detalhes do questionário podem ser visualizados na Tabela 14.

Tabela 14. Itens questionário estratégias de aprendizagem

Os itens do questionário indicam possíveis comportamentos utilizados por você durante o
curso. Leia os itens listados e escolha o ponto da escala (1, 2, 3, 4 ou 5) que representa a
frequência com que você se comportou da maneira descrita em cada item, registrando sua
resposta na coluna à direita (Nota).


Tabela 14. Intens questionário estratégias de aprendizagem (continuação)

\begin{tabular}{|c|c|c|c|c|}
\hline $\begin{array}{c}1 \\
\text { Nunca } \\
\end{array}$ & $\begin{array}{c}2 \\
\text { Raramente } \\
\end{array}$ & $\begin{array}{c}3 \\
\text { Às vezes } \\
\end{array}$ & $\begin{array}{c}4 \\
\text { Frequentemente }\end{array}$ & $\begin{array}{c}5 \\
\text { Sempre } \\
\end{array}$ \\
\hline Itens & & & & Nota \\
\hline
\end{tabular}

1. Mantive a calma quando tive dificuldades durante o curso.

2. Mantive a calma com a possibilidade de ter um rendimento abaixo do esperado.

3. Mantive a calma diante dos erros que cometi ao realizar atividades do curso.

4. Esforcei-me mais quando percebi que estava perdendo a concentração.

5. Esforcei-me mais quando percebi que estava perdendo o interesse no assunto.

6. Esforcei-me para verificar minha compreensão sobre o que estava sendo ensinado.

7. Busquei auxílio de colegas para esclarecer minhas dúvidas sobre os conteúdos do curso.

8. Busquei compreender melhor os conteúdos ao estudá-los nos materiais didáticos do curso.

9. Busquei outras fontes de pesquisa relacionadas ao curso para me ajudar a aprender.

10. Li o conteúdo do curso várias vezes como método para aprender.

11. Repeti mentalmente os conteúdos do curso que gostaria de aprender até perceber que havia entendido.

12. Fiz anotações, resumos e/ou esquemas dos conteúdos do curso como método para aprender.

13. Revisei os conteúdos relativos aos exercícios em que cometi erros.

14. Realizei os exercícios práticos propostos ao longo do curso para me ajudar a aprender.

15. Refletir sobre as implicações que os conteúdos aprendidos poderiam ter.

16. Identifiquei situações diárias em que eu pudesse aplicar os conteúdos do curso.

17. Busquei desenvolver uma ideia global sobre como os conteúdos do curso se relacionavam entre si.

18. Associei os conteúdos do curso aos meus conhecimentos anteriores.

Fonte: Martins, et al., 2018.

A distribuição dos itens entre as quatro estratégias de aprendizagem consideradas pelo instrumento foi realizada da seguinte forma:

- Estratégias Cognitivas e Busca de Ajuda: itens 7, 8, 9, 10, 11, 12 e 13;

> Controle da Emoção: itens 1, 2 e 3;

Dlaboração e Aplicação Prática: itens 14, 15, 16, 17 e 18;

> Controle da motivação: itens 4, 5 e 6.

Quanto ao Inventário de Personalidade NEO, conforme visto na revisão da literatura, devido à extensão e extensão da versão original do NEO PI-R (240 itens), as construções de versões reduzidas deste instrumento (60 itens), tipicamente designadas por NEO-FFI-R, têm sido desenvolvidas em diferentes países. Como visto na Tabela 7 da revisão de literatura, os valores de consistência interna destas versões, entre culturas, têm se mostrado genericamente 
aceitáveis e similares, refletindo o potencial do instrumento para ser utilizado em diferentes contextos.

Pelo panorama de credibilidade que vem apresentando, este instrumento foi escolhido para a execução da presente pesquisa, que contou com sua versão adaptada para a cultura brasileira. Foi utilizada a versão informatizada do questionário, desenvolvida pela Editora Vetor, a qual gentilmente doou as aplicações e correções online para a realização deste estudo.

De acordo com Mendoza-Flores (2010), o estudo brasileiro do NEO-FFI-R manteve uma razoável qualidade técnica no que diz respeito à consistência interna, conforme demonstram os dados das estruturas empíricas obtidos nos estudos anteriores e expostos na Tabela 15.

Tabela 15 - Resumo das informações sobre o NEO-FFI-R

\begin{tabular}{ccccccc}
\hline & & \multicolumn{5}{c}{ Cargas Fatoriais } \\
\cline { 3 - 7 } Domínios & $\begin{array}{c}\text { Carga } \mathbf{5 0} \text { em } \\
\text { No itens } \\
\text { esperados }\end{array}$ & Alfa & $\begin{array}{l}\text { Carga entre .30 } \\
\text { teórico } \\
\mathbf{~ . 5 0 ~ e m ~ s e u ~} \\
\text { fator teórico }\end{array}$ & $\begin{array}{l}\text { Nenhuma carga } \\
\text { significativa em } \\
\text { qualquer } \\
\text { dimensão }\end{array}$ & $\begin{array}{c}\text { Carga } \\
\text { secundária em } \\
\text { outra } \\
\text { dimensão }\end{array}$ \\
\hline $\mathrm{N}$ & 12 & .81 & 9 & 3 & - & 4 \\
$\mathrm{E}$ & 12 & .78 & 6 & 5 & 1 & 3 \\
$\mathrm{O}$ & 12 & .74 & 6 & 5 & 1 & 1 \\
$\mathrm{~A}$ & 12 & .70 & 2 & 10 & - & - \\
$\mathrm{C}$ & 12 & .83 & 10 & 2 & - & 1 \\
\hline
\end{tabular}

Fonte: Mendonza-Flores (2010).

O instrumento mensura a predominância entre os cinco fatores da personalidade, sendo que, a escala de frequência das respostas varia de DF ("Discordo Fortemente") a CF ("Concordo Fortemente").

Não foi identificada no manual da versão brasileira no instrumento a distribuição dos itens entre os cinco grandes fatores da personalidade. Assim, para fins de análise de dados, foi considerada a distribuição feita por Cupani, Vaiman, Font, Pizzichini e Saretti (2012), a qual distribui os itens conforme exposto a seguir:

> Neuroticismo $=1,6,11,16,21,26,31,36,41,46,51$ e 56;

$>$ Extroversão $=2,7,12,17,22,27,32,37,42,47,52$ e 57;

$>$ Abertura $=8,3,13,18,23,28,33,38,43,48,53$ e 58; 
$>$ Amabilidade $=4,9,14,19,24,29,34,39,44,49,54$ e 59;

$>$ Conscienciosidade $=5,10,15,20,25,30,35,40,45,50,55$ e 60 .

Os instrumentos foram hospedados em página da internet para a coleta eletrônica de dados. A seguir são apresentados os procedimentos de coleta de dados utilizados neste estudo.

\subsection{Procedimentos PARA Coleta de dAdos}

A coleta de dados ocorreu à distância, por meio de ambiente online. Antes de disponibilizar os questionários, os colaboradores foram informados pelo gestor do setor de Recursos Humanos da empresa sobre os objetivos da pesquisa e seus procedimentos. Posteriormente, foi enviado a todos os funcionários um e-mail que, mais uma vez esclareceu os objetivos da pesquisa, e com os links que os direcionaram para os questionários.

Ao acessar o primeiro link, que era o do questionário de Estratégias de Aprendizagem, o participante visualizava e respondia ao Termo de Consentimento Livre e Esclarecido (Anexo A), e caso desse seu aceite em participar da pesquisa, continuava. Ao responder aos questionários, as respostas automaticamente já ficavam disponíveis na base de dados e visíveis para a pesquisadora, que monitorava diariamente o processo. $\mathrm{O}$ questionário de Estratégias de Aprendizagem foi hospedado no Google Forms e o de Personalidade na própria plataforma da Editora responsável pelo instrumento no Brasil.

A empresa disponibilizou o e-mail de todos os colaboradores e autorização o envio de lembretes sobre a participação na pesquisa a cada três. Além disso, os participantes podiam enviar suas dúvidas diretamente para a pesquisadora, o que facilitou a comunicação. Inicialmente foi planejada entre empresa e pesquisadora a duração de 30 dias para a coleta de dados (de 13/06 à 13/07/2017). Contudo, no meio da coleta a empresa fechou contrato com um grande cliente e a equipe ficou muito sobrecarregada de trabalho, o que diminuiu as taxas diárias de respostas aos questionários. Até este momento apenas 33\% (n=35) haviam participado. Assim, a própria empresa propôs deixar os questionários disponíveis por mais um mês. Sendo assim, os questionários ficaram disponíveis de 13/07 à 13/08/2017, o que aumentou a taxa de retorno para 74,78\% $(\mathrm{n}=86)$. 


\subsection{Procedimentos para ANÁlise de DAdOS}

As decisões de todas as análises estão pautadas nas possibilidades advindas no número de participantes $(N)$. Desta forma, não foram realizadas análises de Consistência Interna devido à limitação do $N$ além do fato dos dois instrumentos utilizados terem sido avaliados recentemente. Para proceder as análises foi utilizado o software de análise estatística SPSS (Statistical Package for the Social Science) versão 21.0 e as orientações de Hair, Anderson, Tatham e Black (2005), Pasquali (2004) e Tabachnick e Fidell (2007).

Inicialmente foram realizadas análises exploratórias para investigar a exatidão da entrada dos dados, a presença de casos extremos, a distribuição dos casos omissos, a distribuição de frequência das variáveis e o tamanho da amostra. Ressalta-se que o questionário de Estratégias de Aprendizagem foi disponibilizado com a obrigatoriedade de responder a todos os itens, não apresentando casos omissos. Já o questionário de Traços de Personalidade, disponibilizado diretamente no site da Editora, não tinha a mesma obrigatoriedade. Assim, foram identificados 10 casos omissos, distribuídos entre as respostas dos 60 itens. Todos os 86 questionários respondidos foram considerados válidos pelos parâmetros da correção online no NEO-FFI-R.

Segundo Tabachinick e Fidell (2007), diante de casos omissos pode-se proceder de três maneiras: substituí-los pela média, eliminá-los em uma ou duas variáveis, quando os mesmos são tomados aos pares (parwise) ou considerar apenas casos que contêm dados válidos em todos os indicadores/variáveis (listwise). Neste caso, optou-se pela primeira opção.

Foi identificada a presença de quatro casos extremos multivariados nas respostas do questionário de Estratégias de Aprendizagem (7, 63, 61 e 76), os quais foram retirados do arquivo de dados, totalizando 82 casos válidos, sem outliers, sendo estes os utilizados nas análises. Tabachnick e Fidell (2007) orientam que todas as variáveis sejam transformadas em escores $Z$ para a identificação de casos extremos univariados. Os casos extremos multivariados são definidos pelos autores como valores resultantes de uma combinação anormal de escores em duas ou mais variáveis. Os mesmos foram identificados a partir da distância Mahalanobis - distância de um caso do centro do restante dos casos, quando o centro é o ponto criado pelas médias de todas as variáveis $-(\alpha=0,001)$.

Posteriormente foram realizadas as análises das estatísticas descritivas (média, desvio-padrão, moda, mínimo e máximo) de cada um dos itens e dimensões dos dois 
questionários utilizados na coleta de dados. Foi aplicado ainda o Teste de Normalidade de Shapiro-Wilk para cada uma das variáveis consideradas nesta pesquisa, isto é, em cada um dos questionários de Estratégias de Aprendizagem e de Traços de Personalidade, considerando que o p-valor (nível descritivo) dos testes menores que 5\% trata-se de uma distribuição dos dados não normal (a uma significância de 5\%).

Por fim, foram realizados os Testes de Coeficiente de Correlação de Pearson com o intuito de satisfazer ao principal objetivo desta pesquisa, que é verificar possíveis relações entre traços de personalidade e uso de determinadas estratégias de aprendizagem em treinamentos corporativos presenciais. Ressalta-se que para as análises, foram considerados os Escores $T$ fornecidos pela correção automática do questionário de Traços de Personalidade e os Escores Médios do Questionário de Estratégias de Aprendizagem, visto que este possui mais itens em dados fatores do que em outros. A seguir, apresentam-se os resultados e discussões mais detalhadas das análises. 


\section{Capítulo 4 - Resultados e Discussões}

\section{ObJetivo do Capítulo 4}

Este capítulo tem como objetivo apresentar e discutir os resultados advindos das análises de dados à luz da revisão de literatura.

\subsection{ANÁLISES DESCRITIVAS}

\subsubsection{QUESTIONÁRIO DE ESTRATÉGIAS DE APRENDIZAGEM}

Na Tabela 16, são apresentados os resultados descritivos dos itens do questionário de Estratégias de Aprendizagem, que mensuram a frequência de uso, ao longo do treinamento, de capacidades cognitivas, habilidades comportamentais e controle da ansiedade e da motivação, utilizadas pelos aprendizes, para controlar os próprios processos psicológicos de aprendizagem. Os 18 itens estão associados a uma escala de frequência de 5 pontos, que varia de 1 ("Nunca") a 5 (“Sempre").

Tabela 16: Estatísticas descritivas do instrumento de estratégias de aprendizagem

\begin{tabular}{ccccccc}
\hline & & & \multicolumn{3}{c}{ Frequências Relativas (\%) } \\
\cline { 5 - 7 } Item & Média & $\begin{array}{c}\text { Desvio- } \\
\text { padrão }\end{array}$ & Moda & $1-2$ & 3 & $4-5$ \\
\hline 1 & 4,4 & 0,79 & 5 & 2,33 & 8,14 & $\mathbf{8 9 , 5 3}$ \\
2 & 3,65 & $\mathbf{1 , 1 8}$ & 4 & $\mathbf{1 6 , 2 8}$ & 25,58 & 58,14 \\
3 & 3,99 & 0,9 & 4 & 5,81 & 16,28 & 77,91 \\
4 & 4,28 & 0,85 & 5 & 5,81 & 8,14 & $\mathbf{8 6 , 0 5}$ \\
5 & 4,06 & 1,01 & 4 & 10,47 & 9,3 & $\mathbf{8 0 , 2 3}$ \\
6 & 4,42 & 0,64 & 4 & 1,16 & 1,16 & $\mathbf{9 7 , 6 7}$ \\
7 & 3,85 & 1,1 & 5 & 10,47 & 23,26 & 66,28 \\
8 & 4,12 & 0,96 & 5 & 5,81 & 16,28 & 77,91 \\
9 & 3,62 & $\mathbf{1 , 1 5}$ & 4 & 15,12 & 25,58 & 59,3 \\
10 & 3,52 & 1,01 & 4 & $\mathbf{1 7 , 4 4}$ & 26,74 & 55,81 \\
11 & 3,49 & 1,04 & 4 & $\mathbf{1 6 , 2 8}$ & 29,07 & 54,65 \\
12 & 3,45 & $\mathbf{1 , 2 5}$ & 4 & $\mathbf{1 9 , 7 7}$ & 25,58 & 54,65 \\
13 & 3,69 & $\mathbf{1 , 1 6}$ & 4 & $\mathbf{1 6 , 2 8}$ & 17,44 & 66,28 \\
14 & 3,87 & $\mathbf{1 , 1 7}$ & 4 & 11,63 & 15,12 & 73,26 \\
15 & 4,06 & 0,82 & 4 & 3,49 & 19,77 & 76,74 \\
16 & 4,12 & 0,76 & 4 & 1,16 & 19,77 & 79,07 \\
17 & 3,83 & 0,83 & 4 & 5,81 & 26,74 & 67,44 \\
18 & 4,31 & 0,77 & 5 & 2,33 & 11,63 & $\mathbf{8 6 , 0 5}$ \\
\hline
\end{tabular}


Observa-se na Tabela 16 que os itens $1,4,5,6,8,15,16$ e 18 do questionário de Estratégias de Aprendizagem possuem uma média maior do que 4, enquanto a média dos outros itens é menor do que 4, mas maior do que 3. Os valores da moda, ou seja, a resposta mais frequente dos itens nesta amostra, confirmaram tal resultado, já que ficam localizados entre 4 e 5 . Os itens $2,3,5,6$ e 9 ao 17 possuem moda 4, enquanto os outros itens possuem moda 5 . Todos estes resultados implicam dizer que as respostas, na maioria dos itens, se localizam no ponto mais alto da escala, com destaque para os itens 1, 4, 5, 6, 7 e 18, que apresentam frequência de respostas superior a $80 \%$ nestes pontos mais altos.

Destes, três itens $(4,5$ e 6$)$ pertencem à estratégia de "Controle da Motivação", um item à estratégia de "Controle da Emoção" (1) e um item à estratégia de "Elaboração e Aplicação Prática" (18). As duas primeiras são estratégias autorregulatórias, que prevêem o controle da ansiedade, motivação e atenção, bem como a prevenção de dispersões de concentração durante os estudos. Já a terceira diz respeito a estratégias cognitiva (elaboração) e comportamental (aplicação prática), segundo classificação proposta por Warr e Allan (1998). Estes consistem, respectivamente, em procedimentos adotados pelos aprendizes no intuito de analisar e refletir sobre implicações e conexões possíveis entre o material aprendido e o conhecimento já existente; e aprimoramento do conhecimento por meio de aplicação prática do que foi aprendido.

Dos 5 itens que apresentam concentração das respostas nos pontos baixos da escala $(2,10,11,12$ e 13), 4 pertencem às estratégias "Cognitivas e de Busca de Ajuda" (10, 11, 12 e 13) e uma à estratégia de "Controle da Emoção" (2). As primeiras medem estratégias comportamentais do aprendiz referente à obtenção de auxílio de outras pessoas, como pares e instrutores, para tirar dúvidas sobre o conteúdo do treinamento.

Devido à natureza do curso, o fato das altas pontuações nos itens pertencentes às estratégias autorregulatórias $\mathrm{e}$ as baixas pontuações para os itens relativos às cognitivas/comportamentais é curioso. Ao longo da vida, normalmente, indivíduos estão mais acostumados a usarem estratégias cognitivas, consideradas as mais comuns em diversos tipos de ações educacionais, principalmente as de curta duração e baixa complexidade (Martins, 2016), como é o caso. Mas, há de se considerar também que o treinamento pesquisado aborda bastante condutas comportamentais, éticas e de relacionamentos esperadas pela organização. Além disso, a organização já tem a cultura de investir em 
treinamentos, normalmente ministrados após um ANT, o que pode contribuir para o alcance de estratégias mais complexas, mesmo em treinamentos de natureza mais simples como este.

Apesar de itens da estratégia de "Controle da Emoção" também terem aparecido em pontos altos da escala, a presença de itens nos pontos mais baixos pode ser pelo fato do treinamento ter sido ministrado tanto para colaboradores mais antigos, quanto para novatos. Uma hipótese é que os funcionários mais antigos pontuam menos nesta estratégia por estar num ambiente que já é familiar, ocasionando mesmo esforço autorregulatório, ao passo que, o contrário acontece com os recém-contratados.

Os desvios-padrão dos itens variam entre 0.64 e 1.25 . Vale lembrar que o desviopadrão é uma medida da variabilidade das respostas, representando se a amostra observada é homogênea (desvio-padrão baixo) ou heterogênea (desvio-padrão alto) no que diz respeito à resposta no item. Neste questionário há uma homogeneidade na maioria das respostas, sendo observados desvios mais consideráveis, apesar de não serem altos, nos itens 2, 9, 12 , 13 e 14, os quais, representam, em sua maioria (9, 12 e 13), estratégias "Cognitivas de Busca de Ajuda", sendo as hipóteses para tal resultado as mesmas discutidas nos parágrafos anteriores.

A Tabela 17 retrata as médias de cada fator do questionário de Estratégias de Aprendizagem, sintetizando as mais e as menos utilizadas por esta amostra.

Tabela 17: Estatísticas dos escores médios dos fatores do questionário de estratégias de aprendizagem

\begin{tabular}{lccc} 
& Média & Desvio padrão & Mediana \\
\cline { 2 - 3 } Estratégias cognitivas e busca de ajuda & 3,68 & 0,83 & 3,86 \\
Controle da emoção & 4,01 & 0,76 & 4,00 \\
Elaboração e aplicação prática & 4,04 & 0,62 & 4,00 \\
Controle da motivação & 4,25 & 0,72 & 4,33 \\
\hline
\end{tabular}

De acordo com os resultados sobre a frequência de uso das estratégias de aprendizagem, assumidos pelo escore médio de cada fator, o treinamento estimulou principalmente a adoção de procedimentos autorregulatórios de controle da emoção e da motivação, bem como a elaboração e aplicação prática. $\mathrm{O}$ uso de processos autorregulatórios não parece ser o mais adequado em treinamentos desta natureza, devido a baixa complexidade. Todavia, outra análise possível é a dos aprendizes estarem no ambiente de trabalho, que por si já demanda esforços de atenção concentrada e automonitoramento da aprendizagem. As estratégias de elaboração e de aplicação prática são compatíveis com a amostra de participantes - trabalhadores - que ao adquirirem novos conhecimentos, busca 
relacioná-los a conhecimentos anteriores, bem como com a utilidade e a aplicabilidade destes nas atividades práticas laborais diárias.

As estratégias de aprendizagem menos utilizadas foram as cognitivas e de busca de ajuda interpessoal. A priori, um curso presencial tende a oferecer ferramentas de interação para que os participantes interatuem durante o curso. Contudo, a menor frequência de uso dessas estratégias, conforme já visto, provavelmente está relacionada às características do treinamento, tais como: a curta duração de tempo, abertura para interação em os participantes e nível de complexidade do curso, que aparentemente não demanda maiores explicações advindas de outros participantes, nem de outros materiais, sendo o material didático e as informações oferecidas pelo instrutor suficientes para sanar as dúvidas.

\subsubsection{Questionário Traços de Personalidade}

Os resultados descritivos dos 60 itens do instrumento de "Traços de Personalidade" são associados a uma escala de frequência de comportamento que varia de DF ("Discordo Fortemente”) a CF (“Concordo Fortemente”). Para análises dos dados foram atribuídos a escala valores de 0 a 4, sendo 0 (Discordo Fortemente), 1 (Discordo), 2 (Neutro), C (Concordo) e CF (Concordo Fortemente) e os resultados são apresentados na Tabela 18.

\begin{tabular}{ccccccccc}
\multicolumn{2}{l}{ Tabela 18: Estatísticas descritivas do instrumento NEO-FFI-R } \\
\hline & & & & & & \multicolumn{3}{c}{ Frequências Relativas (\%) } \\
\cline { 7 - 9 } Item & Válido & Ausente & Média & $\begin{array}{c}\text { Desvio- } \\
\text { padrão }\end{array}$ & Moda & $0-1$ & 2 & $3-4$ \\
\hline 1 & 86 & 0 & 0,95 & 0,87 & 1 & $\mathbf{8 1 , 4 0}$ & 10,47 & 8,14 \\
2 & 83 & 3 & 2,54 & 0,85 & 3 & 12,05 & 32,53 & 55,42 \\
3 & 85 & 1 & 1,99 & 1,03 & 2 & 25,88 & 44,71 & 29,41 \\
4 & 85 & 1 & 3,69 & 0,46 & 4 & 0,00 & 0,00 & $\mathbf{1 0 0 , 0 0}$ \\
5 & 86 & 0 & 3,07 & 0,73 & 3 & 3,49 & 12,79 & $\mathbf{8 3 , 7 2}$ \\
6 & 85 & 1 & 2,36 & 0,95 & 3 & 20,00 & 25,88 & 54,12 \\
7 & 86 & 0 & 2,84 & 0,84 & 3 & 6,98 & 23,26 & 69,77 \\
8 & 86 & 0 & 3,05 & 0,63 & 3 & 1,16 & 13,95 & $\mathbf{8 4 , 8 8}$ \\
9 & 86 & 0 & 1,02 & 1,01 & 1 & 73,26 & 16,28 & 10,47 \\
10 & 86 & 0 & 2,79 & 0,84 & 3 & 8,14 & 19,77 & 72,09 \\
11 & 86 & 0 & 1,36 & $\mathbf{1 , 1 1}$ & 1 & 58,14 & 22,09 & 19,77 \\
12 & 85 & 1 & 1,74 & $\mathbf{1 , 1 2}$ & 1 & 44,71 & 28,24 & 27,06 \\
13 & 86 & 0 & 2,99 & 0,83 & 3 & 2,33 & 27,91 & 69,77 \\
14 & 86 & 0 & 0,83 & 0,97 & 0 & $\mathbf{8 0 , 2 3}$ & 11,63 & 8,14 \\
15 & 86 & 0 & 1,86 & $\mathbf{1 , 1 1}$ & 3 & 44,19 & 18,60 & 37,21 \\
16 & 86 & 0 & 2,51 & $\mathbf{1 , 2 2}$ & 3 & 24,42 & 12,79 & 62,79 \\
\hline
\end{tabular}


Tabela 18: Estatísticas descritivas do instrumento NEO-FFI-R (continuação)

\begin{tabular}{|c|c|c|c|c|c|c|c|c|}
\hline 17 & 86 & 0 & 3,17 & 0,79 & 3 & 2,33 & 16,28 & 81,40 \\
\hline 18 & 86 & 0 & 1,02 & 0,93 & 1 & 75,58 & 16,28 & 8,14 \\
\hline 19 & 86 & 0 & 0,86 & 0,74 & 1 & 81,40 & 17,44 & 1,16 \\
\hline 20 & 86 & 0 & 3,78 & 0,44 & 4 & 0,00 & 1,16 & 98,84 \\
\hline 21 & 86 & 0 & 1,65 & 1,05 & 1 & 54,65 & 20,93 & 24,42 \\
\hline 22 & 86 & 0 & 2,95 & 0,73 & 3 & 1,16 & 25,58 & 73,26 \\
\hline 23 & 86 & 0 & 1,71 & 1,00 & 2 & 40,70 & 40,70 & 18,60 \\
\hline 24 & 86 & 0 & 0,98 & 0,97 & 1 & 75,58 & 17,44 & 6,98 \\
\hline 25 & 86 & 0 & 3,05 & 0,72 & 3 & 5,81 & 5,81 & 88,37 \\
\hline 26 & 86 & 0 & 0,84 & 1,10 & 0 & 77,91 & 8,14 & 13,95 \\
\hline 27 & 86 & 0 & 1,74 & 1,05 & 1 & 43,02 & 29,07 & 27,91 \\
\hline 28 & 86 & 0 & 1,21 & 0,86 & 1 & 75,58 & 13,95 & 10,47 \\
\hline 29 & 86 & 0 & 2,66 & 0,94 & 3 & 12,79 & 24,42 & 62,79 \\
\hline 30 & 86 & 0 & 1,08 & 0,87 & 1 & 72,09 & 20,93 & 6,98 \\
\hline 31 & 86 & 0 & 2,08 & 1,05 & 3 & 32,56 & 27,91 & 39,53 \\
\hline 32 & 86 & 0 & 2,43 & 0,79 & 3 & 13,95 & 33,72 & 52,33 \\
\hline 33 & 86 & 0 & 1,51 & 0,88 & 1 & 51,16 & 34,88 & 13,95 \\
\hline 34 & 86 & 0 & 3,01 & 0,64 & 3 & 2,33 & 12,79 & 84,88 \\
\hline 35 & 86 & 0 & 3,44 & 0,59 & 4 & 0,00 & 4,65 & 95,35 \\
\hline 36 & 86 & 0 & 1,84 & 0,98 & 2 & 38,37 & 33,72 & 27,91 \\
\hline 37 & 86 & 0 & 3,29 & 0,67 & 3 & 1,16 & 8,14 & 90,70 \\
\hline 38 & 86 & 0 & 2,59 & 0,83 & 3 & 8,14 & 31,40 & 60,47 \\
\hline 39 & 86 & 0 & 1,45 & 1,12 & 1 & 56,98 & 22,09 & 20,93 \\
\hline 40 & 86 & 0 & 3,49 & 0,55 & 4 & 0,00 & 2,33 & 97,67 \\
\hline 41 & 86 & 0 & 0,98 & 0,93 & 1 & 77,91 & 13,95 & 8,14 \\
\hline 42 & 86 & 0 & 0,85 & 0,73 & 1 & 82,56 & 16,28 & 1,16 \\
\hline 43 & 86 & 0 & 1,99 & 0,94 & 2 & 25,58 & 44,19 & 30,23 \\
\hline 44 & 85 & 1 & 1,33 & 0,97 & 1 & 57,65 & 29,41 & 12,94 \\
\hline 45 & 86 & 0 & 0,57 & 0,76 & 0 & $\mathbf{8 8 , 3 7}$ & 9,30 & 2,33 \\
\hline 46 & 86 & 0 & 2,87 & 0,97 & 3 & 10,47 & 15,12 & 74,42 \\
\hline 47 & 86 & 0 & 2,72 & 0,93 & 3 & 11,63 & 25,58 & 62,79 \\
\hline 48 & 86 & 0 & 1,41 & 1,02 & 1 & 56,98 & 27,91 & 15,12 \\
\hline 49 & 86 & 0 & 3,29 & 0,61 & 3 & 0,00 & 8,14 & 91,86 \\
\hline 50 & 86 & 0 & 3,08 & 0,69 & 3 & 3,49 & 5,81 & 90,70 \\
\hline 51 & 86 & 0 & 0,88 & 0,82 & 1 & 81,40 & 13,95 & 4,65 \\
\hline 52 & 86 & 0 & 3,08 & 0,67 & 3 & 1,16 & 15,12 & 83,72 \\
\hline 53 & 86 & 0 & 3,02 & 0,77 & 3 & 3,49 & 17,44 & 79,07 \\
\hline 54 & 86 & 0 & 1,20 & 0,94 & 1 & 67,44 & 24,42 & 8,14 \\
\hline 55 & 86 & 0 & 1,02 & 0,85 & 1 & 79,07 & 12,79 & 8,14 \\
\hline 56 & 86 & 0 & 1,58 & 1,18 & 1 & 56,98 & 13,95 & 29,07 \\
\hline 57 & 86 & 0 & 1,44 & 1,02 & 1 & 60,47 & 20,93 & 18,60 \\
\hline 58 & 86 & 0 & 2,30 & 0,95 & 2 & 16,28 & 40,70 & 43,02 \\
\hline 59 & 86 & 0 & 0,77 & 0,95 & 0 & 83,72 & 8,14 & 8,14 \\
\hline 60 & 84 & 2 & 3,15 & 0,84 & 3 & 7,14 & 7,14 & 85,71 \\
\hline
\end{tabular}


Como nota-se na Tabela 18, há bastante variações em todas as estatísticas. Tal resultado é esperado, considerando que se trata de um instrumento que mede características pessoais, que variam de indivíduo para indivíduo. A média dos itens varia de 0,57 a 3,78. O item 20, que teve a média mais alta, diz respeito a afirmação: "Tento cumprir todas as minhas obrigações com responsabilidade" e o que teve a média mais baixa está na afirmação "Às vezes não sou tão confiável como deveria ser. Vale se atentar para o fato de que essas respostas possuem um cunho do que se espera de um colaborador dentro de uma organização. Contudo, ainda que exista esse viés, os questionários foram considerados válidos dentro dos desvios aceitáveis.

A moda dos itens varia entre 0 e 4 , sendo que os itens localizados nos pontos mais altos da escala são: 4, 20, 40, 35, 49, 50, 37, 25, 60, 34, 8, 5, 52 e 17, com frequência de respostas superior a $80 \%$. Destes 14 itens, $7(20,40,35,50,25,60$ e 5) pertencem ao domínio da Conscienciosidade, seguido pelos domínios da Abertura (4, 49 e 34) e da Extroversão (37, 52 e 17). O primeiro domínio citado refere-se ao senso de contenção e sentido prático, envolvendo características como competência, ordem, autodisciplina e etc. O segundo caracteriza-se por um interesse intrínseco por experiência em uma ampla variedade de áreas, abrangendo ideias, valores, fantasia, etc. Por último, a extroversão corresponde ao nível de sociabilidade de um indivíduo, à capacidade de agregar pessoas, buscar sensações positivas, etc.

Os itens que apresentam concentração de respostas superior a $80 \%$ nos pontos baixos da escala são: 14, 1, 51, 19, 42, 59 e 45. O domínio da Abertura, assim como nos pontos mais altos da escala, também pontua nos pontos mais baixos com os itens 14, 19 e 59, o que pode ser explicado pela diversidade individual, mostrando que uma parte da amostra tem essa característica mais aguçada e outra parte menos. O domínio do Neuroticismo apareceu com dois itens, 1 e 51, diz respeito à instabilidade/estabilidade emocional de um sujeito. Por fim, os desvios-padrão dos itens variam entre 0.44 e 1.22 . Observam-se variações nas respostas, sendo as mais altas nos itens $11,15,39,12,56$ e 16, dos quais 3 representam também o domínio de neuroticismo $(11,16$ e 56) e os demais pulverizados entre Conscienciosidade (15), Amabilidade (39) e Extroversão (12), o que aponta para as diferenças nas respostas em relação a estes itens. Assim, apenas o domínio da Abertura se distanciou das variações mais altas, apresentando respostas mais uniformes em seu conjunto de itens. 
A Tabela 19 retrata as médias de cada domínio do questionário de Traços de Personalidade, sintetizando os mais e os menos presentes nesta amostra.

Tabela 19: Estatísticas das médias dos fatores do questionário de traços de personalidade

\begin{tabular}{lccc}
\hline & Média & Desvio padrão & Mediana \\
\cline { 2 - 4 } Conscienciosidade & 3,10 & 0,45 & 3,16 \\
Amabilidade & 3,01 & 0,44 & 3,00 \\
Extroversão & 2,76 & 0,44 & 2,79 \\
Abertura & 2,58 & 0,44 & 2,58 \\
Neuroticismo & 1,58 & 0,52 & 1,58 \\
\hline
\end{tabular}

Como é possível observar nos resultados assumidos pelas médias de cada domínio, os traços de personalidades mais presentes nesta amostra são a Conscienciosidade e a Amabilidade. No caso desta amostra, as maiores médias nestes domínios, principalmente na Conscienciosidade podem estar relacionadas com o perfil de profissionais que a empresa normalmente contrata. Em sua maioria, são profissionais que lidam diretamente com o cliente final da empresa, sendo tais traços considerados muito importantes, como foi possível identificar nas conversas com o gestor do setor de Recurso Humanos.

\subsection{Testes de Normalidade e AnÁlise de Assimetria e CURTose}

Segundo Tabachnick e Fidell (2001) a verificação da normalidade é extremamente importante ao se trabalhar com análises multivariadas. Esta é avaliada por testes estatísticos específicos para essa finalidade. Além dos testes realizados é possível também verificar a forma da distribuição dos dados através dos níveis de assimetria e curtose. Segundo Hair e cols (2005), a assimetria é a medida de simetria de uma distribuição quando comparada com uma distribuição normal: uma variável cuja média não é o centro da distribuição possui assimetria. A curtose é medida da elevação ou do achatamento de uma distribuição quando comparada com uma distribuição normal: uma variável que possui uma distribuição muito achatada ou muito alongada possui curtose. Isto implica dizer que quando a distribuição da variável é normal, os valores de assimetria e curtose são zero.

A Tabela 20 apresenta o Teste de Normalidade de Shapiro-Wilk para cada uma das variáveis contínuas consideradas nesta pesquisa, isto é, os escores fatoriais dos questionários de Estratégias de Aprendizagem e de Traços de Personalidade. Neste teste, se o p-valor for 
menor do que 5\% então concluímos, a uma significância de 5\%, que a distribuição dos dados não é normal.

Tabela 20: Testes de normalidade de Shapiro-Wilk dos escores fatoriais dos questionários

\begin{tabular}{lcc}
\hline Fatores Estratégias de Aprendizagem & Estatística & p-valor \\
\hline Estratégias cognitivas e busca de ajuda & 0,89 & 0,00 \\
Controle da emoção & 0,91 & 0,00 \\
Elaboração e aplicação prática & 0,94 & 0,00 \\
Controle da motivação & 0,86 & 0,00 \\
\hline Domínios Traços de Personalidade & & \\
\hline Neuroticismo & 0,99 & 0,51 \\
Extroversão & 0,98 & 0,22 \\
Abertura & 0,98 & 0,19 \\
Amabilidade & 0,98 & 0,33 \\
Conscienciosidade & 0,98 & 0,18 \\
\hline
\end{tabular}

Como todos os p-valores dos fatores do questionário de Estratégias de Aprendizagem são menores do que 0,05 , conclui-se que a distribuição de nenhum dos escores deste questionário é normal. Já no caso do questionário de Traços de Personalidade, observa-se a distribuição normal dos escores. Ao analisar a assimetria e curtose, tem-se os resultados que seguem Tabela 21.

Tabela 21: Análises de assimetria e curtose dos escores fatoriais dos questionários

\begin{tabular}{lccc}
\hline Fatores Estratégias de Aprendizagem & Desvio-padrão & Assimetria & Curtose \\
\hline Estratégias Cognitivas e Busca de Ajuda & 5,78 & $-1,13$ & 0,86 \\
Controle da Emoção & 2,29 & $-0,82$ & 1,48 \\
Elaboração e Aplicação Prática & 3,11 & $-0,73$ & 0,68 \\
Controle da Motivação & 2,16 & $-1,12$ & 1,21 \\
\hline Domínios Traços de Personalidade & & & $-0,15$ \\
\hline Neuroticismo & 8,44 & 0,30 & $-0,02$ \\
Extroversão & 8,21 & $-0,28$ & $-0,50$ \\
Abertura & 8,61 & $-0,07$ & $-0,44$ \\
Amabilidade & 8,96 & $-0,26$ & 0,03 \\
Conscienciosidade & 7,48 & $-0,35$ & \\
\hline
\end{tabular}

Ressalta-se que a ocorrência de distribuições normais com valores zero de assimetria e curtose é rara, sobretudo em pesquisas de ciências sociais. Tabachnick e Fidell (2001) sugerem que variáveis com assimetria e curtose devem passar por transformações, visando à aproximação de uma distribuição normal, tais como: raiz quadrada para assimetria leve, logaritmo para assimetria substancial, e inversa para assimetria severa (Sant'Anna, 2002). Quando a assimetria é negativa, faz-se primeiro a "reflexão" (reflect) da variável e depois as 
transformações citadas. Mas, as autoras alertam que essas transformações não são recomendadas para todos os tipos de pesquisas, já que dificultam muito a interpretação dos resultados e, mesmo com transformações, não há garantias de que todas as combinações das variáveis serão distribuídas normalmente.

Desta forma, optou-se por não realizar transformações das variáveis nos casos de índices de assimetria e curtose, visto seus baixos valores. Miles e Shevlin (2001) sugerem uma forma de avaliar os valores de assimetria e curtose, mediante a análise do cálculo do desvio-padrão associado a tais valores. Segundo os autores, esses valores podem ajudar a determinar se a assimetria e a curtose diferem significativamente do que se pode esperar de uma distribuição normal razoável: se o valor da assimetria ou curtose é maior do que duas vezes o valor do desvio-padrão (ignora-se o sinal de menos), então a distribuição difere significativamente de uma distribuição normal. Entretanto, os autores atentam para o fato de que muitos pesquisadores não estão interessados em saber se a distribuição é significativamente diferente de uma distribuição normal, mas sim se a distribuição é tão assimétrica ou achatada que pode ser preocupante para as análises inferenciais.

Neste sentido, Miles e Shevlin (2001) sugerem cautelosamente, que: se o valor da assimetria ou curtose (ignora-se o sinal de menos) é menor do que 1.0, então o problema é tão pequeno que não chega ser preocupante; se é maior que 1.0 e menor que 2.0 , é um pouco preocupante, mas provavelmente a distribuição está bem próxima da normalidade; se é maior do que 2.0, o caso é preocupante.

No caso da análise em questão, as variáveis se mostram diferentes de uma distribuição normal, contudo, em muitos casos estas variáveis apresentam resultados abaixo de 1 e, em quase todos os casos, abaixo de 2. Além disso, os resultados também apresentam, em todas as variáveis, resultados duas vezes menores do que seus respectivos desviospadrão. Diante de tais argumentos, apesar da não normalidade dos dados, que sugere testes não-paramétricos, optou-se pela análise paramétrica, utilizando como parâmetro para medir a correlação existente, inicialmente proposta neste trabalho, o Coeficiente de Correlação de Pearson.

\subsection{Teste de Coeficiente de CoRrelaÇÃo de Pearson}

Nesta seção são realizados testes de Coeficiente de Correlação de Pearson, visando satisfazer ao principal objetivo desta pesquisa, que é verificar possíveis relações entre traços 
de personalidade e uso de determinadas estratégias de aprendizagem em treinamentos corporativos presenciais. O $p$-valor testa se o coeficiente é igual a zero, isto é, se as variáveis não são correlacionadas. Se o p-valor for menor do que 0,05 então concluímos que, a uma significância de 5\%, as variáveis são correlacionadas. A Tabela 22 traz os resultados do teste.

Tabela 22: Resultados dos testes de correlação de Pearson

\begin{tabular}{|c|c|c|c|}
\hline Fatores & Dimensões & Coeficiente & p-valor \\
\hline \multirow{5}{*}{ Estratégias Cognitivas e Busca de Ajuda } & Neuroticismo & $-0,12$ & 0,27 \\
\hline & Extroversão & 0,09 & 0,42 \\
\hline & Abertura & 0,13 & 0,23 \\
\hline & Amabilidade & $\mathbf{0 , 2 7}$ & $\mathbf{0 , 0 1}$ \\
\hline & Conscienciosidade & 0,01 & 0,90 \\
\hline \multirow{5}{*}{ Controle da Emoção } & Neuroticismo & $-0,24$ & $\mathbf{0 , 0 3}$ \\
\hline & Extroversão & $-0,01$ & 0,95 \\
\hline & Abertura & 0,09 & 0,41 \\
\hline & Amabilidade & 0,11 & 0,31 \\
\hline & Conscienciosidade & 0,17 & 0,11 \\
\hline \multirow{5}{*}{ Elaboração e Aplicação Prática } & Neuroticismo & $-0,27$ & $\mathbf{0 , 0 1}$ \\
\hline & Extroversão & $\mathbf{0 , 3 8}$ & $\mathbf{0 , 0 0}$ \\
\hline & Abertura & 0,26 & $\mathbf{0 , 0 2}$ \\
\hline & Amabilidade & $\mathbf{0 , 2 7}$ & 0,01 \\
\hline & Conscienciosidade & 0,21 & 0,05 \\
\hline \multirow{5}{*}{ Controle da Motivação } & Neuroticismo & $-0,21$ & 0,05 \\
\hline & Extroversão & $\mathbf{0 , 3 0}$ & $\mathbf{0 , 0 0}$ \\
\hline & Abertura & 0,34 & $\mathbf{0 , 0 0}$ \\
\hline & Amabilidade & 0,23 & $\mathbf{0 , 0 3}$ \\
\hline & Conscienciosidade & 0,26 & $\mathbf{0 , 0 2}$ \\
\hline
\end{tabular}

A Tabela 22 apresenta o Coeficiente de Correlação de Pearson calculado entre cada estratégia de aprendizagem e os traços de personalidade, assim como o $p$-valor do teste que verifica se o coeficiente é igual a zero, isto é, se as variáveis não são correlacionadas. Em destaque na Tabela 22 as variáveis cujos p-valor foram menores que 0,05 como, por exemplo, a estratégia Cognitiva e de Busca de Ajuda, verifica-se que a mesma está positivamente correlacionada com o domínio da Amabilidade. Ou seja, quando maior a presença dessa característica no indivíduo, maior tende a ser o uso das Estratégias Cognitivas e Busca de Ajuda. 
Considerando que estratégias Cognitivas e Busca de Ajuda requerem utilização de recursos de interações interpessoais, faz sentido pensar em sua relação com o domínio da Amabilidade. Indivíduos que, quando avaliados, apresentam altas pontuações neste domínio têm tendências interpessoais, sendo mais propensos a manter uma postura simpática e cordial com as pessoas. Este traço anseia em ajudar e cooperar, tem preocupação com o bem-estar alheio, ao passo que também confia nas boas intenções das pessoas.

Conforme visto na revisão sistemática da literatura sobre traços de personalidade, em uma investigação que abordou as mesmas variáveis da presente pesquisa, ChamorroPremuzic et al. (2007), apesar de não chegarem a resultados conclusivos, inferem que, uma vez que os alunos com traços de Amabilidade aguçados são caracterizados pela simpatia, confiabilidade e cooperação, pode-se assumir que eles preferem o trabalho em grupo. Além disso, estes estão dispostos a pedir ajuda sempre que precisarem, reflexão que vai de encontro com este resultado.

Ainda na Tabela 22 podemos observar que a estratégia de Controle da Emoção é negativamente correlacionada com o domínio do "Neuroticismo", ou seja, quando maior o Neuroticismo, menor tende a ser o Controle da Emoção. Visto que esta estratégia apresenta características totalmente opostas ao que apresentam os indivíduos com altas pontuações em Neuroticismo, tal relação se mostra coerente.

Enquanto a estratégia de Controle da Emoção prevê o controle da ansiedade, motivação, concentração para aprender, etc., o traço de Neuroticismo tende a experimentar afetos negativos, tais como medo, tristeza, vergonha, raiva. Estes são propensos a apresentar ideias irracionais, a serem poucos hábeis em controlar seus impulsos e a lidar pobremente com estresse (Costa \& McCrae, 1992a). Assim, dificilmente conseguiriam adotar estratégias autorregulatórias em contextos de treinamentos.

As estratégias de Elaboração e Aplicação Prática e de Controle da Motivação também estão negativamente correlacionados com o domínio Neuroticismo. Tal informação é corroborada pela revisão da literatura que mostra que altas pontuações neste domínio foram correlatas de baixar as pontuações no uso de estratégias de aprendizagem, bem como de desempenho acadêmico mais fraco, dificuldade de aprendizagem e de níveis inferiores de autoeficácia (Furnham et al., 2013; Kokkinos et al., 2015; Stumm \& Furnham, 2012; De Feyter et al., 2012).

Chamorro-Premuzic et al., (2007), ressaltam que indivíduos com tendências neuróticas têm dificuldades em gerenciar situações estressantes e avaliativas durante 
treinamentos. Nestes casos, uma possibilidade seria desenhos instrucionais com a presença de situações cotidianas de trabalho expostas de maneira mais lúdica.

É possível verificar ainda na Tabela 22, que a Estratégia de Elaboração e Aplicação Prática está positivamente correlacionada com os domínios de Extroversão, Abertura, Amabilidade e Conscienciosidade. Recapitulando, as duas referidas estratégias de aprendizagem dizem, respectivamente, em procedimentos adotados pelos aprendizes no intuito de analisar e refletir sobre implicações e conexões possíveis entre o material aprendido e o conhecimento já existente; e aprimoramento do conhecimento por meio de aplicação prática do que foi aprendido.

$\mathrm{O}$ traço de Extroversão se refere à preferência dos indivíduos por trabalhos em grupos, tendendo para uma postura sociável e assertiva com relação às pessoas. Além disso, normalmente são pessoas bem-dispostas, alegres e com interesse por ocupações empreendedoras. Desta forma, a este traço pode estar relacionado com a elaboração prática, na medida em que facilita o processo de engajamento nas atividades. Além disso, pesquisas mostram que indivíduos com altas pontuações neste fator aprendem melhor ao se envolverem em experiências concretas durante o treinamento, diminuindo as pontuações do uso de estratégias de aprendizagem não-práticas (Furnham et al, 2013), outra característica da estratégia em questão.

No que se refere à abertura, indivíduos com predomínio neste traço apresentam maior interesse pela variedade, por tarefas e por novas ideias. Tendem a manter uma postura curiosa, com maior diversidade de interesses e não tem dificuldades a se adaptarem a mudanças (Costa \& McCrae, 1992a). Assim, este tem sido freqüentemente associado à inteligência (Chamorro-Premuzic \& Furnham, 2005) e à criatividade (Chamorro-Premuzic, 2006).

Tais características estão estritamente ligadas à capacidade cognitiva de elaboração no processo de aquisição, processamento e aplicação de novos conhecimentos. As pesquisas encontradas na revisão de literatura deste trabalho também mostram a correlação deste domínio com o alcance da aprendizagem e sua relação positiva com o uso de diferentes estratégias de aprendizagem (Furnham, 2012; Kargiotidis \& Markos, 2015).

Como visto, o traço da Amabilidade diz da tendência aos relacionamentos interpessoais, o que também faz sentido neste resultado, uma vez que para a capacidade da aplicação prática dos conhecimentos adquiridos depende, geralmente, da habilidade de trabalhar em equipe e de compartilhar experiências. Por fim, a Conscienciosidade, se 
caracteriza pela escrupulosidade, tendência de manter o propósito de cumprir os compromissos tanto profissionais quanto pessoais. Normalmente, indivíduos com domínio deste traço pensam bastante antes de agir, analisando os riscos e consequências de suas ações. Além disso, tem grande preocupação com a organização e, por vezes, pode se demonstrar metódico quanto a sua conduta.

Tudo isso se aproxima bastante dos relatos do Gerente de $\mathrm{RH}$ da organização participante desta pesquisa, sobre a solidez da empresa no mercado, do cumprimento das metas que são estabelecidas, da satisfação dos clientes internos e externos. Ele atribui a esse sucesso o alinhamento dos objetivos da empresa à seleção e desenvolvimento de uma equipe com características e valores que, em grande parte, estão contidos no domínio da Conscienciosidade. Além deste relato, os próprios resultados das análises descritivas mostram que o traço mais marcante da equipe é o da Conscienciosidade.

Especificamente no contexto de ensino/aprendizagem, as pesquisas confirmam a discussão anterior, mostrando que, entre os cinco domínios da personalidade, este é o que mais se comportou como preditor de desempenho acadêmico, alcance da aprendizagem, motivação para aprender, além da relação positiva com o uso de diferentes estratégias de aprendizagem (Lakhal et al., 2015; Furnham et al., 2013; Kappe \& Der Flier, 2012; De Feyter et al., 2012).

Por último, a estratégia de Controle da Motivação também apresentou correlação com os domínios de Extroversão, Abertura, Amabilidade e Conscienciosidade. Esta estratégia está relacionada ao esforço do aprendiz em se manter engajado e atento ao treinamento. Conforme discutido, os domínios relacionados com a estratégia em questão vêm se mostrando, em particular a Conscienciosidade e a Abertura à Experiência, precursores nas estratégias de aprendizagem que promovem aprendizagem (ChamorroPremuzic et al., 2007), O que pode auxiliar neste controle da motivação ao longo do treinamento. Nesta perspectiva, Komarraju, Karau e Schmeck (2009), descobriram que estudantes com altos índices de abertura à experiência, por exemplo, são muitas vezes motivados intrinsecamente em relação a aprender. 


\section{CAPÍtulo 5 - CONSIDERAÇões FinaIS}

\section{ObJetivo do Capítulo 5}

Este capítulo pretende concluir o estudo, retomando os objetivos de pesquisa. Além disso, são relatadas contribuições e limitações da pesquisa e proposta uma agenda de estudos.

Essa pesquisa teve como principal objetivo analisar relações entre traços de personalidade e uso de determinadas estratégias de aprendizagem em treinamentos corporativos presenciais. Conforme verificado nos testes de correlações, para cada estratégia de aprendizagem há correlações com um ou mais dos cinco fatores de personalidade. Tais correlações se mostraram coerentes ao cruzar a definição de dada estratégia com as características dos traços de personalidade. Além disso, tais achados, como visto na apresentação dos resultados e discussões, em sua maioria, são corroborados pela revisão da literatura. Neste sentido, considera-se que o objetivo foi atendido, bem como a primeira pergunta da pesquisa respondida, a saber: "Existe relação entre traços de personalidade com uso de determinadas estratégias de aprendizagem?"

Os resultados descritivos do questionário de Estratégias de Aprendizagem atingiram a um dos objetivos do trabalho, que é descrever as estratégias de aprendizagem adotadas pelos participantes ao longo do treinamento. Estes mostraram que os aprendizes adotaram mais as estratégias autorregulatórias de Controle da Motivação e Controle da Emoção, o que é pouco diferente do que normalmente se espera. Martins (2016) discute que cursos de baixa complexidade e essencialmente pertencentes ao domínio cognitivo, oferecem poucas possibilidades de investigação de processos superiores de aprendizagem (como estratégias de aprendizagem autorregulatórias) ou a necessidade de apoios mais contundentes auxiliares nesse processo.

Uma das explicações para tal fato pode ser o nível de maturidade e envolvimento dos aprendizes no processo de treinamento e desenvolvimento. Conforme dito neste trabalho, a organização parceira investe fortemente em gestão de pessoas, em especial, em ações de TD\&E. Logo, apesar deste treinamento, especificamente, ser de curta duração e baixa complexidade, os colaboradores participam anualmente de várias ações instrucionais, inclusive, agora, sugeridas a partir de um ANT. Apesar de tais suspeitas, mais pesquisas para 
obter respostas mais precisas quanto a questões como esta, principalmente no contexto corporativo, que ainda é difícil acesso para a realização de estudos desta natureza.

Outro objetivo específico alcançado foi o de identificar e descrever os traços de personalidade dos participantes, segundo NEO-FFI-R (Mendonza-Flores, 2010), sendo que, os resultados mostraram que a amostra investigada é mais representada pelos traços de Conscienciosidade e Amabilidade e menos representa pelo traço de Neuroticismo. Isso vai de encontro com a descrição de características individuais feita pelo gestor de Recursos Humanos, considerada como importantes para ser admitido na organização. Essa descrição não foi algo formal nesta entrevista, mas que foi possível conhecer e ouvir ao longo do processo de pesquisa. Tal elemento também é um indicativo da necessidade de pesquisas futuras coletarem dados em diferentes organizações, com realidades e culturas diferentes.

Quanto às contribuições teórico-metodológicas, esta pesquisa cumpriu o intuito fundamental de obter informações acerca da situação atual da temática escolhida, por meio da análise das produções nacionais e internacionais, em campos de conhecimento diversos, com o mesmo enfoque de estudo, evidenciando um panorama que instiga a pensar sobre a inserção de uma nova variável para o subsistema de avaliação de TD\&E. Ressalta-se a revisão sistemática realizada neste estudo, que identificou lacunas e novas possibilidades no que se refere às características da clientela nos modelos de avaliação de TD\&E, podendo trazer importantes contribuições para o processo de ensino/aprendizagem, como tem sugerido as pesquisas internacionais.

Tomando como referência a população da pesquisa, a taxa de retorno foi excelente $(74,78 \%)$, sendo um diferencial entre estudos da área. Entretanto, ainda assim, o número de participantes foi insuficiente para a realização de análises estatísticas mais robustas. Parcerias com outras empresas foram pleiteadas a fim de aumentar o tamanho da população investigada, de maneira a garantir a significância estatística dos resultados. Mas, como se sabe, ainda há muita resistência das empresas em participar de pesquisas desta natureza e o tempo disponível para realizar todo o processo também não é tão grande.

Zerbini (2007) e Martins (2012) recomendam Análises Fatoriais Confirmatórias dos instrumentos, bem como a modelagem por equação estrutural (MEE) como análises mais robustas e rigorosas para o teste de relações entre variáveis de TD\&E. Autoras enfatizam que tais análises auxiliam no desenvolvimento do campo teórico da área de avaliação institucional. As próprias pesquisas internacionais, que estão em estágios mais avançados, no que se refere ao uso da variável traços de personalidade em contextos de TD\&E utilizam 
essas análises mais robustas, conforme apresentado na revisão sistemática da literatura. Mas, em razão do $N$ obtido nesta pesquisa, não foi possível atender a tais recomendações.

Assim, foram procedidas, rigorosamente, as análises possíveis, a partir de dados coletados com medidas validadas e confiáveis. Pesquisas futuras, que pretendam abordar essas variáveis, ainda tem muito que avançar em termos metodológicos. Ressalta-se, no entanto, que uma das maiores contribuições deste trabalho está em sua originalidade, no que se refere a investigações nacionais.

Quanto às implicações práticas dos resultados obtidos, como mostrado nas investigações internacionais e, em muitos aspectos confirmados nesta pesquisa, utilizar as medidas das variáveis em questão, em investigações nacionais, em diferentes contextos e amostras, pode contribuir para a coleta de informações relevantes ao aprimoramento das ações educacionais, no que diz respeito aos aspectos instrucionais já existentes.

Ressalta-se ainda que as medidas de personalidade já são utilizadas em contextos corporativos para diversas finalidades, tais como processo seletivo, sucessão e progressão de carreira, etc. Assim, aliá-la ao conhecimento dos meios como os indivíduos aprendem, oferecem novas orientações para profissionais da área de avaliação de programas de TD\&E, influindo sobre o desempenho de suas atividades e facilitando as intervenções em contextos organizacionais e de trabalho.

Salas, Tannenbaum, Kraiger \& Smith-Jentsch (2012), já mostraram que identificar estratégias de aprendizagem mais eficazes, as quais influenciam o processo subsequente de aplicação das novas habilidades adquiridas em treinamento no trabalho, pode ajudar designers de eventos instrucionais ou gerentes de Recursos Humanos/Gestão de Pessoas, responsáveis pelo planejamento, oferecimento e avaliação de programas de formação e desenvolvimento, a orientar e incentivar os treinandos a usar as estratégias mais adequadas para alcançar resultados positivos.

A identificação do uso de estratégias de aprendizagem, de acordo com as características individuais dos colaboradores de uma empresa, permite adequar e compatibilizar as estratégias de ensino dos treinamentos às preferências dos participantes, tornando-os mais adequados. Assim, a segunda pergunta da pesquisa "De que forma o reconhecimento dessa relação entre traços de personalidade e uso de estratégias podem contribuir para o planejamento instrucional de treinamentos corporativos mais adequados às características dos aprendizes" foi respondida. 
Meneses et al. (2006) corroboram tal análise quando dizem que as características individuais dos aprendizes, os hábitos de vida, as expectativas, as estratégias utilizadas para alcançar aprendizagens, as motivações, os interesses e as metas podem influenciar na aquisição de competências durante um evento instrucional e na sua posterior aplicação em situações de trabalho. Apesar dos resultados advindos de pesquisas do contexto de educação também oferecerem, em alguma medida, contribuições para o âmbito corporativo, estender as pesquisas a este, como feito neste trabalho, pode gerar resultados mais eficientes, haja vista as particularidades de cada ambiente, conforme sugerem Lakhal, Sévigny e Frenette (2015).

Entre as limitações desta pesquisa está a impossibilidade de generalizar os resultados encontrados, dado o número de participantes e o fato da coleta de dados ter sido realizada em uma única organização. Destaca-se também o fato do curso investigado ser de baixa complexidade e curta duração, sendo o único avaliado. Outra limitação mora no fato do estudo ter sido focado na investigação apenas no nível individual. E, por seguinte, a impossibilidade de proceder análises de dados mais robustas.

Diante dos resultados e discussões promovidas no presente estudo, a seguinte agenda de pesquisa é proposta:

1) Inserção da variável "Traços de Personalidade" em mais investigações sobre modelos de avaliação de treinamentos presenciais corporativos;

2) Inserção de outras variáveis em pesquisas da área de TD\&E que considerem Traços de Personalidade.;

3) Realização de investigações com a temática proposta envolvendo uma amostra maior, preferencialmente em empresas e cursos diferentes;

4) Realização de análise fatorial exploratória e confirmatória do instrumento de Estratégias de Aprendizagem, conforme sugerido por Martins (2016) e não realizado neste estudo devido a limitação do $N$.

5) Realização de estudos adicionais e complementares, com o uso de outras metodologias, como os estudos de diário, e combinar simultaneamente abordagens quantitativas e qualitativas;

6) Inclusão de diferentes fontes de informações, por se tratar de uma pesquisa em que as variáveis abordam mecanismos psicológicos e são auto informadas;

7) Construção de modelos de predição envolvendo as variáveis deste estudo e outras relevantes no contexto de TD\&E. 
Por fim, é importante dizer que perguntas desta pesquisa mostraram relevência e trouxeram novos conhecimentos que contribuem para os avanços dos estudos à área. Ademais espera-se que o tema sucitado tenha servido de estímulo a outros pesquisadores interessados no reconhecimento de características da clientela. 


\section{REFERÊNCIAS}

Abbad, G. (1999). Um modelo integrado de avaliação de impacto de treinamento no trabalho (Tese Doutorado). Instituto de Psicologia, Universidade de Brasília.

Abbad, G., Pilati, R., \& Pantoja, M. J. (2003). Avaliação de treinamento: análise da literatura e agenda de pesquisa. Revista de Administração da USP, 38(3), 205-218.

Abbad, G., \& Borges-Andrade, J. E. (2004). Aprendizagem humana em organizações de trabalho. In J. C. Zanelli, J. E. Borges-Andrade \& A.V. B. Bastos (Orgs.). Psicologia, Organizações e Trabalho no Brasil (pp. 237-275). Porto Alegre: Artmed.

Abbad, G., Borges-Ferreira, M. F., \& Nogueira, R. (2006). Medidas de aprendizagem em avaliação de TD\&E. In J. E. Borges-Andrade, G. Abbad, L. Mourão (Orgs.). Treinamento, desenvolvimento e educação em organizações e trabalho: fundamentos para a gestão de pessoas (pp. 469-488). Porto Alegre: Artmed.

Abbad, G., Nogueira, R. \& Walter, A. M. (2006). Abordagens instrucionais em planejamento de TD\&E. Em: J. E. Borges-Andrade, G. Abbad, L. Mourão \& colaboradores. Treinamento, desenvolvimento e educação em organizações e trabalho: fundamentos para a gestão de pessoas (pp.255 - 281). Porto Alegre: Artmed.

Abbad, G.; Zerbini, T. \& Souza, D. B. L. (2010). Panorama das pesquisas em Educação a Distância no Brasil. Estudos de Psicologia (UFRN), 15, 291-298.

Abbad, G., Mourão, L. Meneses, P. P. M., Zerbini, T., Borges-Andrade, J. E., \& Vilas-Boas, R. (Orgs.). (2012a). Medidas de Avaliação em Treinamento, Desenvolvimento $e$ Educação. Porto Alegre: Artmed.

Abbad, G., \& Borges-Andrade, J. E. (2014). Aprendizagem humana em organizações de trabalho. In J. C. Zanelli, J. E. Borges-Andrade \& A.V. B. Bastos (Orgs.). Psicologia, Organizações e Trabalho no Brasil (2 ${ }^{\mathrm{a}}$ ed., pp. 237-275). Porto Alegre, RS: Artmed.

Abbad, G. (2018, julho). Cem anos de pesquisas sobre TD\&E e as contribuições da produção nacional para a área. Comunicação breve de pesquisa. Área temática Comportamento Humano no Trabalho e nas Organizações, apresentado no Congresso Brasileiro de Psicologia Organizacional e do Trabalho, Giânia, GO, Brasil, 8.

Aguinis, H., \& Kraiger, K. (2009). Benefitis of training and development for individuals and teams, organizations, and society. Annual Review of Psychology, 60, 451-474

Akçãoglu, M. O. (2016). Teacher Candidates' Learning Strategies and Academic SelfEfficacy Levels: Is There a Relation Between the Two? Cumhuriyet International Journal of Education-CIJE, 5 (3), 48 - 66.

Alvarez, K., Salas, E., \& Garofano, C.M. (2004). An integrated model of training evaluation and effectiveness. Human Resource Development Review, 3(4), 385-416. 
Balarin, C. S., Zerbini, T. \& Martins, L. B. (2014). A relação entre suporte à aprendizagem e impacto de treinamento no trabalho. Revista Eletrônica de Administração, 78(2), 341370.

Bell, B. S., Tannenbaum, S. I., Ford, J. K., Noe, R. A., \& Kraiger, K. (2017). 100 Years of Training and Development Research: What We Know and Where We Should Go.

Journal of Applied Psychology. Advance online publication. http://dx.doi.org/10.1037/ap10000142.

Borges-Andrade, J. E. (1982). Avaliação somativa de sistemas instrucionais: integração de três propostas. Tecnologia Educacional, 11(46), 29-39.

Borges-Andrade, J. E. (1997). Treinamento de pessoal: em busca de conhecimento e tecnologia relevantes para as organizações brasileiras. Em: A. Tamayo, J.E. BorgesAndrade \& W. Codo (Orgs.). Trabalho, Organizações e Cultura (p. 129-149). São Paulo: Cooperativa de Autores Associados.

Borges-Andrade, J. E. (2002). Desenvolvimento de medidas em avaliação de treinamento. Estudos de Psicologia, 7 (Número especial), 31-43.

Borges-Ferreira, M. F. (2005). Avaliação de reações e aprendizagem em disciplinas de curso técnico profissionalizante oferecidas a distância. Dissertação de Mestrado, Instituto de Psicologia, Universidade de Brasília.

Borges-Andrade, J. E. (2006). Avaliação integrada e somativa em TD\&E. In J. E. BorgesAndrade, G. Abbad, L. Mourão (Orgs.). Treinamento, desenvolvimento e educação em organizações e trabalho: fundamentos para a gestão de pessoas (pp. 343-358). Porto Alegre: Artmed.

Brandão, H. P., \& Borges-Andrade, J. E. (2011). Desenvolvimento e validação de uma escala de estratégias de aprendizagem no trabalho. Psicologia: Reflexão e Crítica, 24(3), 448-457.

Brant, S. R. C., Pilati, R., \& Borges-Andrade, J. E. (2015). Estratégias de aplicação do aprendido: Análise baseada em TRI. Psicologia: Reflexão e Crítica, 28, 1-10.

Bloom, B. S., Engelhart, M. D., Furst, E. J., Hill, W. H., \& Krathwohl, D.R. (1972a). Taxonomia dos objetivos educacionais - domínio afetivo. Porto Alegre: Editora Globo.

Boruchovitch, E., \& Santos, A., A. A. dos. (2015). Psychometric Studies of the Learning Strategies Scale for University Students. Paidéia (Ribeirão Preto), 25(60), 1927. doi.org/10.1590/1982-43272560201504.

Burke, L. A., \& Hutchins, H. M. (2007). Training transfer: An integrative literature review. Human Resource Development Review, 6(3), 263-297. 249.

Cairns, L. and Malloch, M. (2011), "Theories of work, place and learning: new directions", in Malloch, M., Cairns, L., Evans, K. and O'Connor, B.N. (Eds), The Sage Handbook of Workplace Learning, Sage, London, pp. 3-15. 
Camillis, P. K.; Antonello, C. S. (2010). Um estudo sobre os processos de aprendizagem dos trabalhadores que não exercem função gerencial. RAM - Revista Administração Mackenzie, 11(2), p.1-39, 2010.

Campbell, J. P. (1971). Personnel training and development. Annual Review of Psychology, $22,565-602$.

Carrasco Z Constanza, Pérez V Cristhian, Torres A Graciela, Fasce H Eduardo. (2016). Relacionamento entre práticas pedagógicas e estratégias de aprendizagem em professores de carreiras de saúde. Medical Journal of Chile , 144 (9), 1199-1206. doi.org/10.4067/S0034-98872016000900015.

Chamorro-Premuzic, T., \& Furnham, A. (2005). Personality and intellectual competence. London: Lawrence Erlbaum.

Chamorro-Premuzic, T. (2006). Creativity versus conscientiousness: which is a better predictor of student performance? Applied Cognitive Psychology, 20(4), 521-531.

Chamorro-Premuzic, T., Furnham, A., \& Lewis, M. (2007). Personality and approaches to learning predict preference for different teaching methods. Learning and Individual Differences, 17, 241-250.

Chamorro-Premuzic, T., \& Furham, A. F. (2009). Mainly Openness: The relationship between the Big Five personality traits and learning approaches. Learning and Individual Differences, 19, 524-529.

Chamorro-Premuzic, T., Quiroga, M. A., \& Colom, R. (2009). Intellectual competence and academic performance: A Spanish study. Learning and Individual Differences, 19, 486491.

Coelho Junior, F. A., Borges-Andrade, J. E. (2015). Suporte à Aprendizagem Informal no Trabalho. In K. Puentes-Palacio \& A. L. A. Peixoto (Orgs.), Ferramentas de diagnóstico para organizações e trabalho: Um olhar a partir da psicologia (pp. 261-271). Porto Alegre: Artmed.

Costa, P. T., \& McCrae, R. R. (1989). The NEO-PI/NEO-FFI manual supplement. Florida: Psycological Assessment Resources.

Costa, P. T., \& McCrae, R. R. (1992). Revised NEO Personality Inventory (NEO-PI-R) and NEO Five Factor Inventory (NEO-FFI) professional manual. Florida: Psycological Assessment Resources.

Costa, P. T., \& McCrae, R. R. (1992a). Professional manual. Revised NEO Personality Inventory. Florida: Psycological Assessment Resources.

Costa, P. T., Jr., \& McCrae, R. R. (1992a). Normal personality assessment in clinical practice: The NEO Personality Inventory. Psychological Assessment, 4, 5-13. 
Costa, P. T. e McCrae, R. R. (2010). NEO PI-R: Inventário de Personalidade Neo Revisado e Inventário de Cinco Fatores Neo Revisado NEO-FFI-R (versão curta). Manual. São Paulo: Vetor.

Crouse, P., Doyle, W., \& Young, J. D. (2011). Workplace learning strategies, barriers, facilitators and outcomes: A qualitative study among human resource management practitioners. Human Resource Development International, 14(1), 39-55.

Cupani, M., Vaiman, M., Font, M. L., Pizzichini, F., Saretti, B. (2012). Análisis factorial confirmatorio del neo-ffi utilizando parcelización de ítems y método bootstrap. Avaliação Psicológica. 11 (2): 159-168.

Cunha, N. B. de., \& Boruchovitch, E. (2016). Percepção e conhecimento de futuros professores sobre seus processos de aprendizagem. Pro-Posições, 27(3), 31-56.

Damasceno, S. M. S., Abbad, G., \& Meneses, P. P. M. (2012). Logic models and organizational training evaluations. Paidéia (Ribeirão Preto), 22(52), 217-228.

De Feyter. T., Caers. R., Vigna. C., Berings. D. (2012). Unraveling the impact of the Big Five personality traits on academic performance: The moderating and mediating effects of self-efficacy and academic motivation. Learning and Individual Differences, $22,439-448$.

D’Netto, B., Bakas, F., \& Bordia, P. (2008). Predictors of management development effectiveness: An Australian perspective. International Journal of Training and Development, 12(1), 2-23.

Ferreira, R. R., \& Abbad, G. S. (2014). Avaliação de necessidades de treinamento no trabalho: ensaio de um método prospectivo. Revista Psicologia Organizações e Trabalho, 14(1), 1-17.

Flavell, J. H. (1970). Developmental studies of mediated memory. In: H. W. Reese \& L. P. Lipsitt (Eds.), Advances in child development and behavior (Vol. 5). New York: Academic Press.

Freiberg Hoffmann, A., Ledesma, R., \& Fernández Liporace, M. (2017). Estilos y estrategias de aprendizaje en estudiantes universitarios de Buenos Aires. Revista de Psicología (PUCP), 35(2), 535-573. Journal of Psychology (PUCP), 35 (2), 535-573.

Furnham. A., Nuygards, S., \& Chamorro-Premuzic, T. (2013). Personality, assessment methods and academic performance. Instructional Science, 41, 975-987. doi: $10.1007 / \mathrm{s} 11251-012-9259-9$.

Gagné, R. M. (1988). Mastery learning and instructional design. Performance Improvement Quarterly, 1(1), 7-18.

Gonçalves, A., \& Mourão, L. (2011). A expectativa em relação ao treinamento influencia o impacto das ações de capacitação? Revista de Administração Pública, 45(2), 483-513. 
Hair, J. F., Anderson, R. L., Tatham, R. L. \& Black, W. C. (2005). Análise Multivariada de dados (5a ed.). Porto Alegre: Bookman.

Haeme, H. D, Borges-Andrade, J. E., Cassiano, S. K. (2017). Learning strategies at work and professional development", Journal of Workplace Learning, 29 (6), 490-506. doi.org/10.1108/JWL-05-2016-0037.

Hamblin, A. C. (1978). Avaliação e controle do treinamento. São Paulo: McGraw-Hill do Brasil.

Hansenne, M. (2003). Psicologia da Personaliade. Lisboa: Climepsi.

Iglesias, M; \& Salgado, J. F. (2012). Effectiveness of Occupational Training Through Videoconferencing: Comparison with Classroom Training and Individual Differences. Revista de Psicología del Trabajo y de las Organizaciones, 28(3), 183-188.

Illeris, K. A model for learning in working life (2004). Journal of Workplace Learning, 16 (8), 431-441.

Illeris, K. (2011), "Workplace and learning", in Malloch, M., Cairns, L., Evans, K. and O’Connor, B.N. (Eds), The Sage Handbook of Workplace Learning, London, pp. 32-45.

Illeris, K. (2013). Teorias contemporâneas de Aprendizagem. Porto Alegre, RS: Penso.

Kappe, R., Der Flier, H.V. (2012). Predicting academic success in higher education: what's more important than being smart? Euro Psychol Educ, 27, 605-619. DOI 10.1007/s10212-011-0099-9.

Kirkpatrick, D. L. (1976). Evaluation of training. In R. L. Craig (Org.), Training and Development Handbook. New York: McGraw-Hill, 18.1-18.27.

Kock, H.; Ellstrom, P. (2010). Formal and integrated strategies for competence development in SMEs. Journal of European Industrial Training, 35, (1),71-88, 2010.

Kokkinos, C. M., Kargiotidis, A., \& Markos, A. (2015). The relationship between learning and study strategies and big five personality traits among junior university student teachers. Learning and Individual Differences, 43, 39-47.

Komarraju, M., \& Karau, S.J. (2005). The relationship between the big five personality traits and academic motivation. Personality and Individual Differences, 39, 557-567.

Komarraju, M., Karau, S.J., \& Schmeck, R.R. (2009). Role of the big five personality traits in predicting college students' academic motivation and achievement. Learning and Individual Differences, 19, 47-52.

Lakhal. S., Sévigny. S., \& Frenette, E. (2015). Personality and student performance on evaluation methods used in business administration courses. Education Assesment Evaluation and Accooutability. 27, 71-199. doi: 10.1007/s11092-014-9200-7. 
Li, M., Armstrong, S.J., (2015). The relationship between Kolb's experiential learning styles and Big Five personality traits in international managers. Personality and Individual Differences, 86, 422-426.

Lins, M. P. B. E., \& Borges-Andrade, J. E. (2014). Expressão de competências de liderança e aprendizagem no trabalho. Estudos de Psicologia (UFRN), 19, 159-168.

Magalhães, E., Salgueira, A., Gonzalez, A.J., Costa, J. J., Costa, M. J., Costa, P., \& Lima, M. Pedroso de. (2014). NEO-FFI: Psychometric properties of a short personality inventory in Portuguese context. Psicologia: Reflexão e Crítica, 27(4), 642657. doi.org/10.1590/1678-7153.201427405.

Magno e Silva, W. (2008). Um modelo para o desenvolvimento da autonomia. DELTA, 24: esp., 469-492.

Malcolm, J., Hodkinson, P. and Colley, H. (2003), "The interrelationships between informal and formal learning”, Journal of Workplace Learning, Vol. 15 Nos 7/8, pp. 313-318.

Martins, L. B. (2012). Aprendizagem em ações educacionais a distância: fatores influentes no desempenho acadêmico de universitário. Dissertação de Mestrado, Faculdade de Filosofia, Ciências e Letras de Ribeirão Preto, Universidade de São Paulo, São Paulo.

Martins, L. B., \& Zerbini, T. (2014b). Escala de estratégias de aprendizagem: Evidências de validade em contexto universitário híbrido. Psico-USF, 19(2), 317-328.

Martins, L. B. (2016). Impacto do treinamento no trabalho: determinantes individuais e contextuais em cursos a distância. Proforma da Tese apresentada para o Exame de Qualificação, Faculdade de Filosofia, Ciências e Letras de Ribeirão Preto, Universidade de São Paulo, São Paulo.

Martins, L. B., Zerbini, T., \& Medina, F. J. (2018). Learning strategies scale: adaptation to Portuguese and factor structure. Psicologia: Reflexão e Crítica, 31:12. doi.org/10.1186/s41155-018-0092-1

McAdams, D. P., \& Pals, J. L. (2006). A new big five: Fundamental principles for an integrative science of personality. American Psychologist, 61(3), 204-217.

McAdams, D. P., \& Olson, B. D. (2010). Personality development: Continuity and change over the life course. Annual Review of Psychology, 61, 517-542.

McCrae, R. R., \& John, O. P. (1992). An introduction to the Five-Factor Model and its applications. Journal of Personality, 60, 175-215.

McCrae, R., Costa, P., del Pilar, G. H., Rolland, J. P., \& Parker, W. D. (1998). Cross-Cultural Assessment of the Five-Factor Model: The Revised NEO Personality Inventory. Journal of Cross-Cultural Psychology, 29, 171-188.

McCrae R. R., \& Costa P. T. (2004). A contemplated revision of the NEO five-factor inventory. Personality and Individual Differences, 36(3), 587-596. 
McCrae R. R., Terracciano A., \& 78 Members of the Personality Profiles of Cultures Project (2005). Universal features of personality traits from the observer's perspective: Data from 50 cultures. Journal of Personality and Social Psychology, 88(3), 547-561.

Mendoza-Flores, C. E. (2010). Estudo Brasileiro do NEO-FFI-R. In Costa, P. T. e McCrae, R. R. NEO PI-R: Inventário de Personalidade Neo Revisado e Inventário de Cinco Fatores Neo Revisado NEO-FFI-R (versão curta). Manual. (pp. 93-98). São Paulo: Vetor.

Meneses, P. P. M., Abbad, G, Zerbini, T., \& Lacerda, E. (2006). Medidas de características da clientela em avaliação de TD\&E. In: J. E. Borges-Andrade, G. Abbad, L. Mourão (Orgs.). Treinamento, desenvolvimento e educação em organizações etrabalho: Fundamentos para a gestão de pessoas (pp. 422-442). Porto Alegre: Artmed. 254

Meneses, P. P. M., Zerbini, T., \& Abbad, G. (2010). Manual de treinamento organizacional. Porto Alegre: Artmed.

Meneses, P., \& Abbad, G. S. (2012). Medidas de insumo: autoeficácia. In G. Abbad, L. Mourão, P. P. M. Meneses, T. Zerbini, J. E. Borges-Andrade, R. Vilas-Boas (Orgs.), Medidas de Avaliação em Treinamento, Desenvolvimento e Educação: Ferramentas para gestão de pessoas (pp. 190-197). Porto Alegre: Artmed.Meneses, P., Zerbini, T., \& Abbad, G. S. (2011). Manual de treinamento organizacional. Artmed.

Meneses, P. P. M., Zerbini, T., \& Martins, L. B. (2012). Determinantes situacionais e individuais da aprendizagem em ensino a distância: desenvolvimento de escala. PSICOPUCRS, 43(2), 208-218.

Miles, J. \& Shevlin, M. (2001). Applying regression \& correlation: a guide for students and researchers. London: SAGE Publications.

Moraes, V. V. D., \& Borges-Andrade, J. E. (2010). Aprendizagem relacionada ao trabalho. Revista Psicologia Organizações e Trabalho, 10(2), 112-128.

Moraes, V., \& Borges-Andrade, J. E. (2010b). Validação de escala de estratégias de aprendizagem no trabalho entre Prefeitos (as) e Secretários (as) Municipais. Estudos de Psicologia (UFRN), 15, 325-334.

Moraes, V.V. and Borges-Andrade, J.E. (2015b), "Informal learning and development", in Kraiger, K., Passmore, J., Santos, N.R. and Malvezzi, S. (Eds), The Wiley Blackwell Handbook of the Psychology of Training, Development and Performance Improvement, John Wiley \& Sons, West Sussex, pp. 419-435.

Moreira, M.A. e Massoni, N.T. (2011). Epistemologias do Século XX. São Paulo: Editora Pedagógica e Universitária.

Nikandrou, I., Brinia, V., \& Bereri, E. (2009). Trainee perceptions of training transfer: na empirical analysis. Journal of European Industrial Training, 33(3), 255-270. 
O'Connor, M.C., \& Paunonen, S.V. (2007). Big five personality predictors of post-secondary academic performance. Personality and Individual Differences, 43, 971-990.

Oliveira, K. C., Boruchovitch, E., \& Santos, A. A. A. (2009). Estratégias de aprendizagem e desempenho acadêmico: Evidências de validade. Psicologia: Teoria e pesquisa, 25(4), 531-536.

Osmon, D. C., Santos, O.,Kazakov, D., Kassel, M. T., Mano,Q. R., Morth, A. (2018). Big Five personality relationships with general intelligence and specific Cattell-HornCarroll factors of intelligence. Personality and Individual Differences. 131, 51-56.

Pantoja, M. J. (2004). Estratégias de aprendizagem no trabalho e percepções de suporte à aprendizagem - uma análise multinível. Tese de Doutorado, Instituto de Psicologia, Universidade de Brasília.

Pantoja, M. J., \& Borges-Andrade, J. E. (2009). Estratégias de aprendizagem no trabalho em diferentes ocupações profissionais. RAC-Eletrônica, 3(1), 41-62.

Pasquali, L. (2004). Análise fatorial para pesquisadores. Petrópolis: Vozes.

Pedroso-Lima, M., Magalhães, E., Salgueira, A., Gonzalez, A. J., Costa, J. J,, Costa, M. J, \& Costa, P. (2014). A versão portuguesa do NEO-FFI: Caracterização em função da idade, género e escolaridade. Psicologia, 28(2), 01-10.

Pegalajar-Palomino, M. C. del. (2016). Estrategias de aprendizaje en alumnado universitario para la formación presencial y semipresencial. Rev. latinoam.cienc.soc.niñe. 14 (1): 659676.

Pervin, L. A., \& John, O. P. (2004). Personalidade: teoria e pesquisa. (R. C. Costa, trad.). $8^{a}$ ed. Porto Alegre: Artmed.

Pineda, P. (2010) "Evaluation of training in organisations: a proposal for an integrated model", Journal of European Industrial Training, 34(7), 673-693.

Pilati, R. (2004). Modelo de efetividade do treinamento no trabalho: Aspectos dos treinandos e moderação do tipo de treinamento. Tese de Doutorado, Instituto de Psicologia, Universidade de Brasília.

Pilati, R. \& Borges-Andrade, J. E. (2005). Estratégias para Aplicação no Trabalho do Aprendido em Treinamento: Proposição Conceitual e Desenvolvimento de uma Medida Psicologia. Reflexão e Crítica, 18(2), pp.207-214.

Pilati, R. \& Borges-Andrade, J. E. (2006). Construção de medidas e delineamentos em avaliação de TD\&E. Em: J. E. Borges-Andrade, G. Abbad, L. Mourão \& colaboradores. Treinamento, desenvolvimento e educação em organizações e trabalho: fundamentos para a gestão de pessoas (pp. 359 - 384). Porto Alegre: Artmed. 
Pilati, R., \& Borges-Andrade, J. E. (2012). Training effectiveness: Transfer strategies, perception of support and worker commitment as predictors. Revista de Psicología Del Trabajo y de las Organizaciones, 28(1), 25-35.

Pozo, J. I. (2002). Aprendizes e Mestres: a nova cultura da aprendizagem. Porto Alegre, RS: Artmed.

Praslova, L. (2010). Adaptation of Kirkpatrick's four level model of training criteria to assessment of learning outcomes and program evaluation in higher education. Educational Assessment, Evaluation and Accountability, 22(3), 215-225.

Ramírez-Martínez Ivonne F., Gallardo-Matienzo Germán, Mita-Arancibia Ángela, Escanero-Marcén Jesús F (2015). Estratégias de aprendizagem de acordo com as abordagens de aprendizagem em estudantes do internato rotativo da Faculdade de Medicina da Universidade de São Francisco Xavier de Chuquisaca (Sucre, Bolívia). FEM: Journal of the Medical Education Foundation, 18(1), 15 25. doi.org/10.4321/S2014-98322015000100004.

Raymond, A. N., Clarke, A. D. M., \& Klein, H. J. (2014). Learning in the Twenty-FirstCentury Workplace. Annu. Rev. Organ. Psychol. Organ. Behav, 1, 4.1-4.31.

Reio, T. G., Rocco, T. S., Smith, D. H. and Chang, E. (2017), A Critique of Kirkpatrick's Evaluation Model. New Horizons in Adult Education and Human Resource Development, 29, 35-53.

Garrote Rojas, D., Garrote Rojas, C., \& Jiménez Fernández, S. (2016) Factores Influyentes en Motivación y Estrategias de Aprendizaje en los Alumnos de Grado. Revista Iberoamericana sobre Calidad, Eficacia y Cambio en Educación, 14(2), 31-44. doi: 10.15366/reice2016.14.2.002.

Salahi, E., Hedjazi, Y., Mahmood, H., \& Ebrahimi, M. S. (2014). The Effect of Personality Types on the Learning Styles of Agricultural Students (A case study in Iran). The Online Journal of New Horizons in Education, 4 (2) 126-135.

Salas, E., \& Cannon-Bowers, J. A. (2001). The science of training: A decade of progress. Annual Review of Psychology, 52, 471-499.

Salas, E., Tannenbaum, S. I., Kraiger, K., \& Smith-Jentsch, K. A. (2012). The Science of Training and Development in Organizations: What Matters in Practice. Psychological Science in the Public Interest, 13(2) 74-101.

Santos, A. A. A., Boruchovitch, E., Primi, R., Zenorini, R. P. C., \& Bueno, J. M. H (2004). Escala de avaliação de estratégias de aprendizagem para universitários (EAP-U): aplicação do Modelo de Rasch de créditos parciais. Braga-PT: Psicologia: Teoria, Investigação e Prática, 9(2), 227-242.

Santrock, J. W. (2009). Psicologia Educacional (3ª ed.). São Paulo, SP: McGraw-Hill. 
Sant'anna, A. S (2002). CompetetÊncias individuais Requeridas, Modernidade Organizacional, e Satisifacação no Trabalho: uma análise de organizações mineiras sob a ótica de profissionais da área de administração. Tese de Doutorado, Faculdade de Ciências Econômicas, Universidade Federal de Minas Gerais.

Scharle, A. \& Szabo, A. (2000). Learner Autonomy: A Guide to Developing Learner Responsibility. Cambridge: Cambridge University Press.

Souza, L. F. N. I. (2010). Estratégias de aprendizagem e fatores motivacionais relacionados. Educar, 36, 95-107.

Stumm, V., S., Furnham, A. F. (2012). Learning approaches: Associations with Typical Intellectual Engagement, intelligence and the Big Five. Personality and Individual Differences, 53, 720-723.

Tabachnick, B.G. \& Fidell, L.S. (2001). Using multivariate statistics. New York: HarperCollins College Publishers.

Tabachnick, B. G., \& Fidell, L. S. (2007). Using multivariate statistics. New York: HarperCollins College Publishers.

Tannenbaum, S. I., \& Yukl, G. (1992). Training and development in work organizations. Annual Review of Psychology, 43, 399-441.

Tezci, E., Sezer, F., Aktan, S., Gurgan, U. (2016). Do Lifestyles Shape Self-Regulated Learning Strategies? Eurasian Journal of Educational Research, 65, 239-258. doi.org/10.14689/ejer.2016.65.14

Trentini, C. M., Hutz, C. S., Bandeira, D. R., Teixeira, M. A. P., Gonçalves, M. T. A., \& Thomazoni A. R. (2009). Correlações entre a EFN - Escala Fatorial de Neuroticismo e o IFP - Inventário Fatorial de Personalidade. Avaliação Psicológica, 8(2), 209-217.

Trógolo. M., Medrano, L.A. (2012). Personality traits, difficulties in emotion regulation and academic satisfaction in a sample of argentine college students. International Journal.

Tziner, A., Fisher, M., Senior, T., \& Wiesberg, J. (2007). Effects of Trainee Characteristics on Training Effectiveness. Internacional Journal of Selection and Assessment, 15(2), 167-174.

Ushiro, E. J., \& Bido, D. S. (2016). Estratégias de aprendizagem em função da finalidade para o aprendizado: um estudo com trabalhadores da linha de produção de uma empresa no ramo automotivo. REAd. Revista Eletrônica de Administração (Porto Alegre), 22(1), 166-192. doi.org/10.1590/1413-2311.05614102014.53645.

Vargas, M. R. M. \& Abbad, G. S. (2006). Bases Conceituais em Treinamento, Desenvolvimento e Educação (TD\&E). In J. E. Borges-Andrade, G. Abbad, L. Mourão (Orgs.), Treinamento, desenvolvimento e educação em organizações e trabalho: fundamentos para a gestão de pessoas (pp. 137-158). Porto Alegre: Artmed. 
Visbal-Cadavid, D., Mendoza-Mendoza, A., \& Díaz Santana, S. (2017). Estrategias de $\begin{array}{llll}\text { aprendizaje en la educación } & \text { superior. Sophia, 13(2), } & \text { 70- }\end{array}$ 81. https://dx.doi.org/10.18634/sophiaj.13v.2i.461.

Warr, P., \& Allan, C. (1998). Learning strategies and occupational training. International Review of Industrial and Organizational Psychology, 13, 83-121.

Warr, P., \& Downing, J. (2000). Learning strategies, learning anxiety and knowledge acquisition. British Journal Psychology, 91, 311-333.

Wen, M. L. Y., \& Lin, D. Y. C. (2014). Trainees' characteristics in training transfer: The relationship among self-efficacy, motivation to learn, motivation to transfer and training transfer. International Journal of Human Resource Studies, 4(1), 114.

Wexley, K. N. (1984). Personnel training. Annual Review of Psychology, 35, 519-551.

Yang, S. X., Jowett, S., \& Chan, D. K. C. (2014). Effects of big-five personality traits on the quality of relationship and satisfaction in Chinese coach-athlete dyads. Scand Journal of Medicine \& Science in Sports, 2015, 25, 568-580. doi: 10.1111/sms.12329.

Zabalza, M. (2005). O ensino universitário: Seu cenário e seus protagonistas. Porto Alegre: Artmed.

Zerbini, T. (2007). Avaliação da transferência de treinamento em curso a distância (Tese de doutorado não publicada). Universidade de Brasília, Brasília, DF.

Zerbini, T. \& Abbad, G. (2008). Estratégias de Aprendizagem em Curso a Distância: Validação de uma Escala. Psico-USF, 13(2), 177-187.

Zerbini, T., \& Abbad, G. (2010b). Transferência de treinamento e impacto do treinamento no trabalho: Análise crítica da literatura. Revista Psicologia: Organizações e Trabalho, 10(2), 97-111.

Zerbini, T., Coelho, F. A., Abbad, G. S., Mourão, L., Alvim, S., \& Loiola, E. (2012). Transferência de treinamento e impacto do treinamento em profundidade. In G. S. Abbad, L.

Zerbini, T., Coelho, F. A., Abbad, G. S., Mourão, L., Alvim, S., \& Loiola, E. (2012a). Transferência de treinamento e impacto do treinamento em profundidade. In: G. S. Abbad, L. Mourão, P. P. M. Meneses, T. Zerbini, J. E. Borges-Andrade, R. Vilas-Boas (Orgs.). Medidas de avaliação em treinamento, desenvolvimento e educação: Ferramentas para gestão de pessoas (pp. 127-144). Porto Alegre: Artmed. 


\begin{abstract}
ANEXOS
ANEXO A - TERMO DE CONSENTIMENTO LIVRE E ESCLARECIDO

Esta pesquisa intitulada "Influência de traços de personalidade no uso de estratégias de aprendizagem em cursos corporativos presenciais" faz parte de um projeto de Mestrado do curso de Pós-graduação em Psicologia da Faculdade de Filosofia, Ciências e Letras de Ribeirão Preto (FFCLRP-USP). Através dos resultados obtidos, espera-se contribuir para a adequação de ações educacionais às maneiras como os treinandos recebem e processam informações. Assim, sua colaboração é uma etapa fundamental, a qual consiste nas suas respostas a dois questionários (Estratégias de Aprendizagem e NEO-FFI-R) disponíveis em plataformas online. A duração para preenchimento dos testes normalmente não ultrapassa 20 (vinte) minutos.

Como forma de sigilo, seu nome não será utilizado em qualquer fase da pesquisa, garantindo o seu anonimato. Outras informações são relevantes, a saber: não lhe será cobrado nada; não haverá gastos nem riscos decorrentes da sua participação neste estudo; não estão previstas indenizações; não haverá benefícios imediatos na sua participação.

No caso de eventuais despesas, fica garantido o ressarcimento. Registro mais uma vez que sua participação é voluntária e que você poderá se recusar a participar da pesquisa, retirar seu consentimento, ou ainda descontinuar sua participação a qualquer momento. Sua colaboração é muito importante e agradecemos pela atenção e disponibilidade.

Em caso de dúvidas e outros esclarecimentos sobre a pesquisa você também poderá entrar em contato com a Prof ${ }^{a}$. Dr ${ }^{\mathrm{a}}$. Thaís Zerbini, responsável pela orientação deste projeto, através do telefone (16) 3315-4687 ou pelo e-mail thaiszerbini@ffclrp.usp.br. Ademais, eventuais dúvidas sobre questões éticas deste estudo poderão ser esclarecidas pelo Comitê de Ética em Pesquisa da Faculdade de Filosofia, Ciências e Letras de Ribeirão Preto - USP, situado na Avenida Bandeirantes, 3900 - Bloco 23 - Casa 37 - CEP: 14040-901 - Ribeirão Preto/SP - Brasil, telefones para contatos é o (16) 3315-4811 / Fax: (16) 3633-266 e E-mail: coetp@ffclrp.usp.br. Confirmo que Luana Paula de Oliveira me explicou os objetivos desta pesquisa, bem como a forma de participação. Confirmo ainda que li e compreendi este termo de consentimento livre e esclarecido.
\end{abstract}

De acordo em dar meu consentimento para participar como voluntário desta pesquisa. 


\section{ANEXO B - QUESTIONÁRIO DE ESTRATÉGIAS DE APRENDIZAGEM}

Os itens do questionário indicam possíveis comportamentos utilizados por você durante o curso de "Gestão à Vista". Leia os itens listados e escolha o ponto da escala (1, 2, 3, 4 ou 5) que representa a frequência com que você se comportou da maneira descrita em cada item, registrando sua resposta na coluna abaixo (Nota).

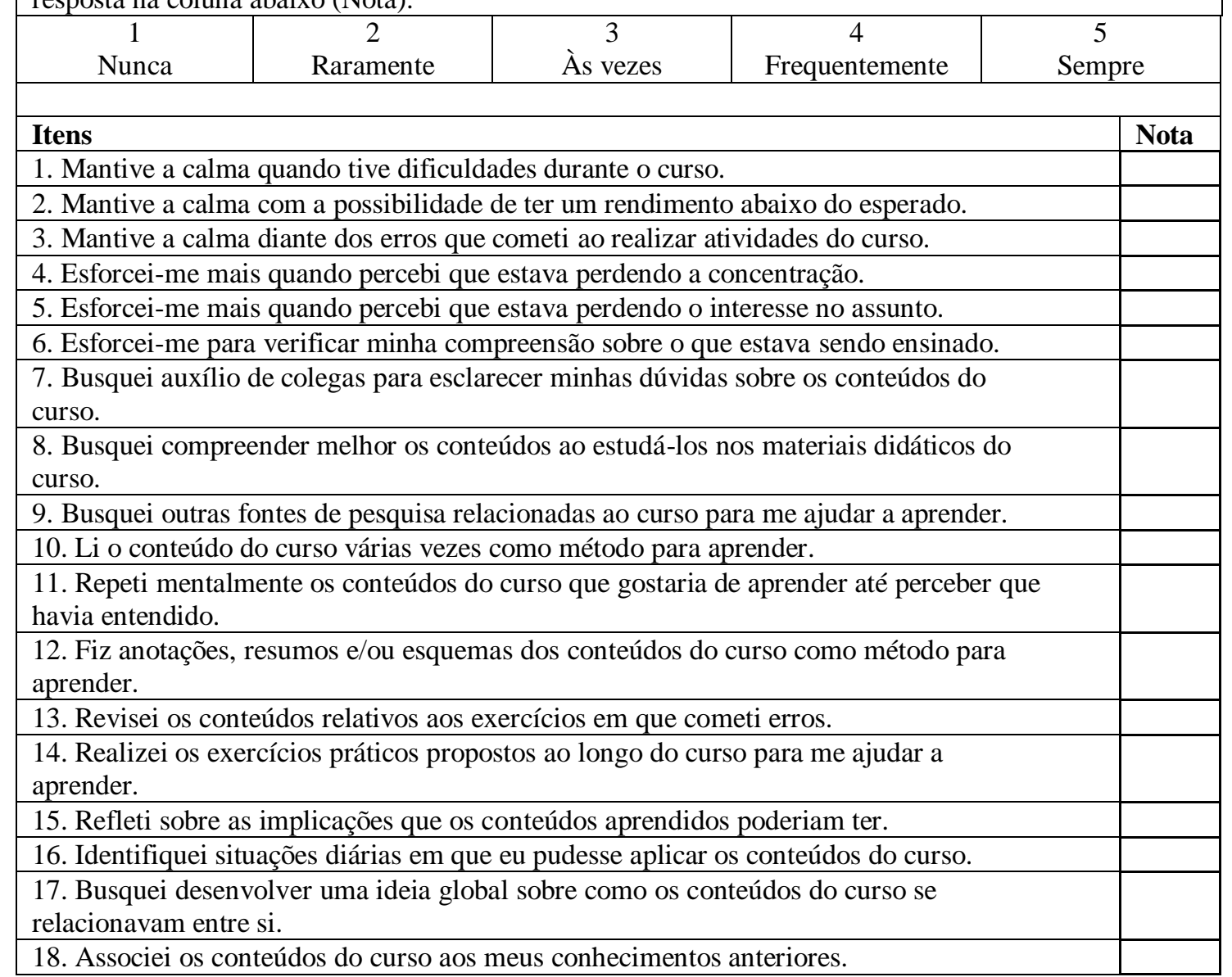




\section{ANEXO C - DEMONSTRATIVO DA APLICAÇÃO ONLINE QUESTIONÁRIO DE ESTRATÉGIAS DE APRENDIZAGEM}

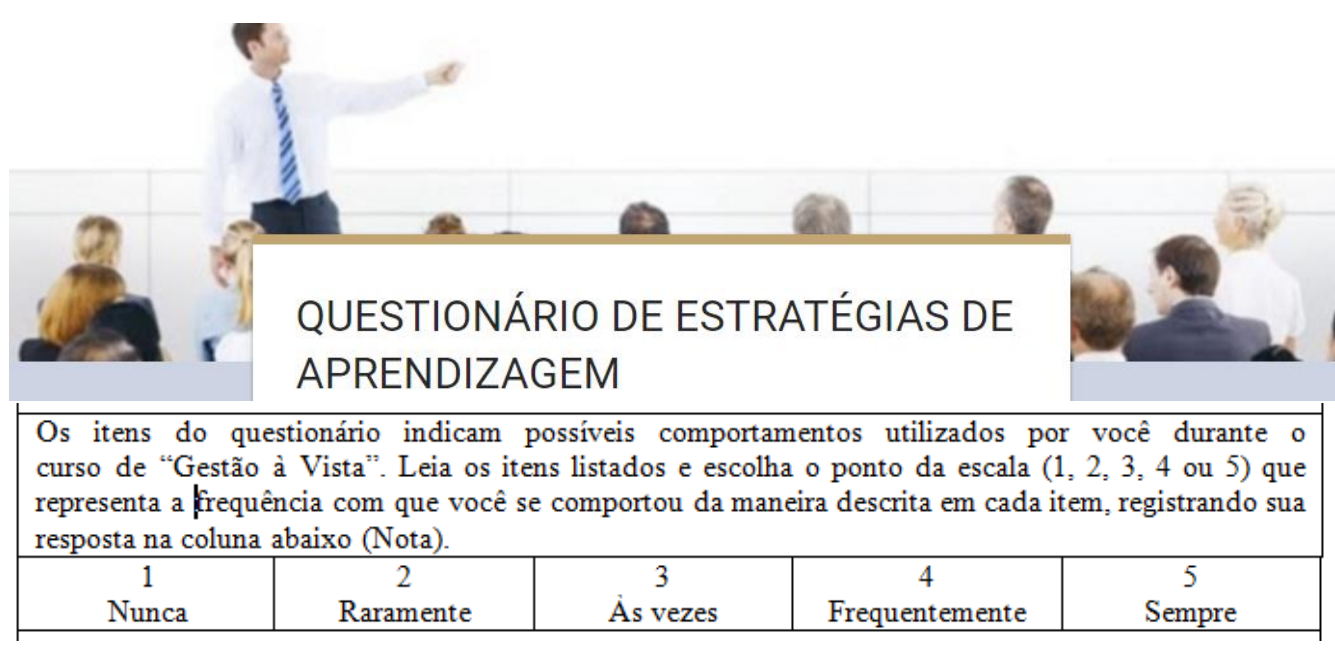

\footnotetext{
1 Nunca

2 Raramente

3 Às vezes

4 Frequentemente

6 Sempre
}

1. Mantive a calma quando tive dificuldades durante o curso. *

2. Mantive a calma com a possibilidade de ter um rendimento abaixo do esperado. *

1 Nunca

2 Raramente

3 Às vezes

4 Frequentemente

5 Sempre

3. Mantive a calma diante dos erros que cometi ao realizar atividades do curso. *

1 Nunca

2 Raramente

3 Às vezes

4 Frequentemente

5 Sempre

4. Esforcei-me mais quando percebi que estava perdendo a concentração. *

1 Nunca

2 Raramente

3 Às vezes

4 Frequentemente

5 Sempre

5. Esforcei-me mais quando percebi que estava perdendo o interesse no assunto. *

1 Nunca

2 Raramente

3 Às vezes

4 Frequentemente

5 Sempre 


\section{ANEXO D - DEMONSTRATIVO DA APLICAÇÃO ONLINE QUESTIONÁRIO DE PERSONALIDADE}

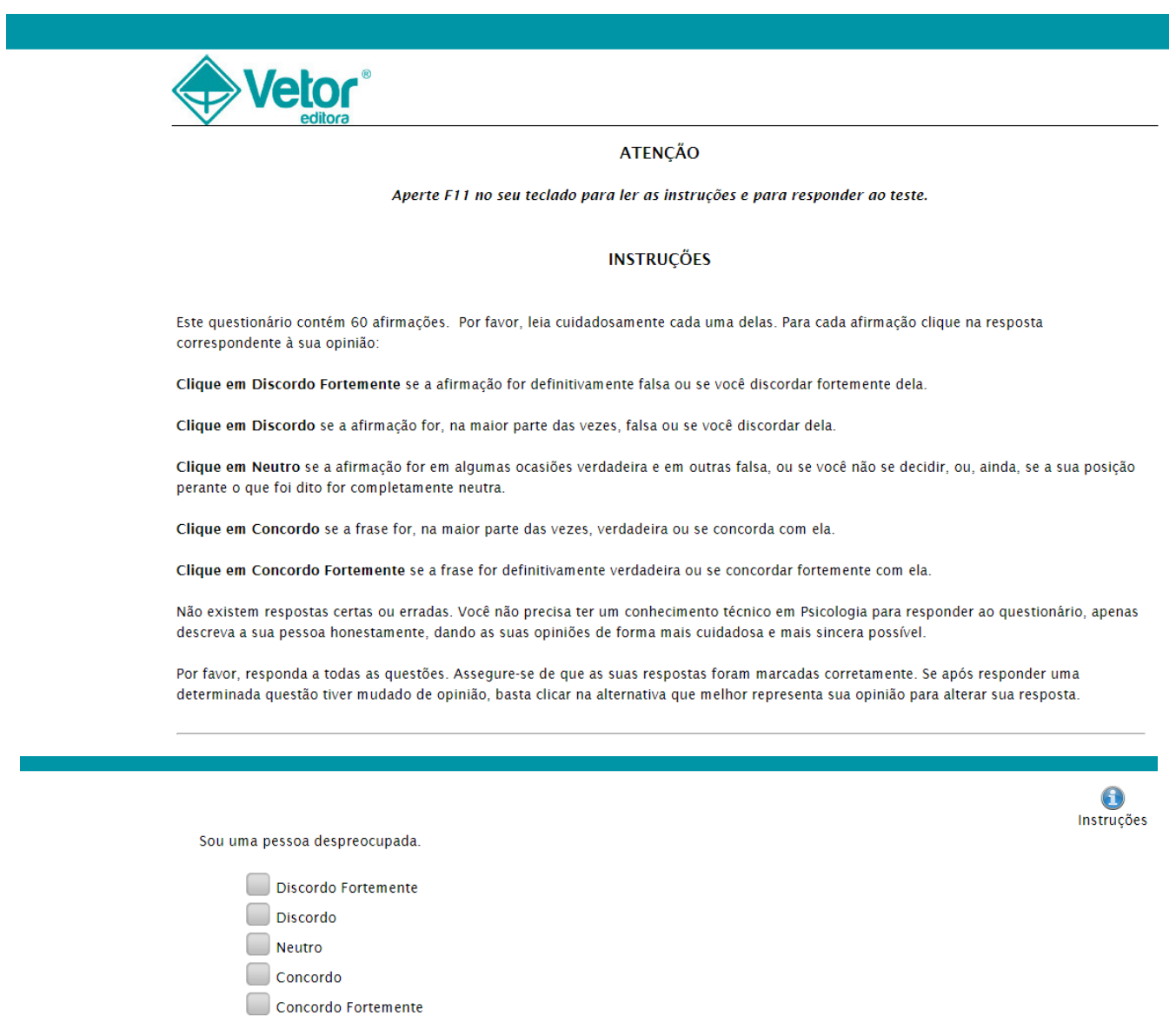

Próxima

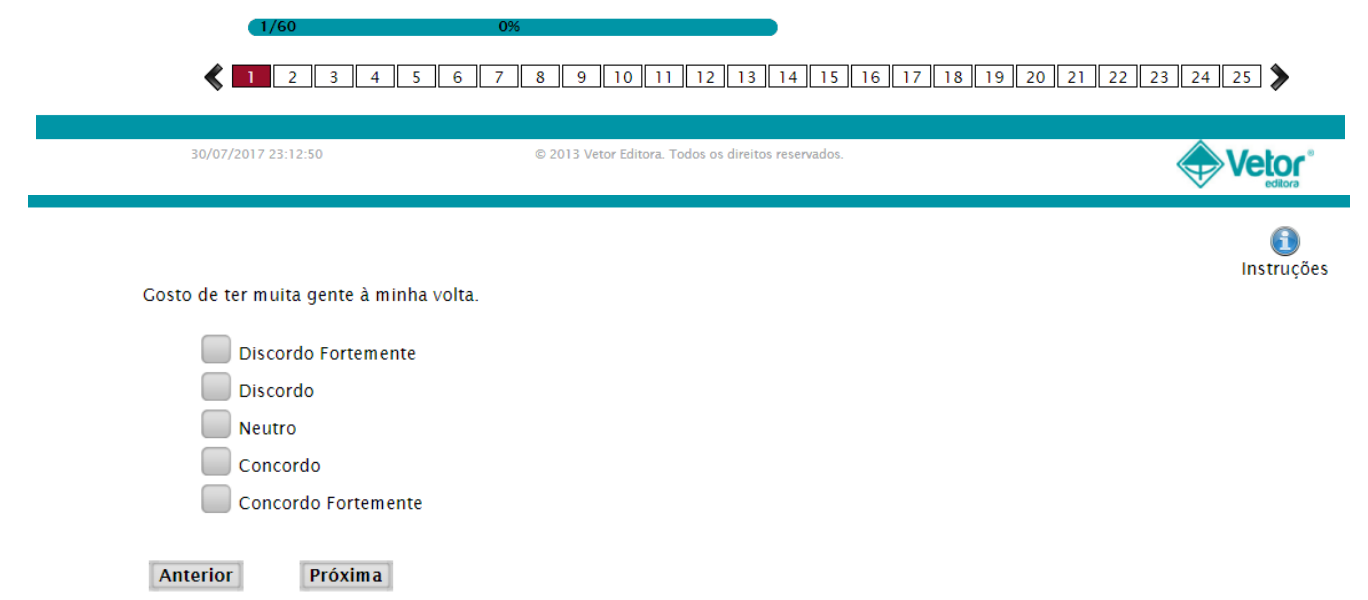

$2 / 60$

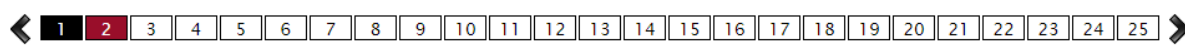




\section{ANEXO E - PESQUISAS SOBRE ESTRATÉGIAS DE APRENDIZAGEM (MARTINS, 2016)}

Pesquisas sobre Estratégias de Aprendizagem (Martins, 2016)

\begin{tabular}{|c|c|c|c|c|c|}
\hline Autores & Objetivo & Amostra/Contexto & $\begin{array}{l}\text { Procedimentos de } \\
\text { coleta de dados }\end{array}$ & $\begin{array}{c}\text { Procedimentos } \\
\text { de análise de } \\
\text { dados }\end{array}$ & Resultados \\
\hline $\begin{array}{l}\text { Warr \& } \\
\text { Downing } \\
(2000)\end{array}$ & $\begin{array}{l}\text { Validar uma escala de } \\
\text { estratégias de aprendizagem e } \\
\text { investigar a relação entre } \\
\text { estratégias de aprendizagem, } \\
\text { ansiedade para aprender e } \\
\text { aquisição de conhecimento }\end{array}$ & $\begin{array}{l}152 \text { participantes de } \\
\text { um curso de mecânica } \\
\text { básica }\end{array}$ & $\begin{array}{l}\text { Aplicação de } \\
\text { questionários }\end{array}$ & $\begin{array}{l}\text { Análise fatorial } \\
\text { exploratória }\end{array}$ & $\begin{array}{l}\text { Apenas busca por ajuda interpessoal e } \\
\text { monitoramento da compreensão não } \\
\text { foram positivamente relacionadas a } \\
\text { mudanças no conhecimento; } \\
\text { Estratégias de ensaio, busca de ajuda } \\
\text { interpessoal e de material escrito, } \\
\text { controle emocional e motivacional são } \\
\text { mais utilizadas pelos participantes com } \\
\text { alta ansiedade em relação a tarefa de } \\
\text { aprendizagem; } \\
\text { Participantes com altos níveis de } \\
\text { motivação anterior a aprendizagem usam } \\
\text { mais reflexão ativa, controle emocional e } \\
\text { monitoramento da compreensão; } \\
\text { Participantes com trabalhos anteriores } \\
\text { relevantes usam menos busca de ajuda } \\
\text { interpessoal e de material escrito e } \\
\text { controle emocional; } \\
\text { Participantes mais velhos usam mais a } \\
\text { estratégia de ensaio. }\end{array}$ \\
\hline
\end{tabular}


Pesquisas sobre Estratégias de Aprendizagem (Martins, 2016) (continuação)

\begin{tabular}{|c|c|c|c|c|c|}
\hline Autores & Objetivo & Amostra/Contexto & $\begin{array}{l}\text { Procedimentos de } \\
\text { coleta de dados }\end{array}$ & $\begin{array}{l}\text { Procedimentos de } \\
\text { análise de dados }\end{array}$ & Resultados \\
\hline $\begin{array}{l}\text { Holman, } \\
\text { Epitropaki \& } \\
\text { Fernie (2001) }\end{array}$ & $\begin{array}{l}\text { Validar uma escala de } \\
\text { estratégias de aprendizagem, } \\
\text { provinda de ambiente } \\
\text { educacional, em um contexto } \\
\text { organizacional }\end{array}$ & $\begin{array}{l}628 \text { agentes de call } \\
\text { center de um Banco } \\
\text { (Reino Unido) }\end{array}$ & $\begin{array}{l}\text { Aplicação de } \\
\text { questionários }\end{array}$ & $\begin{array}{l}\text { Análises fatoriais } \\
\text { exploratórias e } \\
\text { confirmatórias }\end{array}$ & $\begin{array}{l}\text { - } \text { As estratégias de aprendizagem } \\
\text { utilizadas por adultos em contextos } \\
\text { de trabalho são similares às usadas } \\
\text { em ambientes educacionais; } \\
22 \text { itens; } 6 \text { fatores divididos em } 2 \\
\text { tipos de estratégias: cognitivas } \\
\text { (reprodução, organização e } \\
\text { elaboração) e comportamentais } \\
\text { (busca de ajuda interpessoal, busca } \\
\text { de ajuda ao material didático e } \\
\text { aplicação prática). }\end{array}$ \\
\hline $\begin{array}{l}\text { Zerbini \& } \\
\text { Abbad (2005) }\end{array}$ & $\begin{array}{l}\text { Relacionar o uso de } \\
\text { estratégias de aprendizagem } \\
\text { às reações aos procedimentos } \\
\text { instrucionais de um curso via } \\
\text { internet e reações ao tutor e } \\
\text { impacto do treinamento no } \\
\text { trabalho }\end{array}$ & $\begin{array}{l}188 \text { e } 354 \text { participantes } \\
\text { do curso a distância } \\
\text { IPGN (SEBRAE) }\end{array}$ & $\begin{array}{l}\text { Aplicação de } \\
\text { questionários online }\end{array}$ & $\begin{array}{l}\text { Análise fatorial } \\
\text { exploratória } \\
\text { Análise de regressão } \\
\text { múltipla }\end{array}$ & $\begin{array}{l}\text { Apenas as estratégias de } \\
\text { elaboração e aplicação prática } \\
\text { explicaram o impacto do } \\
\text { treinamento no trabalho. }\end{array}$ \\
\hline Pantoja (2004) & $\begin{array}{l}\text { Investigar o relacionamento } \\
\text { entre estratégias de } \\
\text { aprendizagem, características } \\
\text { da organização e percepções } \\
\text { de suporte à aprendizagem } \\
\text { contínua }\end{array}$ & $\begin{array}{l}900 \text { trabalhadores de } \\
16 \text { categorias distintas } \\
\text { atuantes em diferentes } \\
\text { segmentos } \\
\text { organizacionais }\end{array}$ & $\begin{array}{l}\text { Aplicação de } \\
\text { questionários }\end{array}$ & $\begin{array}{l}\text { Teste de } 5 \text { modelos } \\
\text { multiníveis para } \\
\text { verificação do efeito } \\
\text { específico de } \\
\text { variáveis preditoras } \\
\text { nas estratégias de } \\
\text { aprendizagem no } \\
\text { local de trabalho } \\
\text { Análise fatorial } \\
\text { exploratória }\end{array}$ & $\begin{array}{l}\text { Diferentes correlações encontradas } \\
\text { entre as variáveis individuais } \\
\text { (idade, gênero, anos de estudo, } \\
\text { categoria profissional) e a } \\
\text { utilização de estratégias de } \\
\text { aprendizagem no local de trabalho; } \\
\text { Destaque para a estratégia } \\
\text { aplicação prática para a } \\
\text { aprendizagem dos indivíduos; } \\
\text { - Há diferenças significativas entre } \\
\text { as estratégias de aprendizagem } \\
\text { utilizadas no local de trabalho } \\
\text { conforme a categoria profissional. }\end{array}$ \\
\hline
\end{tabular}


Pesquisas sobre Estratégias de Aprendizagem (Martins, 2016) (continuação)

\begin{tabular}{|c|c|c|c|c|c|}
\hline Autores & Objetivo & Amostra/Contexto & $\begin{array}{l}\text { Procedimentos de } \\
\text { coleta de dados }\end{array}$ & $\begin{array}{l}\text { Procedimentos de } \\
\text { análise de dados }\end{array}$ & Resultados \\
\hline $\begin{array}{l}\text { Pantoja \& } \\
\text { Borges- } \\
\text { Andrade (2009) }\end{array}$ & $\begin{array}{l}\text { Mapear estratégias de } \\
\text { aprendizagem no trabalho } \\
\text { com o objetivo de classificar } \\
\text { dezesseis ocupações } \\
\text { profissionais, em quatro } \\
\text { categorias de postos de } \\
\text { trabalho, bem como descrever } \\
\text { e comparar as estratégias } \\
\text { utilizadas pelos indivíduos } \\
\text { para aprenderem, em seu dia- } \\
\text { a-dia no trabalho, nessas } \\
\text { diferentes categorias } \\
\text { profissionais }\end{array}$ & $\begin{array}{l}12 \text { coordenadores de } \\
\text { RH e } 55 \text { representantes } \\
\text { das dezesseis } \\
\text { ocupações } \\
\text { profissionais estudadas }\end{array}$ & $\begin{array}{l}\text { Entrevistas } \\
\text { semiestruturadas } \\
\text { baseadas na técnica } \\
\text { de incidentes críticos }\end{array}$ & Análise de conteúdo & $\begin{array}{l}\text { As estratégias aplicação prática e } \\
\text { busca de ajuda interpessoal } \\
\text { exerceram papel primordial nos } \\
\text { processos de aquisição, retenção e } \\
\text { transferência de novas } \\
\text { competências em âmbito laboral; } \\
\text { Diferentes configurações de uso de } \\
\text { estratégias de aprendizagem } \\
\text { estiveram associadas às categorias } \\
\text { profissionais estudadas. }\end{array}$ \\
\hline $\begin{array}{l}\text { Zerbini e } \\
\text { Abbad (2008a, } \\
\text { 2010a) }\end{array}$ & $\begin{array}{l}\text { Identificar variáveis } \\
\text { explicativas da aplicação de } \\
\text { habilidades ensinadas aos } \\
\text { participantes de um curso de } \\
\text { qualificação profissional a } \\
\text { distância, via internet }\end{array}$ & $\begin{array}{l}4.719 / 470 \\
\text { participantes do curso } \\
\text { a distância IPGN } \\
\text { (SEBRAE) }\end{array}$ & $\begin{array}{l}\text { Aplicação de } \\
\text { questionários online }\end{array}$ & $\begin{array}{l}\text { Análise fatorial } \\
\text { exploratória } \\
\text { Análise de regressão } \\
\text { múltipla }\end{array}$ & $\begin{array}{l}\text { Participantes que utilizaram com } \\
\text { mais frequência as estratégias de } \\
\text { aprendizagem elaboração e } \\
\text { monitoramento da compreensão } \\
\text { foram os que relataram maior } \\
\text { ocorrência de impacto do } \\
\text { treinamento no trabalho; } \\
\text { Os participantes que elaboraram o } \\
\text { plano de negócios utilizaram com } \\
\text { mais frequência a estratégia de } \\
\text { aprendizagem busca de ajuda } \\
\text { interpessoal. }\end{array}$ \\
\hline $\begin{array}{l}\text { Abbad, Côrrea } \\
\& \text { Meneses } \\
(2010)\end{array}$ & $\begin{array}{l}\text { Analisar as relações entre } \\
\text { estratégias de aprendizagem e } \\
\text { satisfação com treinamentos a } \\
\text { distância }\end{array}$ & $\begin{array}{l}216 \text { participantes de } \\
\text { cinco cursos realizados } \\
\text { a distância }\end{array}$ & $\begin{array}{l}\text { Aplicação de } \\
\text { questionários }\end{array}$ & $\begin{array}{l}\text { Análise fatorial } \\
\text { exploratória } \\
\text { Análises de } \\
\text { correlações bivariadas }\end{array}$ & $\begin{array}{l}\text { Padrões de associação entre } \\
\text { determinadas estratégias cognitivas } \\
\text { de aprendizagem e satisfação com } \\
\text { o desempenho da tutoria, com os } \\
\text { procedimentos e os resultados e } \\
\text { com a interface gráfica do curso. }\end{array}$ \\
\hline
\end{tabular}


Pesquisas sobre Estratégias de Aprendizagem (Martins, 2016) (continuação)

\begin{tabular}{|c|c|c|c|c|c|}
\hline Autores & Objetivo & Amostra/Contexto & $\begin{array}{c}\text { Procedimentos de } \\
\text { coleta de dados }\end{array}$ & $\begin{array}{l}\text { Procedimentos de } \\
\text { análise de dados }\end{array}$ & Resultados \\
\hline $\begin{array}{l}\text { Testa \& } \\
\text { Luciano (2010) }\end{array}$ & $\begin{array}{l}\text { Investigar o papel } \\
\text { desempenhado pelas } \\
\text { estratégias de aprendizagem } \\
\text { utilizadas na regulação de } \\
\text { recursos de aprendizagem em } \\
\text { ambientes virtuais de ensino }\end{array}$ & $\begin{array}{l}\text { Participantes: } 28 \\
\text { (entrevistados) e } 104 \\
\text { (questionários) }\end{array}$ & $\begin{array}{l}\text { Entrevistas } \\
\text { semiestruturadas e } \\
\text { abertas; análise de } \\
\text { documentos e de } \\
\text { registros; observação } \\
\text { direta; e pesquisa } \\
\text { survey }\end{array}$ & $\begin{array}{l}\text { Análise de conteúdo } \\
\text { Análise fatorial } \\
\text { exploratória }\end{array}$ & $\begin{array}{l}\text { Participantes que mais } \\
\text { frequentemente estabeleceram } \\
\text { interações com pares e professores, } \\
\text { para tirar dúvidas ou buscar } \\
\text { auxílio, atingiram as mais elevadas } \\
\text { médias nos itens interesse, } \\
\text { persistência, percepção de } \\
\text { autoconfiança e gestão do } \\
\text { ambiente social da escala MSLQ } \\
\text { (Motivated Strategies for Learning } \\
\text { Questionnaire); } \\
\text { Correlações significativas entre as } \\
\text { elevadas taxas de satisfação com o } \\
\text { estudo e desempenho acadêmico e } \\
\text { a utilização de estratégias para } \\
\text { gestão do tempo e esforço. } \\
\text { Implicações práticas: estabelecer } \\
\text { prazos curtos e frequentes para a } \\
\text { conclusão das tarefas; fixar nos } \\
\text { critérios avaliativos elementos que } \\
\text { tratem do gerenciamento de tempo; } \\
\text { investir em interações viabilizadas } \\
\text { pelo recurso do chat ou por meio } \\
\text { de videoconferências; sugerir } \\
\text { atividades não formais nas quais os } \\
\text { estudantes partilhem preferências, } \\
\text { opiniões, etc. }\end{array}$ \\
\hline $\begin{array}{l}\text { Brandão \& } \\
\text { Borges- } \\
\text { Andrade (2011) }\end{array}$ & $\begin{array}{l}\text { Desenvolver uma escala de } \\
\text { estratégias de aprendizagem } \\
\text { no trabalho e verificar a } \\
\text { frequência com que estas são } \\
\text { utilizadas. }\end{array}$ & $\begin{array}{l}881 \text { gestores de } \\
\text { agências bancárias } \\
\text { públicas brasileiras }\end{array}$ & $\begin{array}{l}\text { Levantamento } \\
\text { documental, } \\
\text { entrevistas e } \\
\text { questionários }\end{array}$ & $\begin{array}{l}\text { Análises descritivas e } \\
\text { fatoriais exploratórias }\end{array}$ & $\begin{array}{l}\text { As estratégias de aprendizagem } \\
\text { busca de ajuda interpessoal e } \\
\text { reflexão ativa foram as mais } \\
\text { utilizadas pela amostra. }\end{array}$ \\
\hline
\end{tabular}

